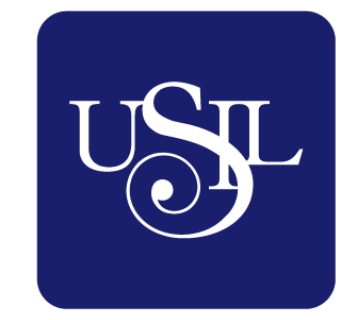

UNIVERSIDAD

SAN IGNACIO

DE LOYOLA

ESCUELA DE POSTGRADO

Maestría en Ciencias Empresariales - MCE

\title{
PLAN DE NEGOCIOS DE UNA EMPRESA DE LAVADO DE AUTOS ENFOCADA EN EL MEDIO AMBIENTE MEDIANTE LA REUTILIZACIÓN DEL AGUA Y LA INCLUSIÓN SOCIAL COMO FACTORES DIFERENCIADORES
}

Tesis para optar el grado de Maestro en Ciencias Empresariales - MCE

MARIA CLAUDIA, GONZALES MESTANZA OMAR GUILLERMO, MIRANDA HUERTA

Asesor:

Ana Fidela Hospina Schaefer

Lima - Perú

2018 
Índice

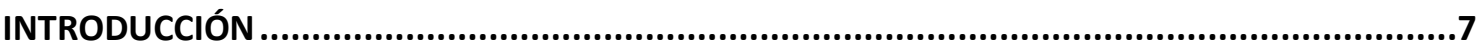

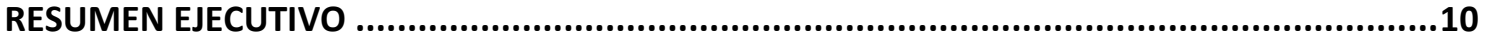

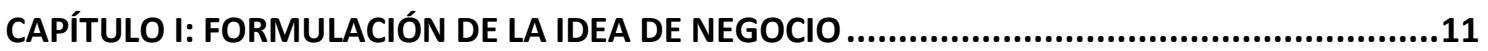

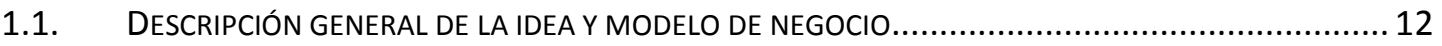

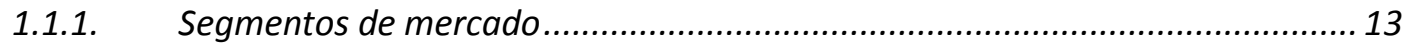

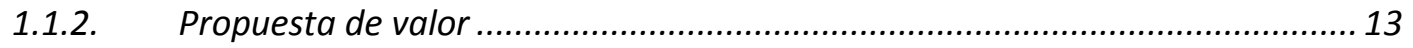

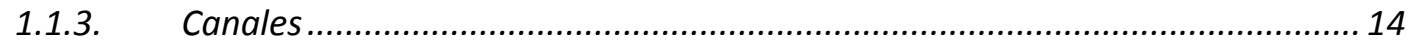

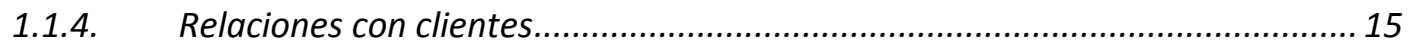

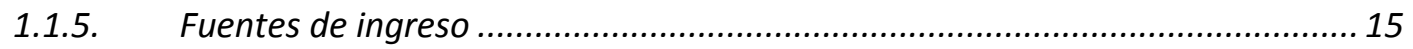

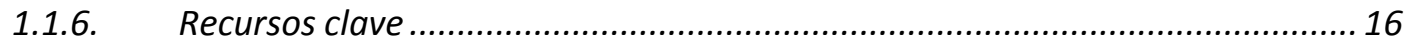

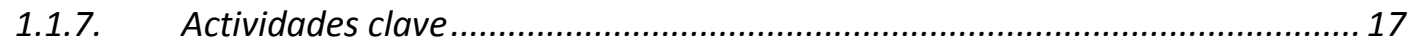

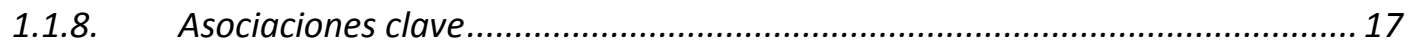

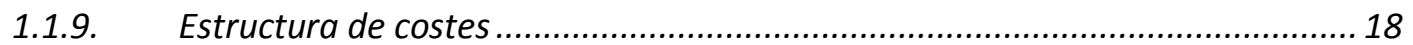

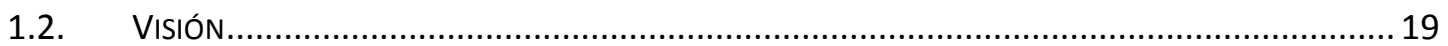



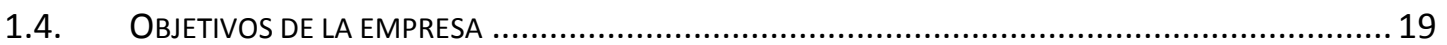

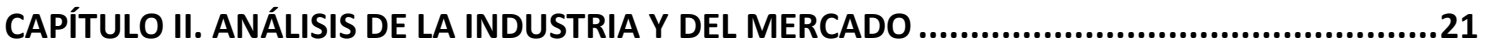

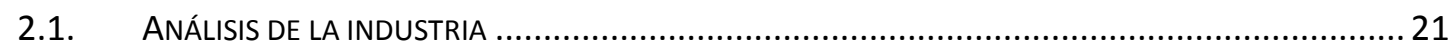

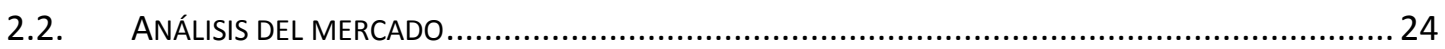

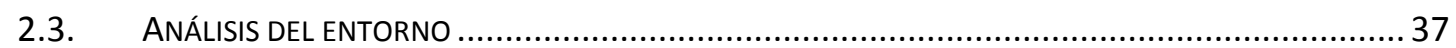

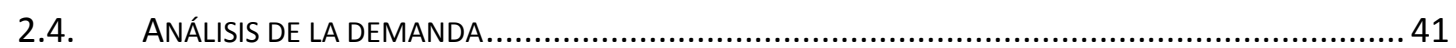

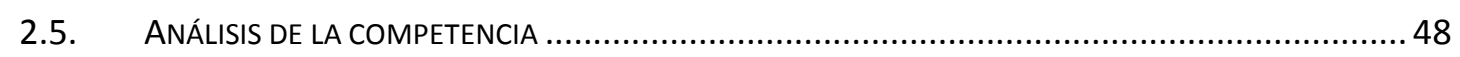



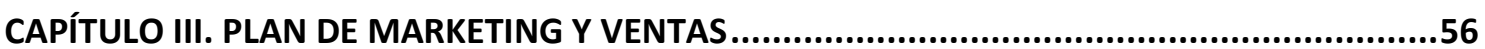



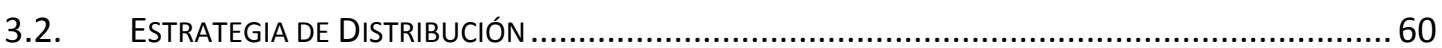

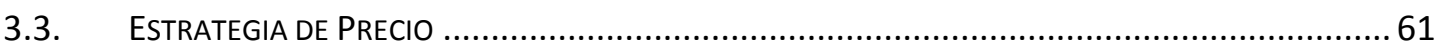

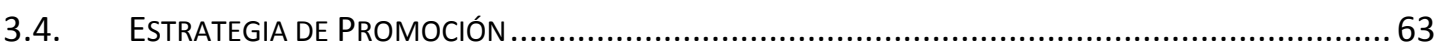

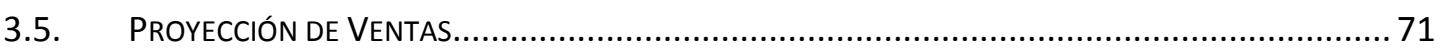

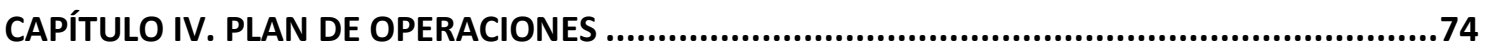

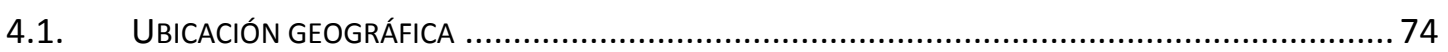



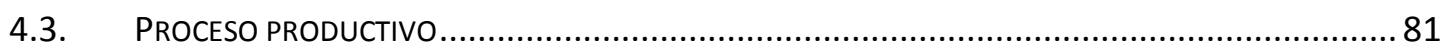

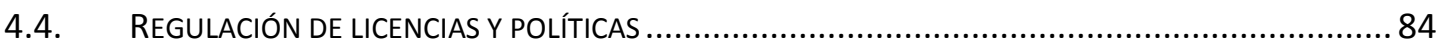

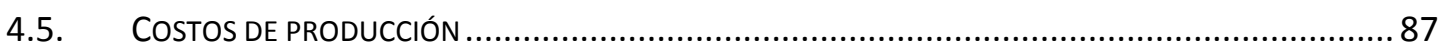

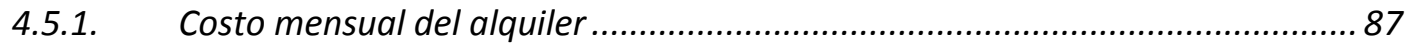

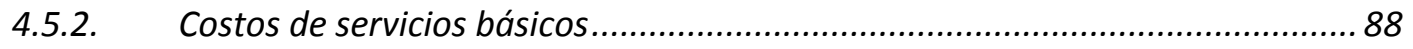

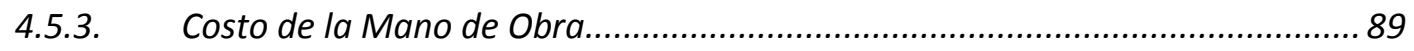

4.5.4. Materiales y equipos que se utilizaran para los servicios de limpieza:..............90

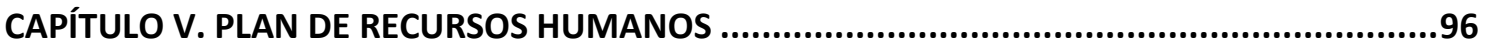



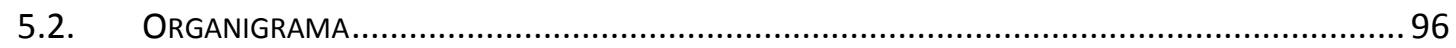

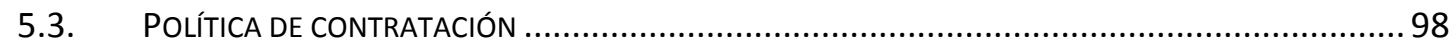

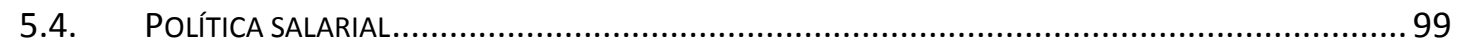

CAPÍTULO VI: PLAN FINANCIERO

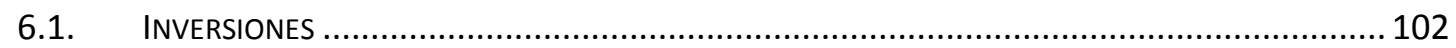

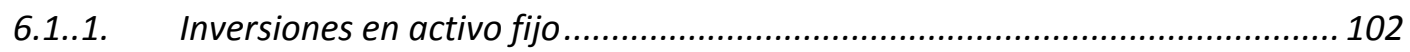




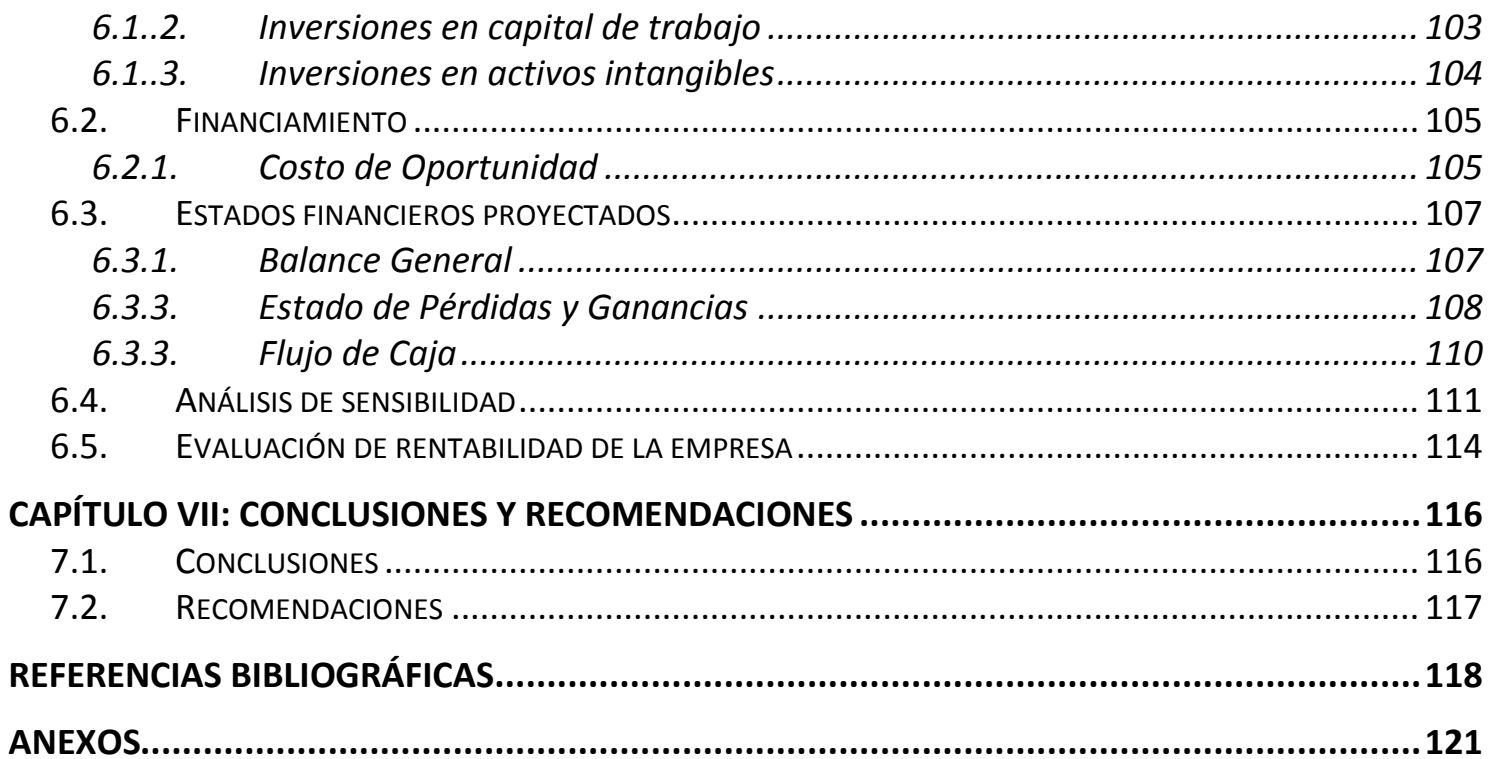

\section{INDICE DE FIGURAS}

Figura 1. Parque automotor nacional, por clase de vehículo 1998-2012. Elaborado por el Instituto Nacional de Estadística e Informática (INEI). Fuente de información tomada de Ministerio de Transporte y Comunicaciones y Superintendencia Nacional de Registros Públicos. Recuperado de http://m.inei.gob.pe/media/MenuRecursivo/Cap19021.xls

Figura 2. Venta de autos nuevos en miles de unidades (2009-2015). Tomado de Situación Automotriz por BBVA Research, 2015. Recuperado de https://www.bbvaresearch.com/wp-content/uploads/2015/12/SectorAutomotriz_Diciembre-2015-Peru_FINAL.pdf.

Figura 3. Evolución del tipo de cambio (2013-2015). Tomado de Situación Automotriz por BBVA Research, 2015. Recuperado de https://www.bbvaresearch.com/wpcontent/uploads/2015/12/Sector-Automotriz_Diciembre-2015-Peru_FINAL.pdf......... 23 Figura 4. Producto Bruto Interno según actividad económica, en millones de soles, nivel 54 (2007-2015). Adaptado de Instituto Nacional de Estadística e Informática (INEI). Recuperado de https://www.inei.gob.pe/estadisticas/indice-tematico/economia/.......... 24 Figura 5. Clasificación de distritos por zonas (2016). Tomado de "Niveles Socioeconómicos 2016" por la Asociación Peruana de Empresas de Investigación de Mercados (APEIM), 2016.

Figura 6. Distribución de NSE A por zonas, Lima Metropolitana. Adaptado de "Niveles Socioeconómicos 2016" por la Asociación Peruana de Empresas de Investigación de Mercados (APEIM), 2016. 28 Figura 7. Distribución de NSE B por zona, Lima Metropolitana. Adaptado de "Niveles Socioeconómicos 2016" por la Asociación Peruana de Empresas de Investigación de Mercados (APEIM), 2016. 28 Figura 8. Distribución de NSE C por zona, Lima Metropolitana. Adaptado de "Niveles Socioeconómicos 2016" por la Asociación Peruana de Empresas de Investigación de Mercados (APEIM), 2016.

Figura 9. Mapa por distritos de Lima Metropolitana 2016. Recuperado de http://www.guiacalles.com ..... 
Figura 10. Parque automotor estimado al 2015. Adaptado de Situación Automotriz por BBVA Research, 2015 e Instituto Nacional de Estadística e Informática (INEI)......... 31 Figura 11. Porcentaje de encuestados que utilizan el servicio de Car Wash. Tomado de encuesta propia. Elaboración propia.

Figura 12. Porcentaje de encuestados dispuestos a tomar el servicio brindado por el proyecto. Tomado de encuesta propia.

Figura 13: Crecimiento PBI (\%) vs Crecimiento autos nuevos (unidades). Adaptado de Adaptado de Situación Automotriz por BBVA Research, 2015, Instituto Nacional de Estadística e Informática (INEI) y Banco Central de Reserva del Perú (BCRP)........... 37 Figura 14: Comparación entre crecimiento del PBI (\%) y el crecimiento del sector de la minería (\%). Adaptado de Excel titulado "Producto Bruto Interno por Sectores Productivos" del BCRP. 38

Figura 15: Comparación entre crecimiento del PBI (\%) y el crecimiento del sector de servicios (\%). Adaptado de Excel titulado "Producto Bruto Interno por Sectores Productivos" del BCRP.

Figura 16: Relación PBI(\%) con Crecimiento anual de autos en Perú (\%). Adaptado de Adaptado de Situación Automotriz por BBVA Research, 2015, Instituto Nacional de Estadística e Informática (INEI) y Banco Central de Reserva del Perú (BCRP)........... 40 Figura 17: Relación Tipo de cambio (Soles por dólar) con Crecimiento anual de autos en Perú (\%). Adaptado de Adaptado de Situación Automotriz por BBVA Research, 2015, Instituto Nacional de Estadística e Informática (INEI) y Banco Central de Reserva del Perú (BCRP).

Figura 18. Frecuencia del lavado del auto de las personas encuestadas. Tomado y adaptado de encuesta propia.

Figura 19. Precio promedio que gastan los encuestados por lavar sus autos. Tomado y adaptado de encuesta propia.

Figura 20. Precio que el público encuestado está dispuesto a pagar por el servicio brindado. Tomado y adaptado de encuesta propia.

Figura 21: Matriz de perfil competitivo - empresas de lavado de autos. Elaboración propia.

Figura 22. Cadena de valor de Michael Porter. Tomado de "The Competitive Advantage: Creating and Sustaining Superior Performance de Michael Porter, 1985. Recuperado de https://www.gestiopolis.com/que-es-la-cadena-de-valor/

Figura 24. Matriz Ansoff - Oportunidades de crecimiento. Tomado de Igor Ansoff. Recuperado de https://aleixrisco.com/2014/06/05/igor-ansoff-la-matriz-de-ansoffmatriz-productomercado/.

Figura 25. Proyección de ventas de vehículos ligeros en el Perú (2001-2026) en miles de unidades y crecimiento porcentual. Tomado de "Perspectivas de la industria automotriz Perú" elaborado por IHS Markit y Asociación Automotriz del Perú, 2016. 73

Figura 26. Matriz de Factores Ponderados para la elección del local. Fuente y elaboración propia. 76

Figura 27. Flujo vehicular, instituciones y negocios cercanos al local. Fuente y elaboración propia. Mapa tomado de www.google.com/maps 77 Figura 28. Distribución del local de lavado de autos. Fuente para elaboración de las medidas "www.urbania.pe". Elaboración propia.

Figura 29. Equipo de reciclaje y recuperación de agua. Tomado de "Manual original contenedor de reciclaje móvil Acuabox" de ISTOBAL, 2017.

Figura 30. Diagrama de proceso general del servicio. Fuente y elaboración propia...... 83 Figura 31. Diagrama de proceso del lavado 1 - Express. Fuente y elaboración propia. 84 
Figura 32. Flujograma para el trámite de la licencia de funcionamiento. Tomado de

Municipalidad de la molina. Recuperado de

http://www.munimolina.gob.pe/index.php/licencias-de-funcionamiento

Figura 33. Organigrama de la empresa. Fuente y elaboración propia.

\section{INDICE DE TABLAS}

Tabla 1: Mercado total (autos y camionetas del parque automotor) ............................ 31

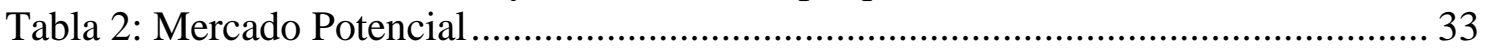

Tabla 3: Cantidad de personas que utilizan el servicio de lavado de autos..................... 34

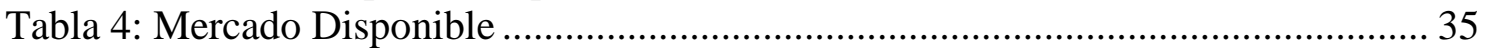

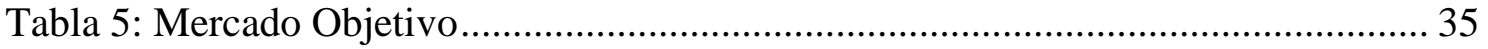

Tabla 6: Número de autos atendidos en una empresa pequeña de Lavado de autos

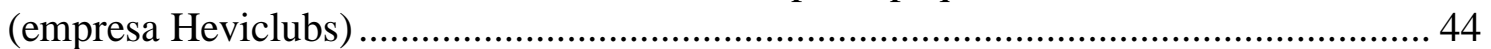

Tabla 7: Flujo Vehicular 2004 (Av. Javier Prado Este/ Av. Flora Tristán)..................... 45

Tabla 8:Flujo Vehicular 2009 (Av. Javier Prado Este/ Av. Flora Tristán)....................... 46



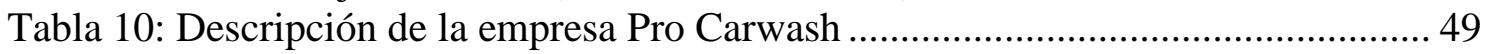

Tabla 11: Descripción de la empresa Pro Detailing ......................................................50

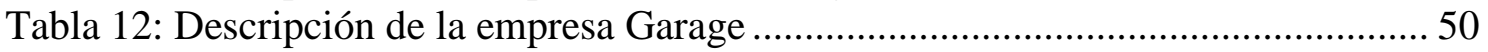

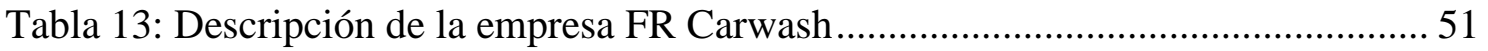

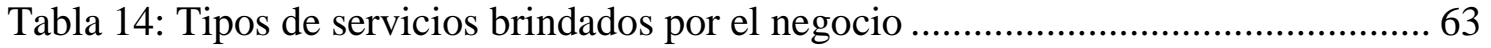

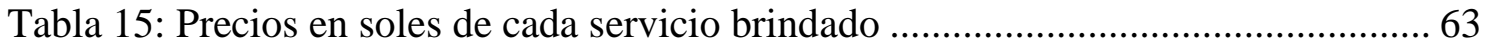

Tabla 16: Proyección de ventas del negocio ....................................................................... 73

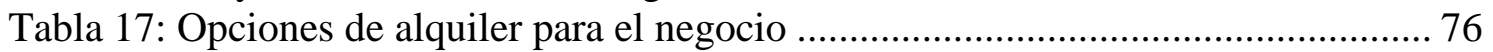

Tabla 18: Costos Serv. básicos anuales en soles (Energía, agua, teléfono) .................... 88

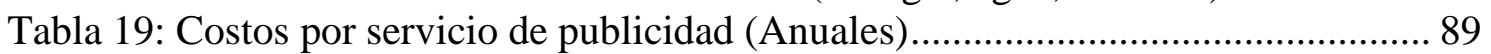

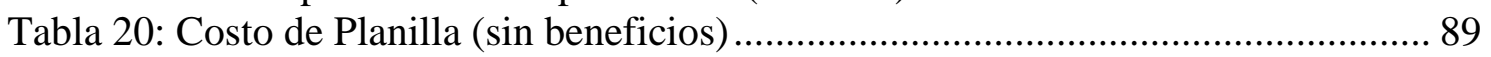

Tabla 21: Costos laborales total de la Planilla (Anuales) en soles ................................. 90

Tabla 22: Precio de insumos y materiales para lavado de autos ................................... 92

Tabla 23: Precio de Maquinaria y Equipos en soles..................................................... 92

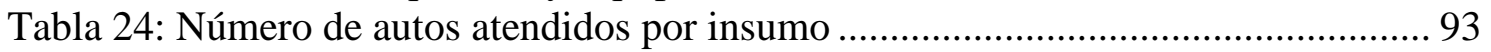

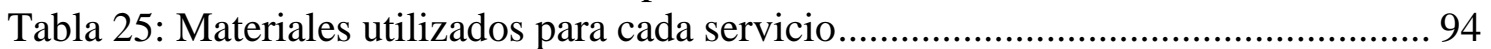

Tabla 26: Costos unitario de los insumos por vehículo atendido................................... 94

Tabla 27: Resumen de costos de producción (soles) ....................................................... 95

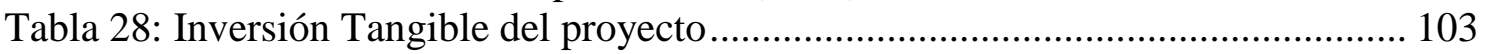

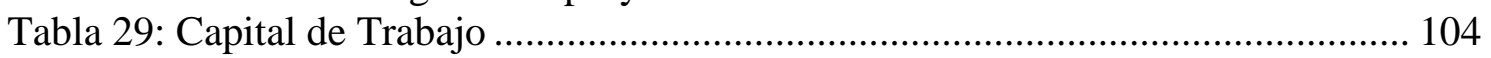

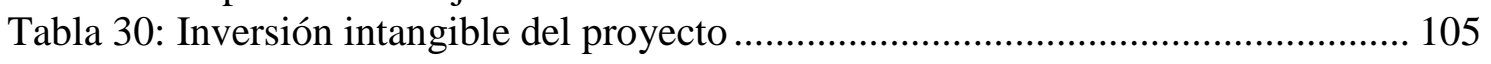

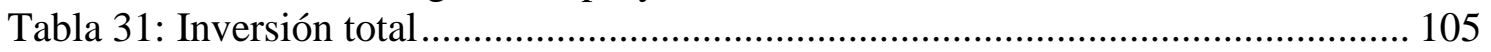

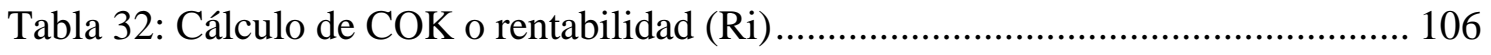

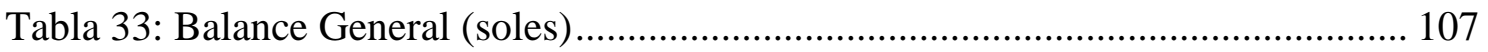

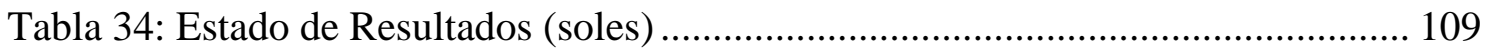

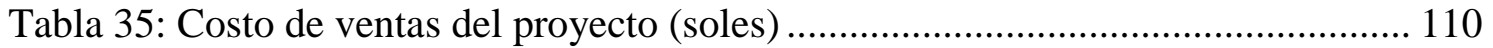

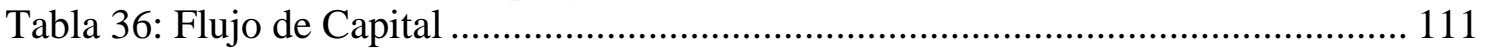

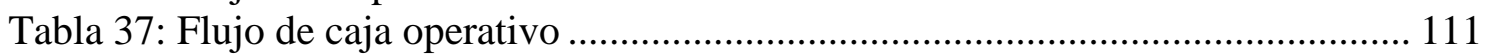

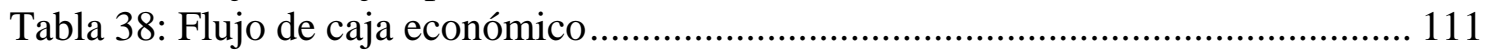

Tabla 39: Escenarios de crecimiento - Sector automotriz peruano ............................. 113

Tabla 40: Resultados análisis sensibilidad (variable: crecimiento del sector automotriz)

Tabla 41: Escenarios de variación de costos de los insumos ..................................... 114 
Tabla 42: Resultados análisis sensibilidad (variable: costo de insumos)

114

Tabla 43: Flujo de Caja a ser analizado (VAN,TIR)

115

Tabla 44: Cálculo del VAN y TIR

115 


\section{INTRODUCCIÓN}

La venta de autos a nivel mundial se ha incrementado en los últimos años. A nivel internacional el segmento que ha crecido con mayor fuerza es el de vehículos ligeros (International Organization of Motor Vehicle Manufacturers, 2016). Esto ha generado una industria paralela de empresas que atienden las necesidades postventa de los vehículos tanto a nivel funcional (venta de repuestos) así como a nivel estético (lavado y personalización de autos).

En el Perú el crecimiento exponencial del parque automotor en los últimos años ha permitido tener una gran cantidad de vehículos concentrados principalmente en la capital del país. Gran parte de estos vehículos pertenecen al grupo de autos y camionetas, representando más del 50\% del mercado (Sunarp, MTC). Este crecimiento de la cantidad de autos en el país debido a la importación y venta de vehículos en Lima ha traído consigo nuevos negocios paralelos tanto de los rubros comerciales y de servicios. Dentro de los cuales tenemos la venta de autopartes, el lavado y la personalización de vehículos.

El rubro de lavado de autos es uno de los rubros en crecimiento en Lima. Es así que, a pesar de la creciente informalidad de empresas en este rubro, las empresas formales comenzaron a tomar fuerza aproximadamente en los últimos 2 años, mostrando empresas mucho más dedicadas y sofisticadas al momento de brindar esta clase de servicios. Además, el aporte de este sector económico sigue creciendo y contribuyendo de manera positiva al PBI no primario, lo cual genera buena perspectiva hacia el futuro (BBVA Research, Situación Automotriz 2015).

Por otro lado, un tema que se consideró en el plan de negocios es el cuidado del medio ambiente. Hoy en día el cuidado medio ambiental en el 
mundo es un factor crítico y de suma importancia a nivel empresarial y social. No solo las grandes empresas son las que contaminan con las ya conocidas emisiones de $\mathrm{CO}$ al ambiente. Específicamente hablando del proyecto propuesto, también existe la contaminación del agua por el uso de este recurso en los procesos industrial o diferentes procesos de negocio. Por ese motivo, es importante también mencionar que los negocios como los lavados de autos utilizan una gran cantidad de agua para poder brindar su servicio, siendo este un factor a analizar en su proceso de negocio. El agua utilizada se contamina con distintos químicos y es descartada por los ductos de desagüe.

Es importante también mencionar la estructura que tendrá el proyecto. Este plan de negocios se desarrolla en 7 capítulos. El primer capítulo habla de la idea de negocio, el modelo Canvas que se siguió para desarrollar los puntos más resaltantes del negocio, la misión, la visión y los objetivos estratégicos de la empresa. En el segundo capítulo, se tiene el desarrollo de la industria y el mercado, haciendo referencia a la situación histórica, actual y futura del sector. Así mismo, se determina el mercado objetivo del negocio, se analiza a la competencia y se proyecta la demanda que tendrá el negocio.

El capítulo tres, habla de los planes comerciales y de marketing que tiene el proyecto. Los cuales están enfocados en mantener y atraer a los clientes. Por otro lado, el cuarto capítulo se enfoca en determinar la ubicación más adecuada del negocio, además, se describe el proceso productivo, la distribución del local y se detallan los costos operativos. El quinto capítulo, desarrollará el organigrama y la estructura de la empresa, así mismo, se hablará de las políticas de contratación y políticas salariales.

En el capítulo sexto, se desarrolla el análisis financiero y de rentabilidad. En este punto se evalúa la viabilidad del proyecto, mediante el VAN y TIR. 
Además, se analiza el costo de oportunidad del proyecto, los estados financieros y el flujo de caja del negocio. Finalmente, se presentarán las conclusiones y recomendaciones en el capítulo siete. 


\section{RESUMEN EJECUTIVO}

El presente plan de negocios detalla a una empresa de lavado de autos, la cual llamaremos Washing Green SRL, la cual tiene como misión brindar servicios de lavado de autos, ofreciendo 3 tipos de servicios de lavado, el servicio de lavado de salón, y los servicios de tratamiento y descontaminación de pintura. Los factores diferenciadores de este proyecto son que la empresa busca proyectar una imagen real de cuidado al medio ambiente, mediante la reutilización del agua empleada en los servicios de lavado. Además, la empresa busca potenciar la experiencia del cliente que se atiende en este tipo de negocios, brindándole un lugar confortable donde esperar.

Actualmente, existe un mercado amplio en el Perú, ya que cada 3 de 4 personas utiliza este tipo de servicios. Sin embargo, es preciso señalar que de los hogares limeños solo el $18 \%$ posee autos y este porcentaje está concentrado en los niveles socio económicos A y B, a los que este proyecto se dirigirá (APEIM). Por otro lado, es importante mencionar que el sector automotriz proyecta crecimiento constante en los próximos 10 años. Con estas premisas el proyecto pretende iniciar sus operaciones atendiendo 7 mil vehículos al año.

Los resultados de viabilidad y rentabilidad financiera mostraron que el análisis del VAN dio como resultado más de 200 mil soles y la TIR alcanzó el valor de $40 \%$. Este último siendo mayor que la rentabilidad esperada de 21.12\% (CAPM). Además, mostrando la solidez del plan, el análisis de sensibilidad mostró que ante escenarios adverso la rentabilidad mínima obtenida sería de 33\% (TIR) y 125 mil soles (VAN). 


\section{CAPÍTULO I: FORMULACIÓN DE LA IDEA DE NEGOCIO}

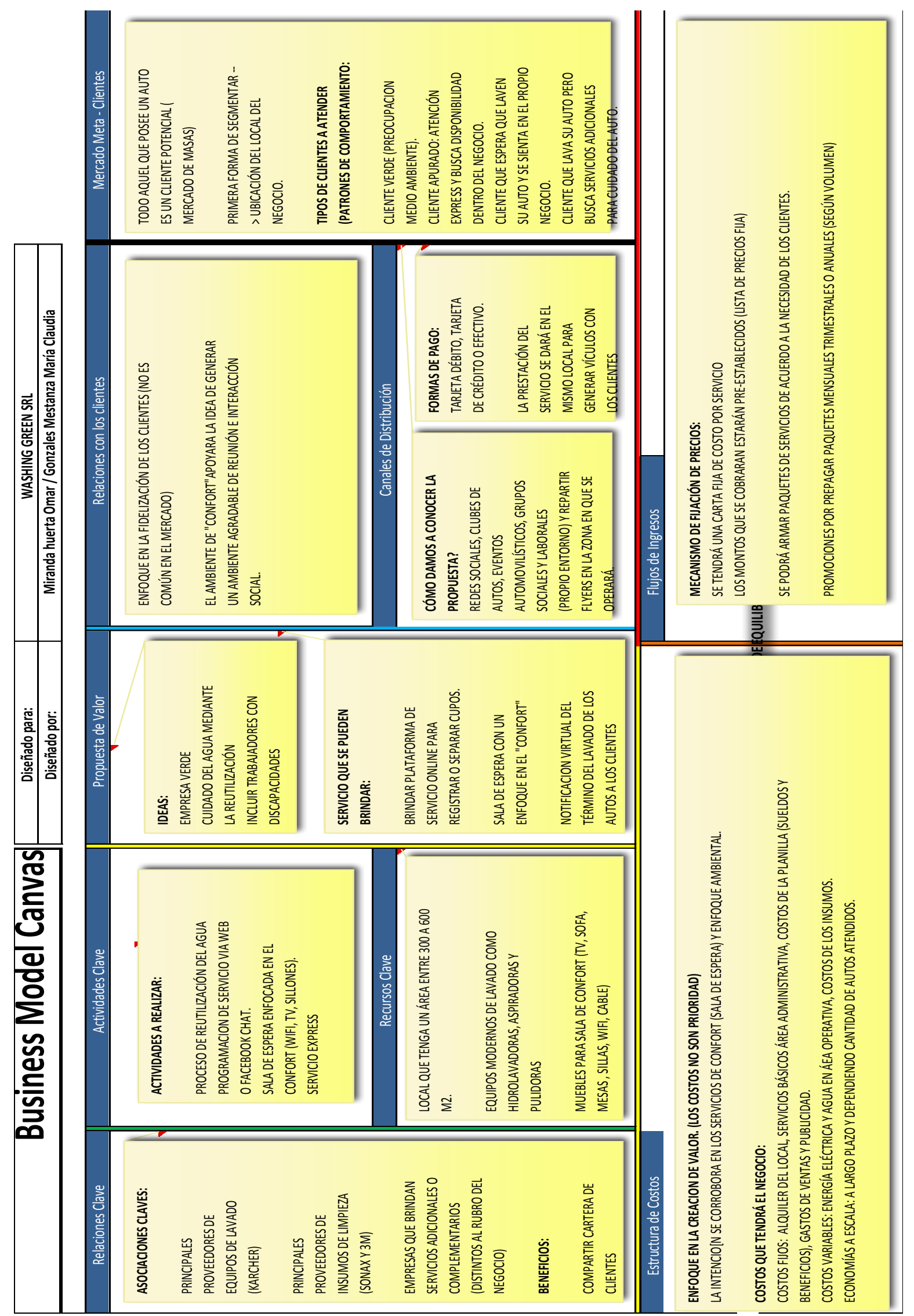




\subsection{Descripción general de la idea y modelo de negocio}

El Proyecto que se desarrollará será un local de lavado de autos enfocado en generar experiencias y relaciones a largo plazo con los clientes. Se buscará dejar el modelo tradicional enfocado en un sistema transaccional entre el cliente y la empresa, dándole distintas opciones de integración con la finalidad de desarrollar un interés e involucramiento con la empresa.

Además, como factores diferenciadores, se buscará ser una empresa que proyecte interés real y preocupación por el cuidado de medio ambiente, específicamente gestionando la utilización del recurso principal del proceso el cual es el agua. Para esto, se incluirá dentro del proceso la reutilización del agua por medio de equipos especializados en el reciclaje y recuperación de la misma.

Como metodología para generar un nuevo modelo de negocio, se utilizará el lienzo de modelo de negocio o también llamado modelo Canvas. Esta metodología buscar crear y capturar valor a través de 9 elementos, los cuales al ser desarrollados dibujan de alguna forma un lienzo de un plan de negocios. Los elementos permiten tener una visión global del negocio y es posible observar y desarrollar a su vez interconexiones entre ellos. Los elementos en mención son los siguientes: (a)Segmentos de mercado, (b)Propuesta de valor, (c)Canales, (d)Relaciones con clientes, (e)Fuentes de ingreso, (f)Recursos clave, (g)Actividades clave, (h)Asociaciones clave y (i)Estructura de costes. (Osterwalder \&Pigneur, 2011). 


\subsubsection{Segmentos de mercado}

En general podemos establecer que todo aquel que posee un auto particular es un cliente potencial (mercado de masas). Sin embargo, un punto inicial de segmentación se dará por la ubicación del local de lavado. Por otro lado, podemos definir algunos tipos de clientes a los que se enfocará el proyecto:

- El cliente que busca ser parte de una marca o empresa verde, que se preocupe por el cuidado del medio ambiente.

- El cliente que tiene el tiempo ajustado para tomar el servicio y necesita saber si hay disponibilidad para una atención rápida.

- El cliente que toma el servicio, pero permanece en el local esperando que termine de darse el servicio a su auto.

- El cliente que busca servicios adicionales al de lavado express o tradicional tales como: descontaminación de pintura, tratamiento de pintura, lavado de salón, entre otros.

- El cliente que confía en dejar su auto y no se queda en el local esperando que le notifique que su servicio ha terminado.

En líneas generales podemos decir que nuestro mercado está segmentado principalmente por las necesidades y patrones de comportamiento que tienen los clientes.

\subsubsection{Propuesta de valor}

La propuesta de negocio tiene como valor principal ser una empresa verde que se preocupe por el cuidado del medio ambiente mediante la reutilización del agua utilizada en los servicios brindados. Esto proyectará una imagen e interés real por el cuidado del medio ambiente ya que se buscará cuidar unos de los recursos más escasos 
del planeta. A su vez, esto permitirá generar ahorro en los costos de agua principalmente.

Como propuesta de servicio al cliente se buscará crear una experiencia en el cliente mientras recibe los servicios del autolavado. Se desea brindar los siguientes servicios que ayudarán a implementar esta experiencia:

- Generar una plataforma de servicio On-line (Página web) o utilizar el Facebook Messenger (Mensajería instantánea) para la programación del servicio para aquellos clientes que tengan el tiempo justo para ser atendidos. Para estos clientes se les ofrecería un servicio Express.

- Ofrecer una sala de espera enfocada en el "Confort" que brinda conexión a internet por wifi, que tenga tomacorriente para conectar equipos electrónicos y espacios amplios para poder trabajar con sus laptops o tablets. Además, se tendrá un televisor con cable para todos aquellos que quieran distraerse mientras esperan ser atendidos.

- Notificar el término del servicio al cliente para que pueda recoger su auto.

\subsubsection{Canales}

Para dar a conocer nuestra propuesta se propone:

- Comunicación a través de redes sociales (Facebook, Twitter, Linkedin, etc).

- Comunicación directa con clubes de autos, promocionando nuestros servicios.

- Asistencia y participación en eventos automovilísticos. 
- Comunicación a grupos sociales y laborales más cercanos.

- Comunicar mediante la repartición de flyer en el distrito en el que operará el negocio.

Para que los clientes puedan evaluar la propuesta se realizará un video de pre-lanzamiento o teaser que permita mostrar cierta información de la empresa y los servicios, con la finalidad de crear expectativa en ellos. Los clientes tendrán la opción de separar su servicio vía web previa cancelación. Las formas de pago son en efectivo, con tarjeta de débito o crédito, estas últimas mediante POS.

Debido a que la propuesta de valor se centra en crear experiencia para el cliente, la entrega o prestación del servicio será directamente en el centro de atención. La idea es generar un vínculo con el cliente para que regrese, es por eso que se dará servicio postventa y garantía de los trabajos realizados.

\subsubsection{Relaciones con clientes}

La estrategia principal que se busca tener es la fidelización de clientes ya que este tipo de empresas dedicadas al lavado de autos no genera una conexión con sus clientes. Este proyecto busca generar lazos entre empresa - cliente y entre cliente - cliente creando un ambiente agradable donde puedan reunirse, brindándoles además atención personalizada.

\subsubsection{Fuentes de ingreso}

De acuerdo al tipo de negocio que se plantea el mecanismo de fijación de los precios brindará una carta fija de costo por servicio. Se 
ofrecerán los servicios del auto lavado mediante montos preestablecidos (Lista de precios fija).

La empresa ofrecerá la flexibilidad de armar paquetes de servicios de acuerdo a lo que necesite cada cliente (Según características del producto). Por otro lado, se realizarán promociones con grandes descuentos por pre-pagar paquetes mensuales, trimestrales, semestrales o anuales de los servicios de lavado (según volumen).

\subsubsection{Recursos clave}

Para llevar a cabo el proyecto deberemos enfocarnos en un local o terreno amplio, que nos permite acondicionarlo como centro de lavado. Consideramos un terreno amplio entre 300 y $600 \mathrm{~m} 2$ para poder implementar el proyecto. También se necesitará equipos de lavado moderno. En este punto buscaremos adquirir un contrato con la empresa KARCHER la cual es reconocida por sus equipos de lavado y secado para vehículos ligeros.

Así mismo se necesitarán activos adicionales para poder brindar algunas comodidades a los clientes. Es importante mencionar que el querer brindar una experiencia en el servicio, el recurso humano, es decir las personas que trabajen en la empresa, será muy importante para poder transmitir el deseo de formar relaciones entre la empresa y los clientes.

Finalmente, como empresa se busca desarrollar una marca y posicionarla en el mercado. Se quiere ser sinónimo de experiencia, 
calidad de servicio y cuidado de medio ambiente, en el rubro ya mencionado.

\subsubsection{Actividades clave}

El proyecto se centrará en brindar servicios de lavado de autos en un ambiente altamente confortable, brindando alta calidad en sus servicios y cuidando el medio ambiente. El cuidado de medio ambiente se dará gestionando el uso eficiente y la reutilización del agua. También se busca dar flexibilidad a los clientes con la reservación de su servicio mediante web o App. Realizando una lista tenemos lo siguiente:

- Proceso de reutilización del agua.

- Programación de servicio vía web o Facebook Messenger.

- Sala de espera centrada en el Confort para el cliente (wifi, tomacorrientes, TV, espacios amplios para trabajar y relajarse).

- Servicio Express para clientes nuevos que estén de paso.

\subsubsection{Asociaciones clave}

El proyecto deberá desarrollar contratos con los principales proveedores de productos tanto para el lavado y secado de autos, como para los servicios adicionales antes mencionados. También se buscará realizar contratos con los proveedores de los insumos de limpieza. Esto permitirá a la empresa dar precios competitivos en sus paquetes de servicio. Los proveedores con los que se buscará trabajar son SONAX, 3M y KARCHER. 
Otros socios estratégicos son empresas que brindan servicios adicionales de personalización y mejora de desempeño para los autos (servicios distintos a los que la empresa brinda). Esto permitirá a la empresa a tener una cartera de clientes más grande y beneficiará tanto a las empresas asociadas como al proyecto en sí.

\subsubsection{Estructura de costes}

El presente proyecto está centrado en una estructura de costes según el valor que se le puede ofrecer al cliente. Como se menciona líneas arriba se prioriza la experiencia y personalización del servicio. Además, en esta estructura planteada los costos no son una prioridad sino la creación de valor. Esto se demuestra en la intención de ofrecer una sala de espera de "confort", amoblada y equipada para la total comodidad de los clientes. Así mismo, se puede notar en el enfoque medio ambiental, lo cual convierte el negocio hacia un público que le importan este tipo de temas.

Dentro de las características de la estructura observamos que el presente plan de negocios contiene lo siguiente:

1. Costes fijos: Alquiler del local, costos de servicios básicos área administrativa, el costo de los sueldos y beneficios de la planilla. Los gastos de ventas y publicidad.

2. Costes variables: Energía eléctrica y agua para el área operativa, costo de los insumos utilizados.

3. Economías de escala: A largo plazo y con el crecimiento del mercado que se atenderá, el proyecto se puede ver beneficiado por el volumen de autos atendidos. 
4. Economías de campo: Son un punto a desarrollar si se desean ampliar más allá de los 5 o 6 tipos de servicios que se ofrecerán.

\subsection{Visión}

Ser la empresa líder en el sector de lavado de autos creando una marca reconocida por la calidad, experiencia de servicio y cuidado del medio ambiente.

\subsection{Misión}

Proveer servicios de lavado de auto y servicios complementarios a todos los clientes amantes del cuidado de su auto, brindando una nueva experiencia y utilizando eficientemente el agua para el cuidado medio ambiental.

\subsection{Objetivos de la empresa}

A continuación, se listan los objetivos más resaltantes de la empresa:

- Buscar la recuperación de la inversión realizada en el menor tiempo posible.

- Conocer más acerca del mercado, las necesidades de los clientes y cómo cubrir sus expectativas con respecto a este tipo de negocios.

- Conocer los principales proveedores tanto de productos para el cuidado del auto como de equipos para lavado.

- Establecer la mejor ubicación posible para el proyecto.

- Mejorar la zona de espera del cliente, haciéndola más llamativa y cómoda para él.

- Posicionarnos como la empresa líder en el sector

- Abrir nuevas sucursales en el mediano plazo. 
- Desarrollar vínculos duraderos con nuestros clientes.

- Crear una marca que sea reconocida como sinónimos de experiencia, calidad y servicio personalizado.

- Ampliar la gama de servicios ofrecidos centrados en el cuidado y personalización de los autos.

- Desarrollo y capacitación de nuestros trabajadores buscando la especialización de la mano de obra. 


\section{CAPÍTULO II. ANÁLISIS DE LA INDUSTRIA Y DEL MERCADO}

\subsection{Análisis de la industria}

Las empresas dedicadas al rubro de lavado de autos han comenzado a crecer en los últimos años. El Perú es una plaza muy interesante por el crecimiento del parque automotor. Desde 1998 hasta el 2012 el parque automotor nacional ha crecido sin detenerse, alcanzando hasta el 2012 una cantidad de casi 3 millones de vehículos en el país. Es importante mencionar que, como se muestra en la Figura 1, según la clase de vehículos, los automóviles son los que representan el mayor porcentaje del total, alcanzando aproximadamente el $47 \%$ del parque automotor. Sin embargo, los vehículos como camionetas representan aproximadamente el 22\%. (Ministerio de Transporte y Comunicaciones[MTC] \& Superintendencia Nacional de Registros Públicos[SUNARP],2012).

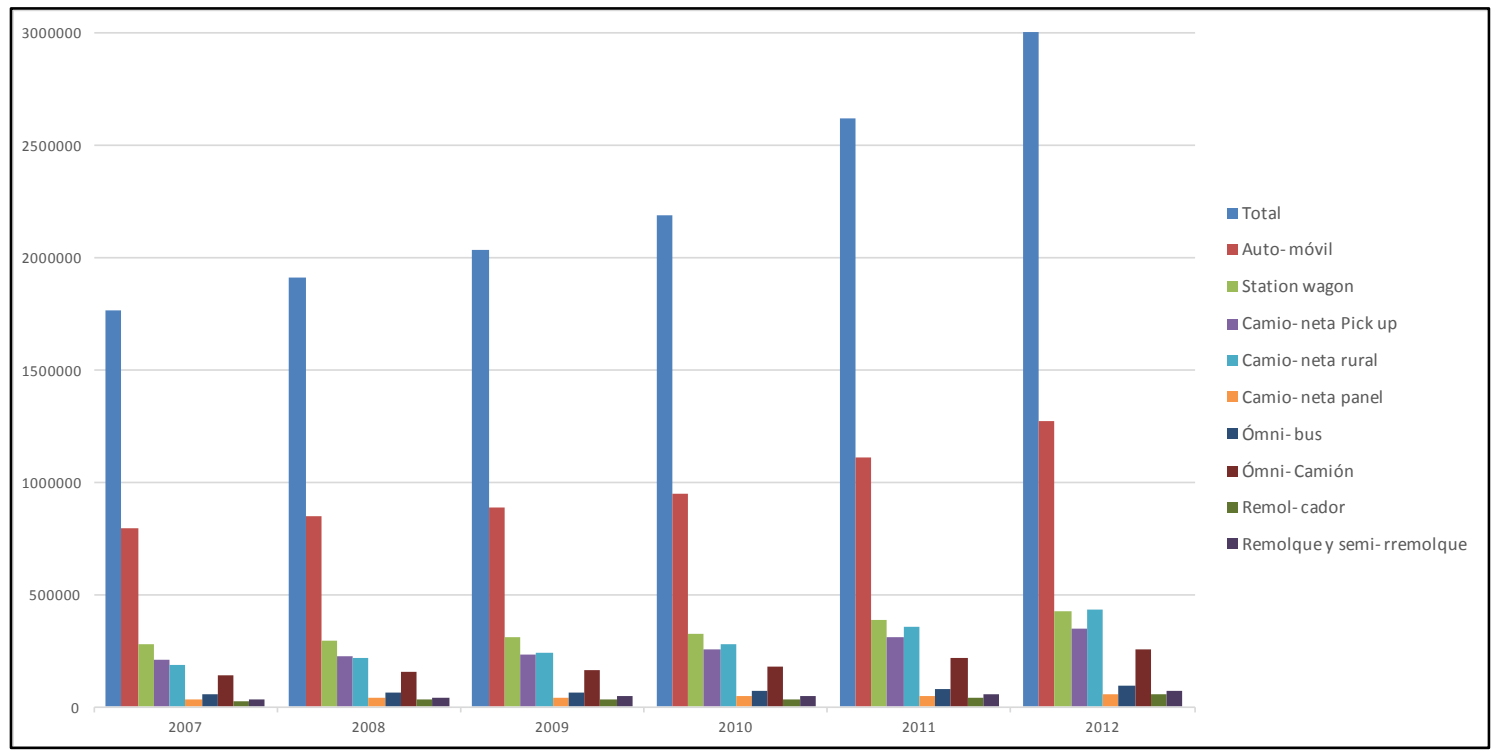

Figura 1. Parque automotor nacional, por clase de vehículo 1998-2012. Elaborado por el Instituto Nacional de Estadística e Informática (INEI). Fuente de información tomada de Ministerio de Transporte y Comunicaciones y Superintendencia Nacional de Registros Públicos. Recuperado de http://m.inei.gob.pe/media/MenuRecursivo/Cap19021.xls 
Como se observa en la Figura 2, durante los años 2014 y 2015, el crecimiento sostenido del parque automotor llegó a su máximo y comenzó a decrecer, viéndose reducida las ventas (nuevas) de las diferentes clases de autos en 7\% del 2013 al 2014. Así también, hubo un decrecimiento de 7\% del 2014 al 2015. En el 2016 la tendencia aún se mantuvo en negativo, a pesar de que se esperó un repunte en la segunda mitad del año (BBVA Continental, 2015).

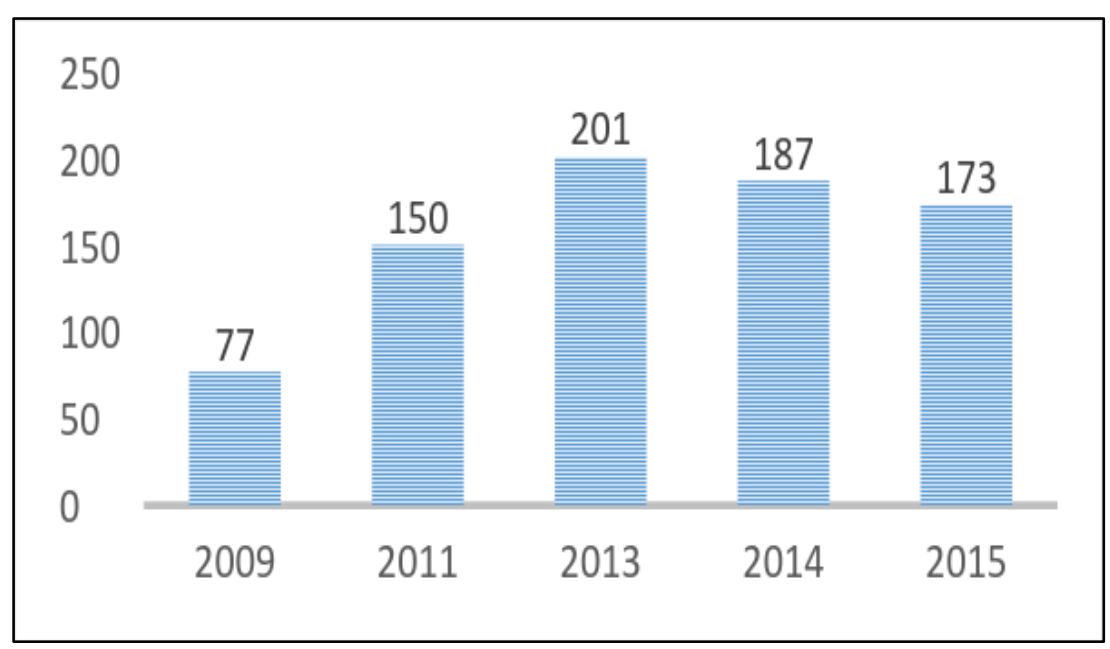

Figura 2. Venta de autos nuevos en miles de unidades (2009-2015).

Tomado de Situación Automotriz por BBVA Research, 2015. Recuperado de https://www.bbvaresearch.com/wp-content/uploads/2015/12/SectorAutomotriz_Diciembre-2015-Peru_FINAL.pdf

A pesar de no ser parte de esta investigación se debe mencionar que se estima que la causa que produjo el decrecimiento del parque automotor en el Perú fue la caída de la moneda local debido a que sufrió una fuerte depreciación desde el 2014, encareciendo la importación de autos (BBVA Continental, 2015). En la Figura 3 podemos ver la evolución del tipo de cambio entre los años 2013 al 2015. 


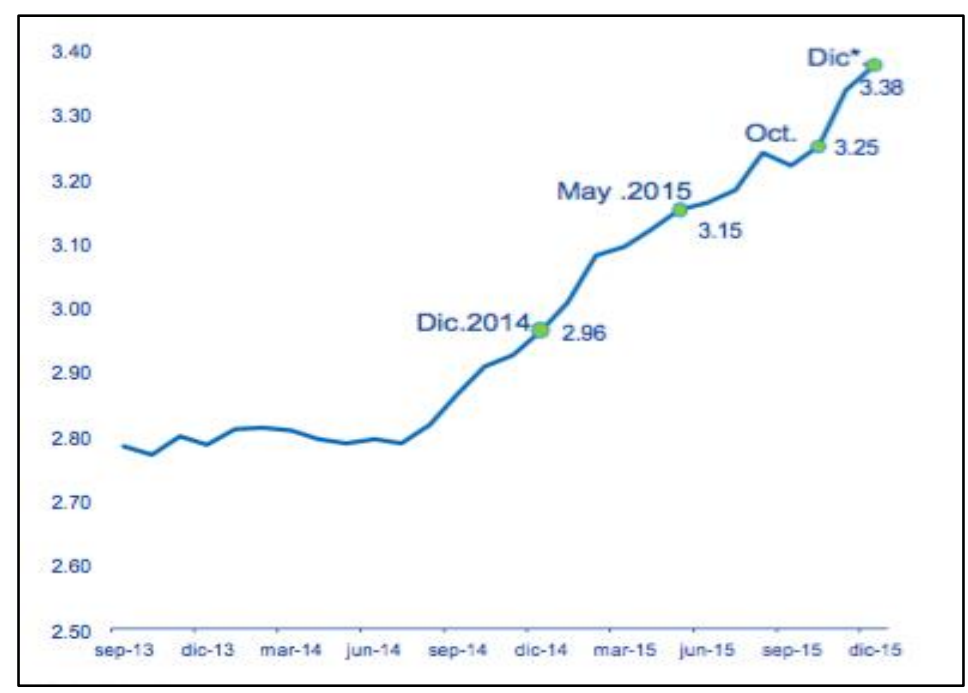

Figura 3. Evolución del tipo de cambio (2013-2015). Tomado de Situación Automotriz por BBVA Research, 2015. Recuperado de https://www.bbvaresearch.com/wp-content/uploads/2015/12/SectorAutomotriz_Diciembre-2015-Peru_FINAL.pdf

Enfocándonos más a la industria de servicios para el sector automotriz observamos que el tipo de actividad primaria a la que pertenece el proyecto es CIIU 9609 - Otras actividades de servicios (Revisión 4). Además, como actividades secundarias tenemos: CIIU 4520 y CIIU 4530 de la categoría comercio al por mayor y al por menor; y reparación de vehículos automotores y motocicletas respectivamente (Instituto Nacional de Estadística e Informática [INEI], 2010).

Para entender como contribuyen los sectores económicos involucrados en este proyecto observemos la Figura 4 y analicemos el comportamiento de los sectores de Comercio y Otros servicios. Como se observa, estas dos actividades económicas mencionadas, han venido aportando de forma positiva al producto bruto interno (INEI, 2007-2015). Además, reforzando esta información, podemos decir que en los últimos años los sectores que le han dado soporte al PBI no primario son comercio y servicios con un crecimiento de $4.0 \%$ y $5.0 \%$ respectivamente (BBVA Continental, 2015). 
Esto nos permite inferir que los negocios relacionamos al sector automotriz han venido creciendo sostenidamente en los últimos años de la mano con el parque automotor. A pesar de la desaceleración del sector automotriz las actividades económicas no se han visto afectadas. Es decir, todos aquellos negocios relacionados con la prestación de servicios para autos siguen creciendo y aportando al PBI.

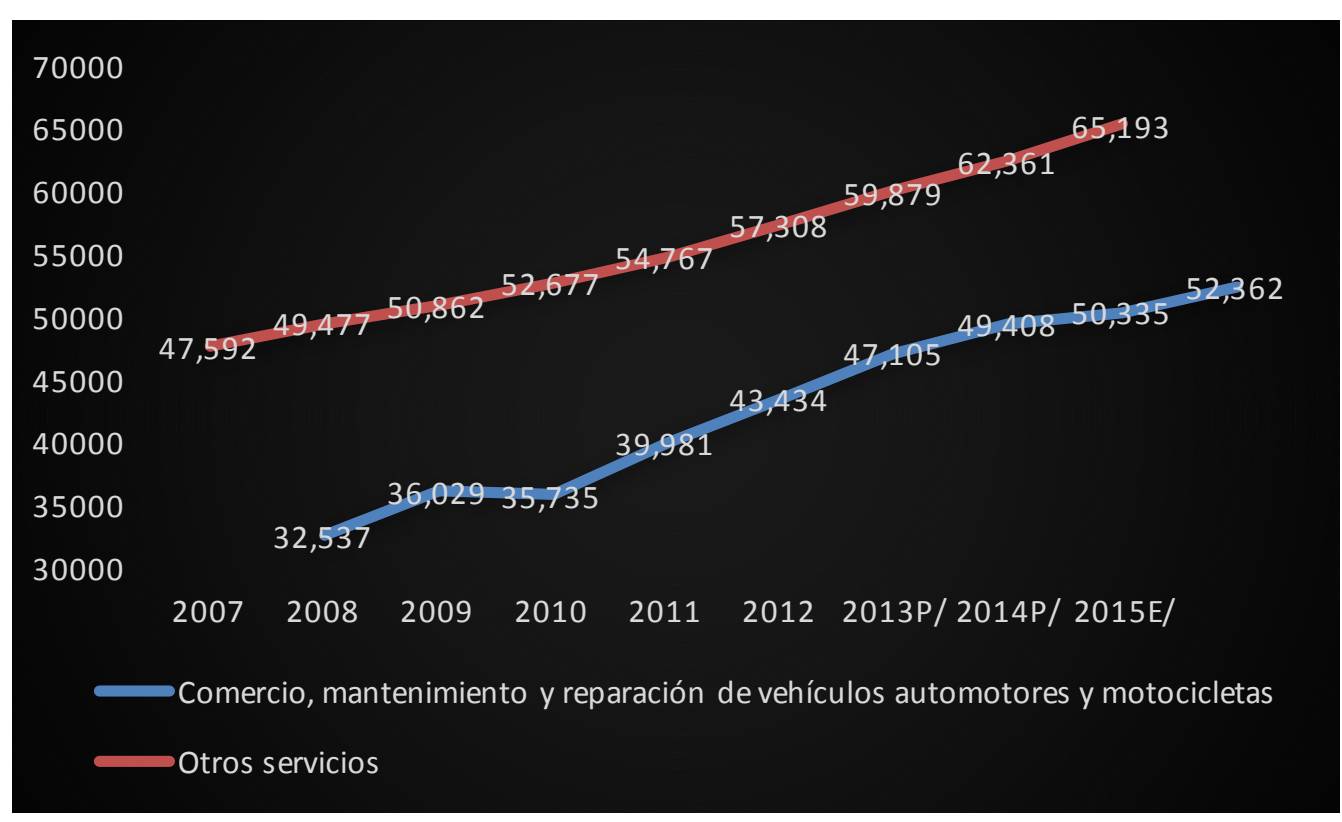

Figura 4. Producto Bruto Interno según actividad económica, en millones de soles, nivel 54 (2007-2015). Adaptado de Instituto Nacional de Estadística e Informática (INEI). Recuperado de https://www.inei.gob.pe/estadisticas/indice-tematico/economia/

\subsection{Análisis del mercado}

El análisis de mercado permitirá conocer la demanda del negocio a través de la adecuada segmentación de los mercados. Además, como consecuencia se podrá determinar la ubicación para el proyecto de acuerdo al mercado que se quiere atender. Una de las variables de segmentación que se tomará en cuenta es el nivel socioeconómico, el cual nos ayudará a 
determinar que niveles son los que poseen autos y que a su vez utilizan servicios de lavado.

El nivel socioeconómico (NSE) constituye una de las variables fundamentales en el proceso de clasificación de información. Se entiende por NSE un conjunto significativo de personas que comparten condiciones económicas y sociales que las hacen similares entre sí y distintas de las demás. Esa clasificación nos permitirá describir el perfil general del total de limeños y de cada nivel socioeconómico (IPSOS Perú, 2012). También se tomará en cuenta los distritos clasificados por zonas según un estudio realizado por la Asociación Peruana de Empresas de Investigación de Mercado [APEIM] en el año 2016. En la Figura 5 se muestra la clasificación de los distritos por zonas.

Complementando el análisis inicial se realizó un sondeo dirigido al siguiente público objetivo: jóvenes entre 20 y 30 años, que poseen auto propio, y que utilizan el servicio de lavado de autos. El sondeo fue realizado en noviembre del 2016.

La finalidad de este sondeo fue obtener respuestas a las siguientes interrogantes: (i) Qué porcentaje de las personas que poseen autos utilizan el servicio de lavado de autos para sus vehículos, (ii) La frecuencia con las que las personas utilizan el servicio en mención, (iii) Cuánto es el gasto promedio que realizan en esta clase de establecimientos, (iv) Conocer la cantidad de personas interesadas en tomar el servicio que brindará el proyecto, (v)El distrito en donde preferiría que se ubique un local de lavado de autos, (vi)El precio que estarían dispuesto a pagar por el servicio brindado por este nuevo proyecto, (viii) Qué les gustaría encontrar en un 
local de servicio de lavado de autos que los haga sentir cómodos en la espera de su servicio.

\begin{tabular}{|l|}
\hline Zona 1 (Puente Piedra, Comas, Carabayllo) \\
\hline Zona 2 (Independencia, Los Olivos, San Martin de Porras) \\
\hline Zona 3 (San Juan de Lurigancho) \\
\hline Zona 4 (Cercado, Rimac, Breña, La Victoria) \\
\hline Zona 5 (Ate, Chaclacayo, Lurigancho, Santa Anita, San Luis, ET \\
\hline Zgustino) \\
\hline Zona 6 (Jesús Maria, Lince, Pueblo Libre, Magdalena, San Miguel) \\
\hline Zona 7 (Miraflores, San Isidro, San Borja, Surco, La Molina) \\
\hline Zona 8 (Surquillo, Barranco, Chorrillos, San Juan de Miraflores) \\
\hline Zona 9 (Villa El Salvador, Villa Maria del Triunfo, Lurin, Pachacamac) \\
\hline Zona 10(Callao, Bellavista, La Perla, La Punta, Carmen de la Legua, \\
Ventanilla) \\
\hline
\end{tabular}

Figura 5. Clasificación de distritos por zonas (2016). Tomado de "Niveles Socioeconómicos 2016" por la Asociación Peruana de Empresas de Investigación de Mercados (APEIM), 2016.

El mercado total está representado por el parque automotor y sus propietarios. Si bien este mercado es amplio para atender, debemos enfocarnos en segmentar tres temas principales: los tipos de vehículos que serán atendidos, las zonas o distritos cercanos a la ubicación del negocio y los NSE a los que se enfoca el servicio. De esta forma obtendremos el mercado potencial. El mercado potencial es el conjunto de consumidores que presenta un nivel de interés suficientemente elevado por la oferta de mercado, estos consumidores deben tener un ingreso suficiente y tener acceso a la oferta (Kotler \& Keller, 2006).

Como se mencionó en el análisis de la industria tomaremos del total del parque automotor dos tipos de vehículos: (i) los autos que representan el 
$47 \%$ y (ii) las camionetas en todos sus tipos, las cuales representan el $22 \%$ (MTC \& SUNARP, 2012).

Para la segmentación por NSE y zonas de residencia, se debe tomar en cuenta que, en Lima Metropolitana, el 18.1\% de los hogares posee auto, el total de hogares estimados es de 2'686,690. Dentro de este porcentaje tenemos que los NSE con mayor porcentaje que poseen este bien son NSE “A” con $87.8 \%$, NSE "B" con 39.5\% y NSE "C1" con 11.4\% (APEIM, 2016).

Continuando con la segmentación y habiendo definido los principales NSE que podrían atenderse en el proyecto que ofrecemos, los cuales son los NSE A y B, veremos en qué distrito puede ubicarse el proyecto. Como muestra la Figura 5, tenemos los distritos de Lima Metropolitana clasificados en 10 distintas zonas. El estudio de APEIM, muestra una clasificación de NSE por zonas (distritos) en la cual detalla el porcentaje de cada NSE en cada zona (distrito).

De acuerdo a lo mencionado anteriormente, en los siguientes gráficos podemos observar que la zona 7 agrupa a los NSE principales a los que se enfoca el negocio. La zona 7 posee los distritos de Miraflores, San Isidro, Surco, San Borja y La Molina. En esta zona el NSE A posee el 55.5\%, el B posee el $14.6 \%$ y el C un $2.6 \%$. Así mismo, observamos que la segunda zona con mayor participación del NSE A es la zona 6 igual que con el NSE B. Esto nos hace pensar que las dos principales zonas que podríamos atender son la 6 y 7, abarcando los distritos de Miraflores, Surco, San Borja, San isidro, La Molina, Jesús María, Lince, Pueblo libre, Magdalena y San Miguel. (APEIM, 2016). 
Por otro lado, observamos que los NSE B y C tienen una mayor participación en las Zonas 2 y 3 las cuales componen los distritos de Independencia, Los Olivos, San Martin de Porres y San Juan de Lurigancho. Este último dato permite pensar que en el futuro se puede abrir una sucursal del negocio cerca de las zonas mencionadas (APEIM, 2016).

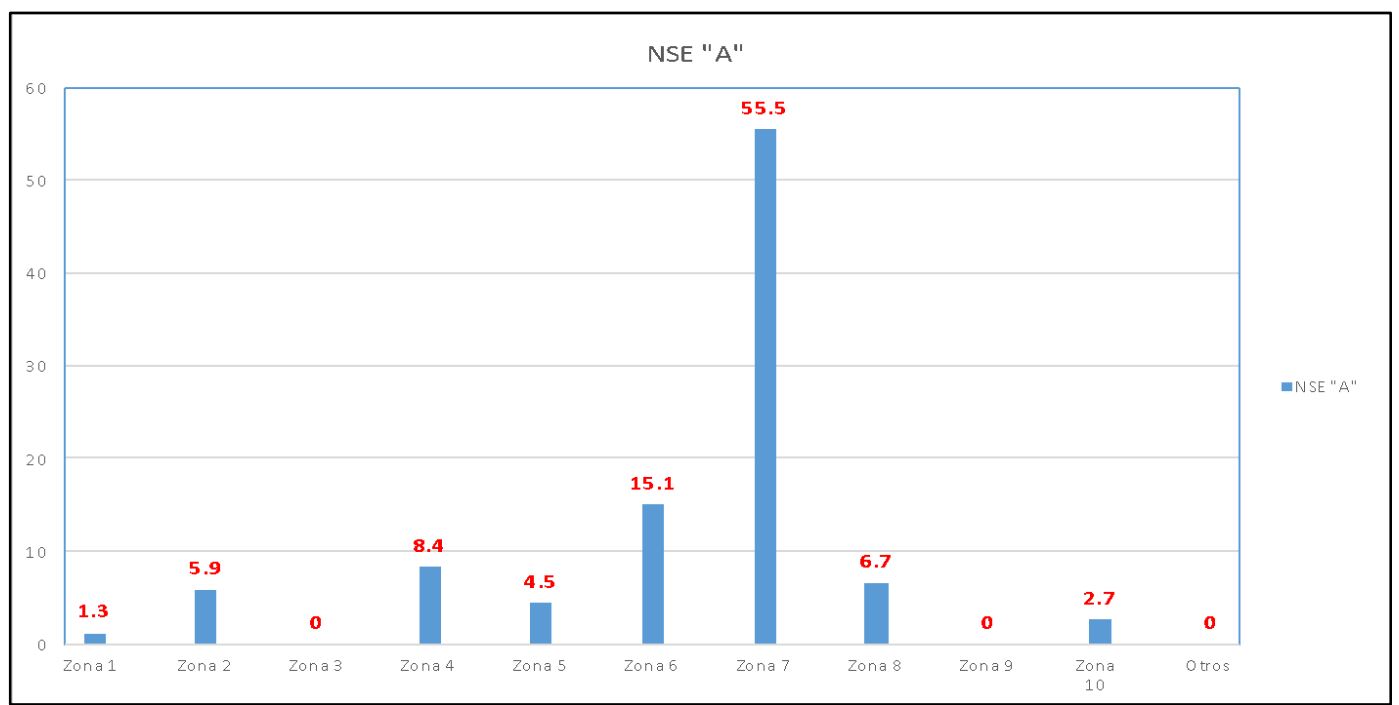

Figura 6. Distribución de NSE A por zonas, Lima Metropolitana. Adaptado de "Niveles Socioeconómicos 2016" por la Asociación Peruana de Empresas de Investigación de Mercados (APEIM), 2016.

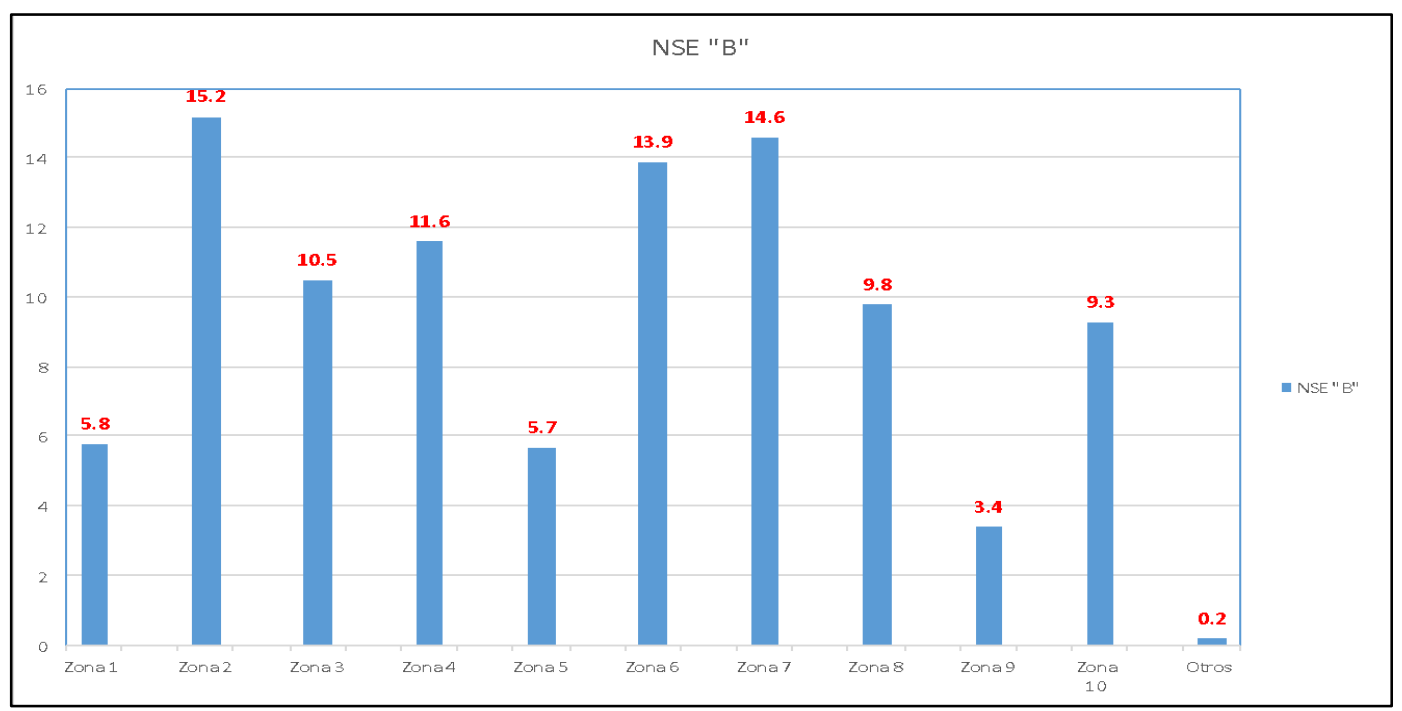

Figura 7. Distribución de NSE B por zona, Lima Metropolitana. Adaptado de "Niveles Socioeconómicos 2016" por la Asociación Peruana de Empresas de Investigación de Mercados (APEIM), 2016. 


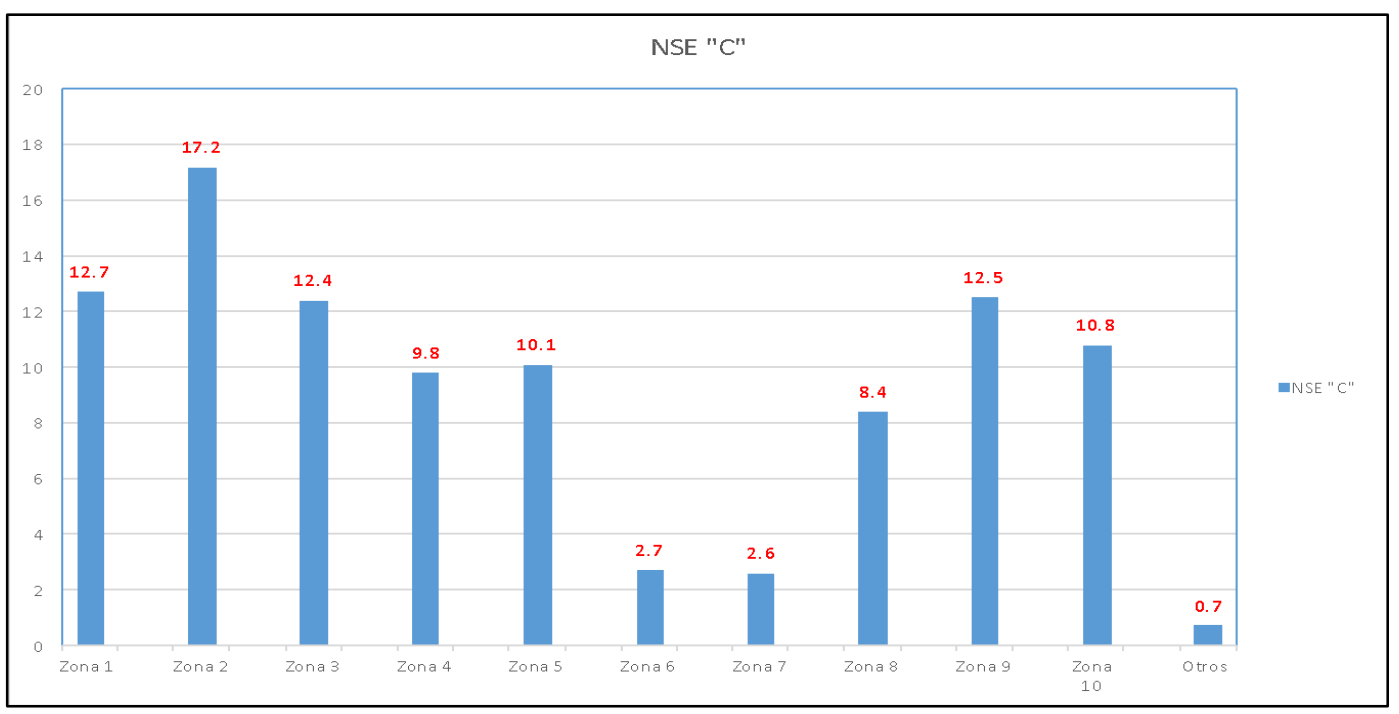

Figura 8. Distribución de NSE C por zona, Lima Metropolitana. Adaptado de "Niveles Socioeconómicos 2016" por la Asociación Peruana de Empresas de Investigación de Mercados (APEIM), 2016.

Habiendo encontrado las principales zonas que serán atendidas considerando: ubicación geográfica y NSE, se tiene el siguiente mapa. El círculo negro enmarca todos los distritos que podrían ser atendidos por el proyecto, además como distrito céntrico se tiene como primera opción San Borja.

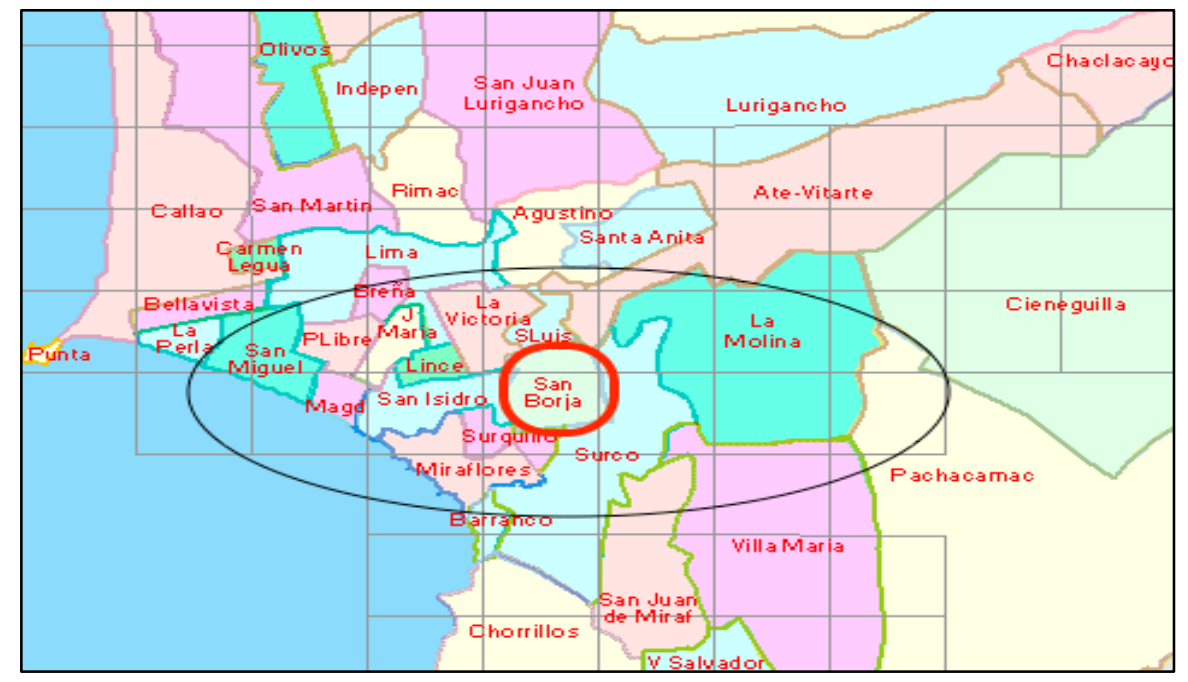

Figura 9. Mapa por distritos de Lima Metropolitana 2016. Recuperado de http://www.guiacalles.com 
Los resultados obtenidos del análisis establecieron que el distrito de San Borja es una de las opciones para localizar el proyecto por tener una ubicación céntrica con respecto a los otros. Sin embargo, según el sondeo que se realizó, se plantearon 4 principales distritos a los encuestados, en los que desearían que estuviera ubicado un centro de lavado de autos. Estos distritos tomados en cuenta para el sondeo pertenecen a la zona 7 , en la cual se centra la mayor parte del NSE que se desean atender.

Los resultados del sondeo dieron los siguientes porcentajes: La Molina (31.43\%), San Isidro (29.73\%), San Borja (13.51\%) y Surco (24.32\%). Como se observa el distrito que prefieren los encuestados es el distrito de la Molina, el cual, está dentro de nuestro estudio de NSE por zonas.

Continuado con el análisis de segmentación se realizan una serie de cálculos con los cuales se busca obtener el mercado total, el mercado potencial y el mercado objetivo. El resultado de este cálculo dará la cantidad de vehículos que el proyecto busca atender en un horizonte de tiempo dado. En el caso de este proyecto la cantidad de vehículos que se desea atender (mercado objetivo) será en el horizonte de un año.

Como se había mencionado los vehículos que se atenderán serán autos y camionetas los cuales en su conjunto representan el 69\% del parque automotor. Se ha realizado una proyección del parque automotor al año 2015. Se tomó como base la información de parque automotor al 2012 brindado por el MTC y SUNARP; y agregándole el crecimiento de automóviles brindado por el informe de BBVA Continental en el año 2015. Después de los cálculos tenemos que el parque automotor llega a una cantidad total de 3,891,594 millones de vehículos. El resultado de 
segmentar el total de vehículos en el mercado nacional nos da como resultado la cantidad de 2,685,200 vehículos.

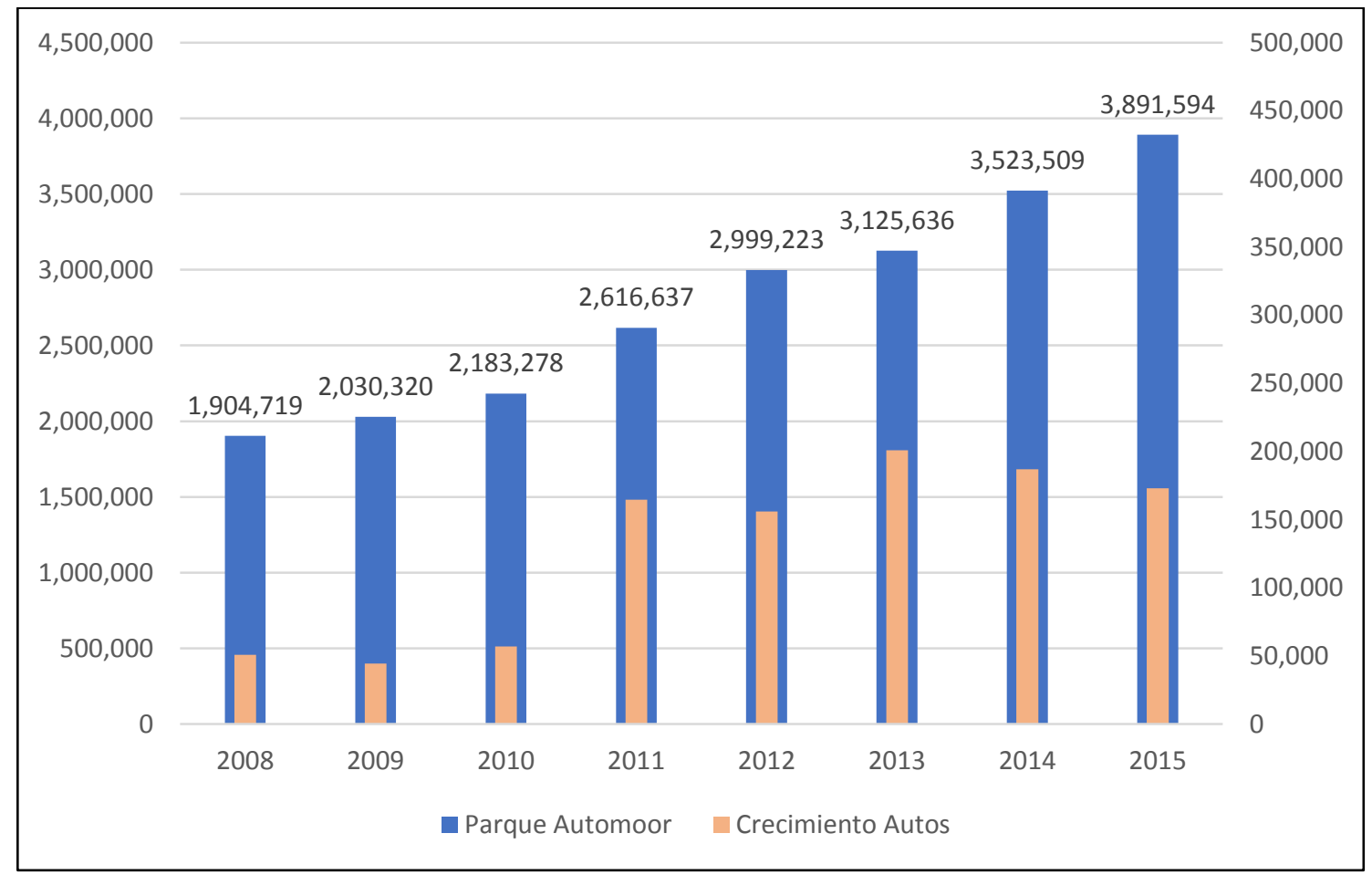

Figura 10. Parque automotor estimado al 2015. Adaptado de Situación Automotriz por BBVA Research, 2015 e Instituto Nacional de Estadística e Informática (INEI).

Tabla 1: Mercado total (autos y camionetas del parque automotor)

\begin{tabular}{|l|r|}
\hline Categorías por tipo de vehículo & Cantidad (und) \\
\hline Total Parque Automotor (100\%) & $3,891,594$ \\
\hline Total de autos (47\%) & $1,829,049$ \\
\hline Total de camionetas (22\%) & 856,151 \\
\hline Mercado total & $2,685,200$ \\
\hline
\end{tabular}

Nota: Tomado de Parque automotor nacional, por clase de vehículo 1998-2012.

Elaborado por el Instituto Nacional de Estadística e Informática (INEI). Fuente de información tomada de Ministerio de Transporte y Comunicaciones y Superintendencia Nacional de Registros Públicos.

Recuperado de http://m.inei.gob.pe/media/MenuRecursivo/Cap19021.xls 
Siguiendo con los cálculos se buscará obtener el mercado potencial. Este mercado comprende todos aquellos clientes que tienen los recursos para poder pagar esta clase de servicio (Kotler \& Keller, 2006).

Para calcular este dato, segmentamos a los propietarios de los vehículos de acuerdo a su NSE. Además, según lo mostrado anteriormente se elegirá las zonas de influencia del proyecto. Según los NSE y las zonas en las que se encuentran nuestros clientes potenciales, tenemos que los niveles A y B son a los que se dará mayor enfoque. Además, de acuerdo al sondeo, los encuestados prefieren la ubicación del negocio en el distrito de la Molina, perteneciendo este a la Zona 7, la cual se tomará en cuenta para el cálculo del Mercado Potencial. Otro dato a tomar en cuenta para calcular el mercado potencial será el porcentaje de personas que poseen auto para los NSE "A" y "B", de este modo podremos dividir el mercado total.

El NSE "A" representa el $87.8 \%$ del total de personas que poseen auto y el NSE "B" representa el 39.5\%. Dentro de estos porcentajes tomaremos en cuenta que en la Zona 7 el NSE "A" tiene el 55.5\% y el NSE "B" tiene el 14.6\%. Realizando los cálculos se tiene que del 55.5\% del NSE "A" el $87.8 \%$ posee auto dando como resultado que el $48 \%$ de personas del NSE “A" poseen auto. Así mismo, del 14.6\% del NSE "B" el 39.5\% posee auto dando como resultado que el $5.8 \%$ de personas del NSE "B" poseen auto.

De este modo el mercado potencial es de 1,463,326 vehículos y está situado en los distritos de La Molina, Surco, San Borja, Miraflores y San isidro. 
Tabla 2: Mercado Potencial

\begin{tabular}{|l|r|}
\hline Personas que poseen auto por NSE & Cantidad (und) \\
\hline NSE "A" Zona 7 & $1,308,471$ \\
\hline NSE "B" Zona 7 & 154,855 \\
\hline Mercado Potencial & $1,463,326$ \\
\hline
\end{tabular}

Nota: Tomado de "Niveles Socioeconómicos 2016" por la Asociación Peruana de Empresas de Investigación de Mercados (APEIM), 2016. Cálculos y elaboración propia.

Una vez hallado a todos aquellos que tienen la posibilidad de tomar los servicios brindados por el proyecto se procederá a realizar los cálculos necesarios para hallar el mercado disponible. El mercado disponible es parte del mercado potencial, los consumidores además de la necesidad tienen la intención de compra, es definido a través de los resultados de la encuesta (Reyes, 2013).

Es así que, dentro del sondeo se preguntó quiénes utilizaban el servicio de lavado de autos y quienes estarían dispuesto a tomar el servicio brindado por este proyecto. Los resultados mostraron que dentro de las personas que poseen vehículos el $74 \%$ utiliza este servicio y el $26 \%$ no lo utiliza. Además, $64.86 \%$ de los encuestados respondieron afirmativamente a la intención de probar los servicios de este proyecto.

La cantidad de vehículos al segmentar el mercado potencial en los clientes que utilizan esta clase de servicios es de 1,082,862 vehículos. Además, dividiendo esta cantidad en las personas que tienen la intención de tomar el servicio, tenemos como resultado que el mercado disponible es de 702,344 vehículos. 


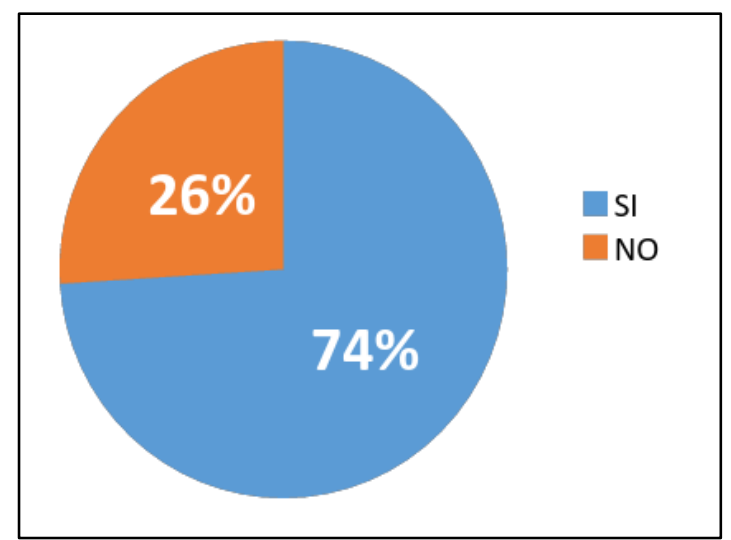

Figura 11. Porcentaje de encuestados que utilizan el servicio de Car Wash. Tomado de encuesta propia. Elaboración propia.

Tabla 3: Cantidad de personas que utilizan el servicio de lavado de autos

\begin{tabular}{|l|r|}
\hline Resultados encuesta propia & Cantidad (und) \\
\hline Lava en Car Wash (\%) & 0.74 \\
\hline No Lava en Car Wash (\%) & 0.26 \\
\hline Total que Lava en Car Wash & $1,082,862$ \\
\hline
\end{tabular}

Nota: Tomado de encuesta propia. Cálculos y elaboración propia.

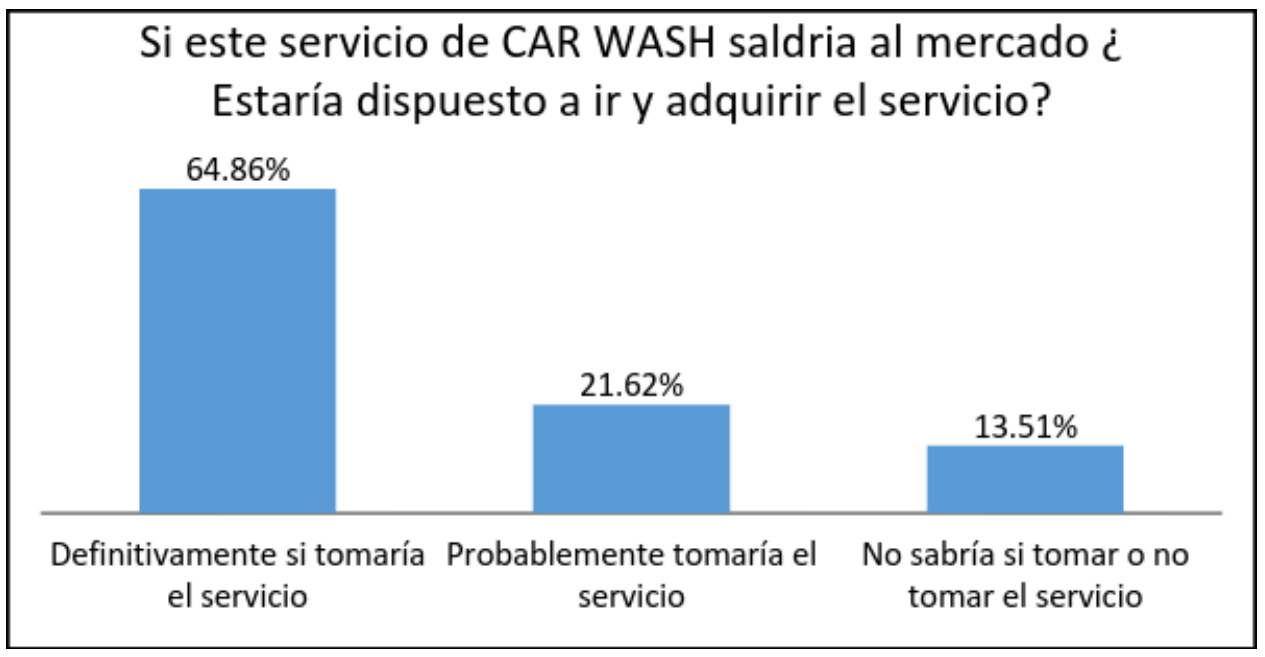

Figura 12. Porcentaje de encuestados dispuestos a tomar el servicio brindado por el proyecto. Tomado de encuesta propia. 
Tabla 4: Mercado Disponible

\begin{tabular}{|l|r|}
\hline Resultados encuesta propia & Cantidad (und) \\
\hline Definitivamente $\mathrm{Si}$ & 0.6486 \\
\hline Probablemente $\mathrm{Si}$ & 0.2162 \\
\hline Probablemente No & 0.1351 \\
\hline Mercado Disponible & 702,344 \\
\hline
\end{tabular}

Nota: Tomado de encuesta propia. Cálculos y elaboración propia.

Finalmente se calculará el mercado objetivo tomando como referencia a una empresa cercana a este proyecto la cual se desempeña en el mismo rubro. Esta empresa llamada Heviclubs tiene un poco menos de un año de operación y en una entrevista a su socio fundador menciona que la cantidad de autos atendidos en los días de semana entendidos entre lunes y viernes está entre 15 y 20 vehículos diarios. Además, la cantidad de vehículos atendidos los fines de semana (sábado y domingo) está entre 35 y 40 autos.

Realizando una proyección tenemos que en un año pueden atenderse cerca de 6,750 vehículos. Esta cantidad representa casi el 1\% del mercado disponible. Considerando estas cifras antes mencionadas, debemos decir que el proyecto podría iniciar con un escenario conservador, atendiendo al $1 \%$ del mercado disponible, el cual con exactitud representaría 7,023 vehículos al año. Este porcentaje se toma de referencia de una empresa similar al proyecto en curso.

\section{Tabla 5: Mercado Objetivo}

\begin{tabular}{|l|r|}
\hline Porcentaje que se proyecta atender & Cantidad (und) \\
\hline $1 \%$ del mercado disponible & 7,023 \\
\hline Mercado Objetivo & 7,023 \\
\hline
\end{tabular}

Nota: Tomado de entrevista al dueño de la empresa Heviclubs. Elaboración propia. 
Además, es importante mencionar que de acuerdo a una entrevista realizada al dueño del negocio que se tomó como referencia, se pudo definir algunas características del perfil del consumidor, las cuales son:

a. El porcentaje de hombres que asisten a un centro de lavado de autos es mayor que el porcentaje de mujer en una relación de 3 a 1 .

b. Por lo general, los hombres cuidan cada detalle del lavado y están observando atentamente cada trabajo realizado en él.

c. Las mujeres muchas veces se sientan en la sala de espera a leer una revista y no están con un seguimiento constante como los hombres.

d. Ambos géneros de personas se notan muy impacientes o aburridos por no tener un lugar donde distraerse. Muchas veces se recibió propuestas de mejorar la sala de espera pequeña que tenía el negocio.

e. Con la tecnología hoy en día muchos están atentos a sus dispositivos electrónicos. Sin embargo, no todos tienen planes con líneas abiertas o no todos quieren gastar sus datos. Muchas veces preguntaban si había Wi-fi.

f. Las mujeres son las que tienen una mayor fuerza en lo que es publicidad de boca a boca o cuando envían a sus referidos.

g. Aunque generalmente el cobro era en efectivo, los clientes pedían mucho el pago con tarjeta, por ese motivo se habilitó esa opción.

Toda esta información será procesada y ayudará a diseñar y plasmar con más detalle el servicio que brindará este proyecto. 


\subsection{Análisis del entorno}

En este punto analizaremos como ha influenciado el PBI a los principales sectores que está relacionado el negocio. En el punto anterior se estableció que las principales actividades económicas eran el sector comercio y el sector de servicios (BBVA,2015). Es importante mencionar estas actividades ya que están relacionadas directamente con el PBI no primario.

Se inicia el análisis con la siguiente figura, en la cual se muestra una comparación entre el PBI y el crecimiento de autos nuevos año tras año en el periodo de 1989 a 2015. (MTC, SUNARP, BCRP).

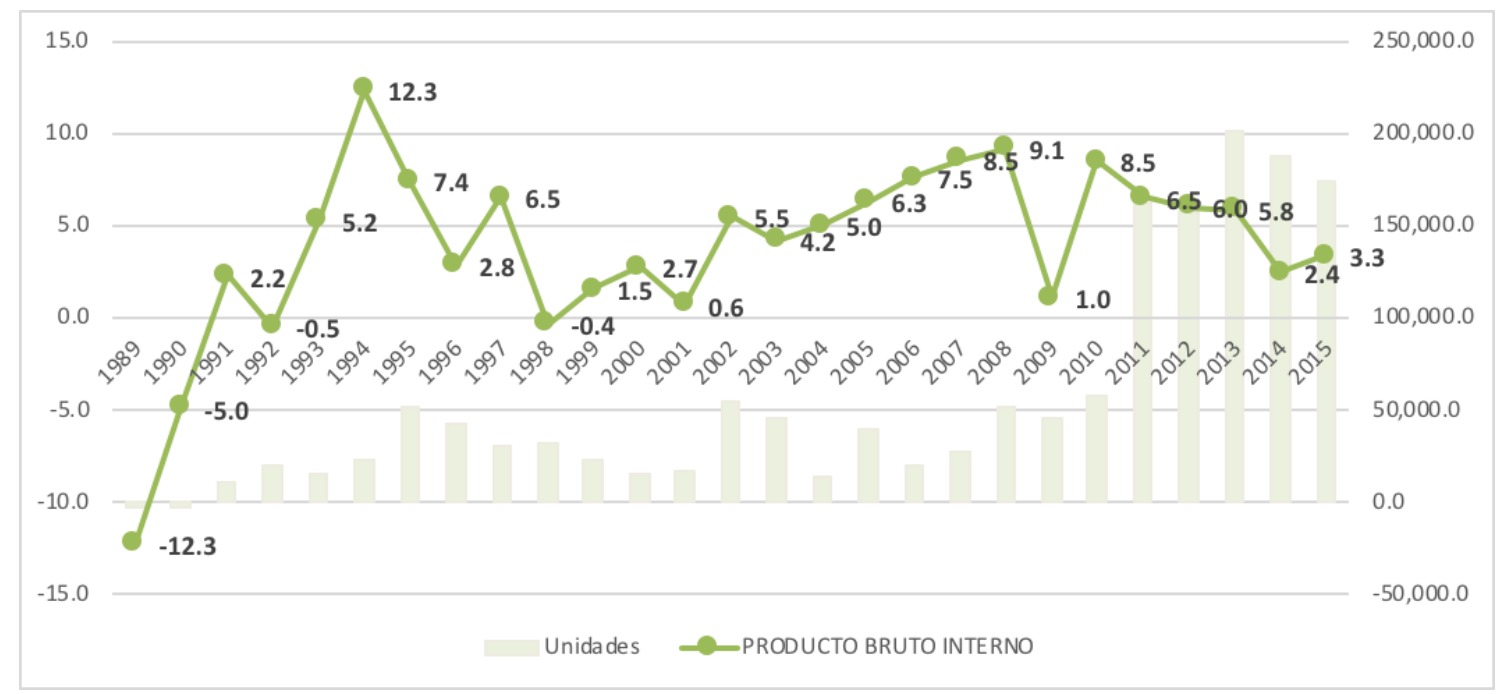

Figura 13: Crecimiento PBI (\%) vs Crecimiento autos nuevos (unidades). Adaptado de Adaptado de Situación Automotriz por BBVA Research, 2015, Instituto Nacional de Estadística e Informática (INEI) y Banco Central de Reserva del Perú (BCRP).

La figura 13 nos muestra que no hay una relación directa entre los valores porcentuales de crecimiento del PBI y el crecimiento de autos nuevos año a año. Sin embargo, nos permite centrarnos entre los años 2000 al 2015, ya que se observa una cierta estabilidad en el crecimiento del PBI. 
Ahora debemos entender que sectores económicos son los que tienen mayor aporte al PBI. Dentro de sector primario, la minería es el rubro que aporta más al crecimiento del PBI, por encima de la pesca y el sector agropecuario. Según el PBI (en millones de soles) en lo últimos 10 años la minería representa el 68\% del PBI Primario y $15 \%$ del PBI total (BCRP,2016). Por otro lado, el sector de servicios es el más importante no sólo para el PBI no primario, representando el 58\%, sino al PBI total, representando el 47\% (BCRP,2016). A continuación, se muestras dos figuras en donde se analiza la relación del PBI con sus principales sectores económicos.

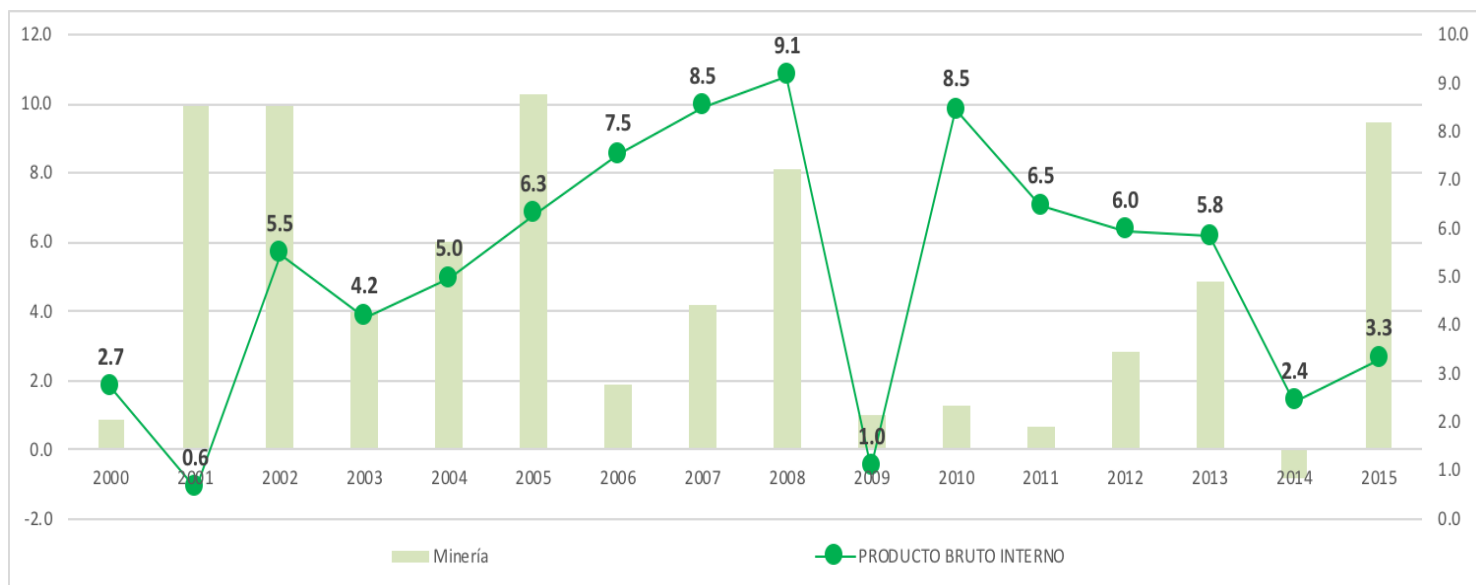

Figura 14: Comparación entre crecimiento del PBI (\%) y el crecimiento del sector de la minería (\%). Adaptado de Excel titulado "Producto Bruto Interno por Sectores Productivos" del BCRP.

En la figura 14 podemos establecer que la variación ya sea de crecimiento o decrecimiento de la minería influye en el PBI. Cuando se tiene un crecimiento menor del sector esto desacelera al PBI. Sin embargo, no observamos gráficamente que esa relación se cumpla en todos los casos. 


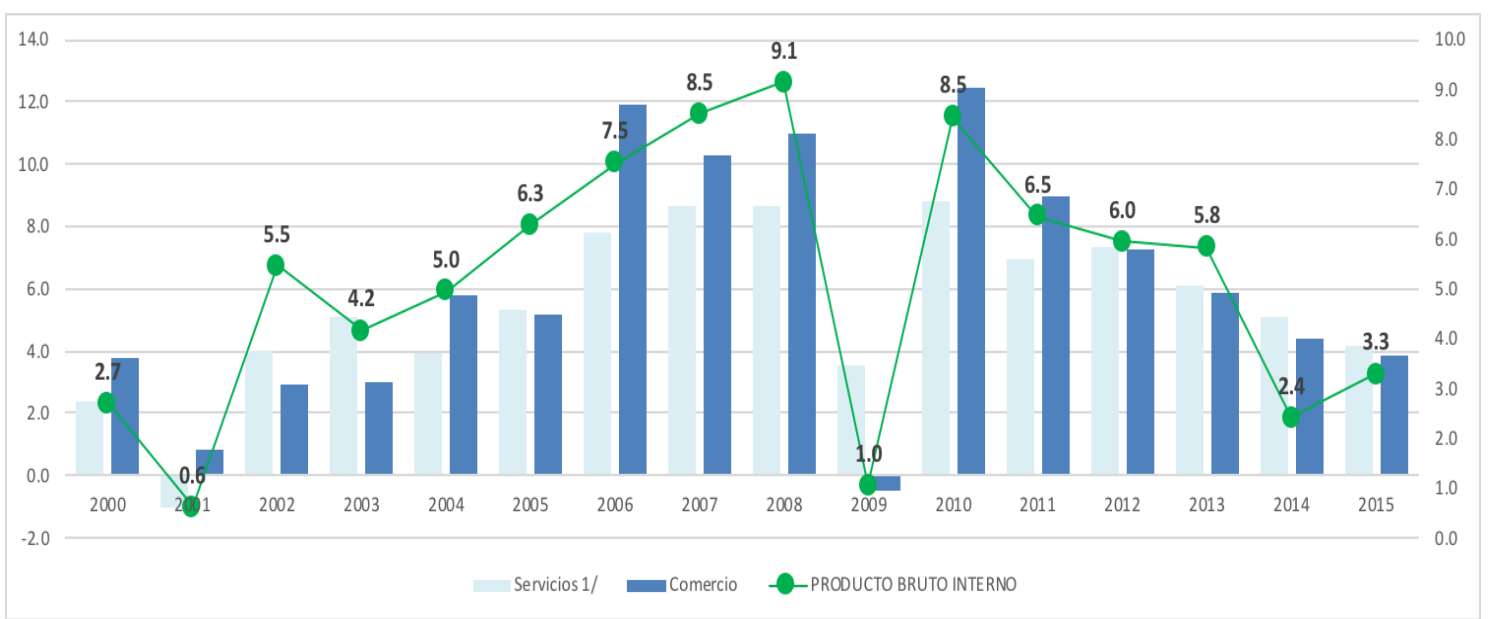

Figura 15: Comparación entre crecimiento del PBI (\%) y el crecimiento del sector de servicios (\%). Adaptado de Excel titulado "Producto Bruto Interno por Sectores Productivos" del BCRP.

En la figura 15 observamos la relación entre el crecimiento porcentual del PBI y los sectores más importantes para este proyecto (Comercio y Servicios). La figura muestra claramente que existe una relación directa entre los sectores en mención y el PBI total. Podemos decir entonces que los sectores económicos de servicios y comercio sostienen el crecimiento del producto bruto interno del país, resaltando la importancia del sector no primario con respecto a su aporte al PBI.

Como conclusión podemos decir que un cambio en las proyecciones del PBI ya sea positivo o negativo impactará notablemente en el crecimiento de los sectores comercio y servicios. Esto a su vez tendrá un impacto con respecto al crecimiento de las ventas de autos nuevos en nuestro país. En la figura 16, podemos observar lo antes mencionado, la relación de un crecimiento positivo del sector automotriz con un mayor crecimiento del PBI. Sin embargo, debemos considerar una variable más, la cual es el tipo de cambio. En la figura 17, observamos que existe una tendencia a crecer con mayor fuerza del sector automotriz cuando el tipo de cambio baja, por el contrario, cuando el tipo de cambio sube el crecimiento se desacelera. 


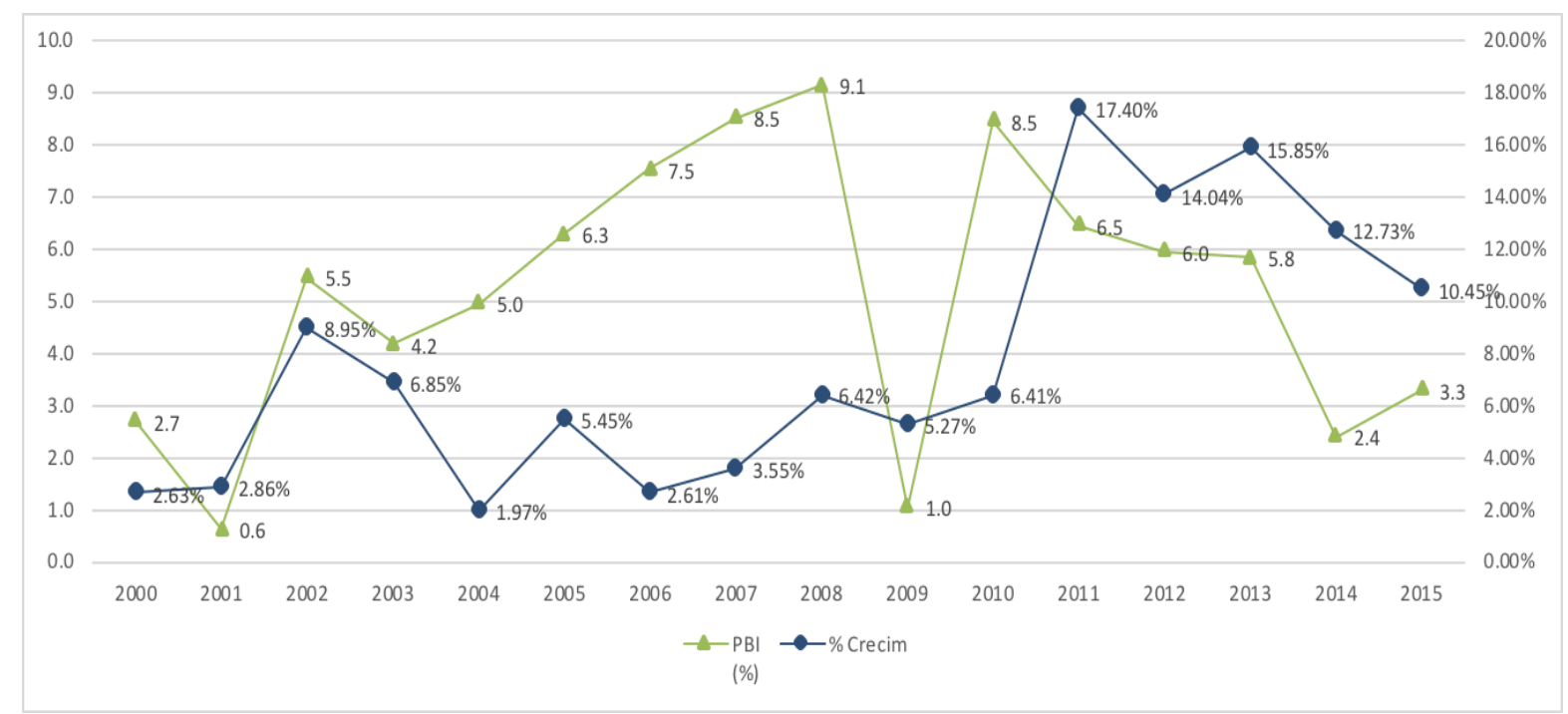

Figura 16: Relación PBI(\%) con Crecimiento anual de autos en Perú (\%). Adaptado de Adaptado de Situación Automotriz por BBVA Research, 2015, Instituto Nacional de Estadística e Informática (INEI) y Banco Central de Reserva del Perú (BCRP).

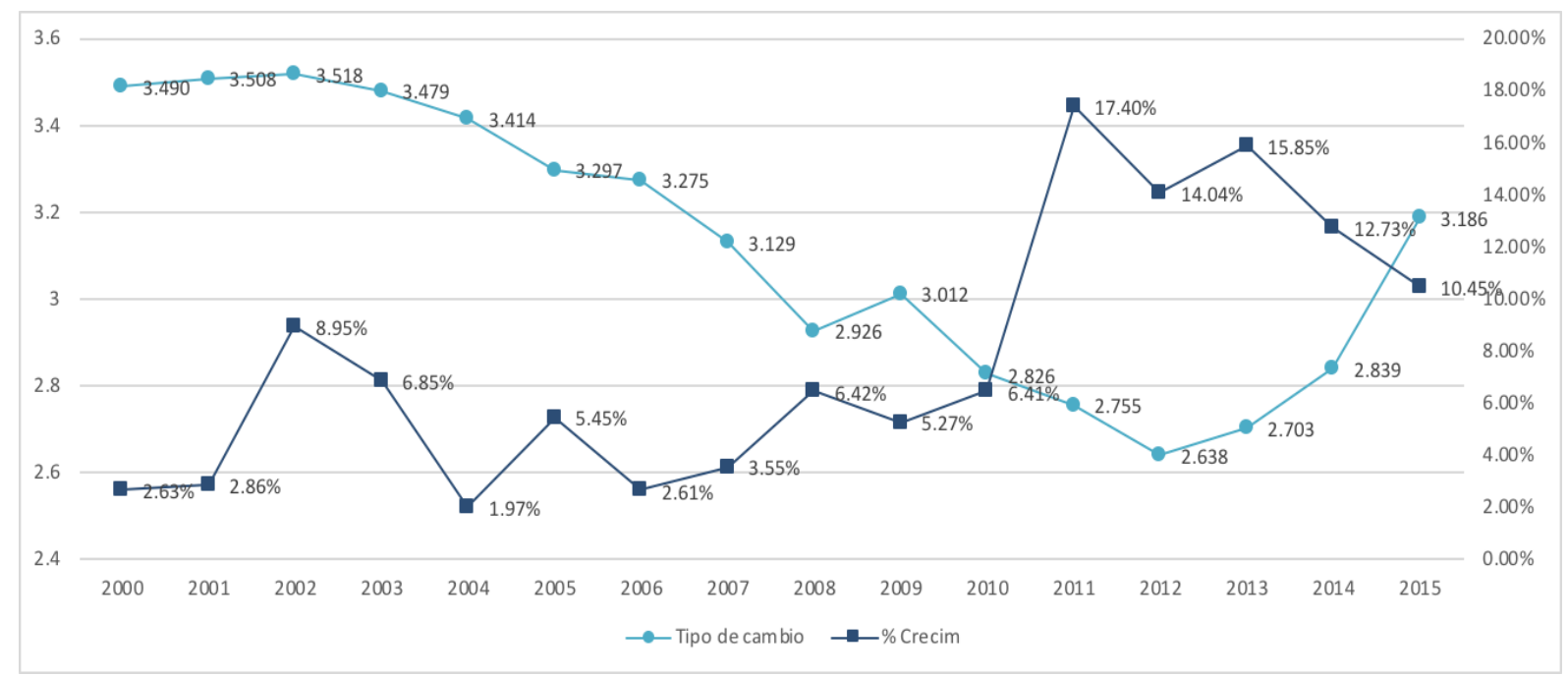

Figura 17: Relación Tipo de cambio (Soles por dólar) con Crecimiento anual de autos en Perú (\%). Adaptado de Adaptado de Situación Automotriz por BBVA Research, 2015, Instituto Nacional de Estadística e Informática (INEI) y Banco Central de Reserva del Perú (BCRP). 


\subsection{Análisis de la demanda}

La demanda actual a este tipo de servicio está calculada con respecto al número de vehículos que utilizan esta clase de establecimientos como lo son los lavados de autos. Por ese motivo, y recordando la información ya mencionada, el $74 \%$ de las personas que fueron encuestadas y que además poseía vehículos, utiliza esta clase de servicios para lavar su auto. Lo cual nos dice que 3 de cada 4 personas prefieren ir a un centro de lavado de autos. Según el sondeo el lavado de autos se toma por la comodidad que brinda el servicio. Por otro lado, es importante mencionar algunas características de la demanda que se obtuvieron como resultado de la encuesta:

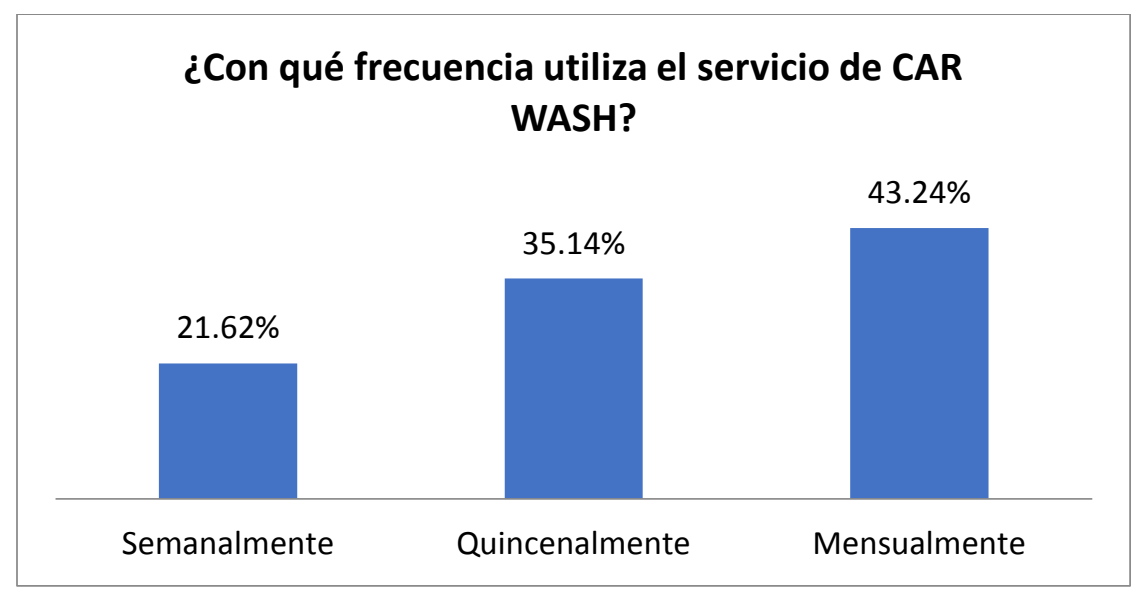

Figura 18. Frecuencia del lavado del auto de las personas encuestadas. Tomado y adaptado de encuesta propia.

- La frecuencia de uso de este tipo de servicios se da principalmente cada mes. Sin embargo, como conclusión a la figura anterior se puede decir que: $43 \%$ de los clientes podría realizará un servicio al mes, $35 \%$ de los clientes dos servicios y $21 \%$ hasta 4 servicios al mes. 


\section{¿Cuánto gasta normalmente en este tipo de servicio?}

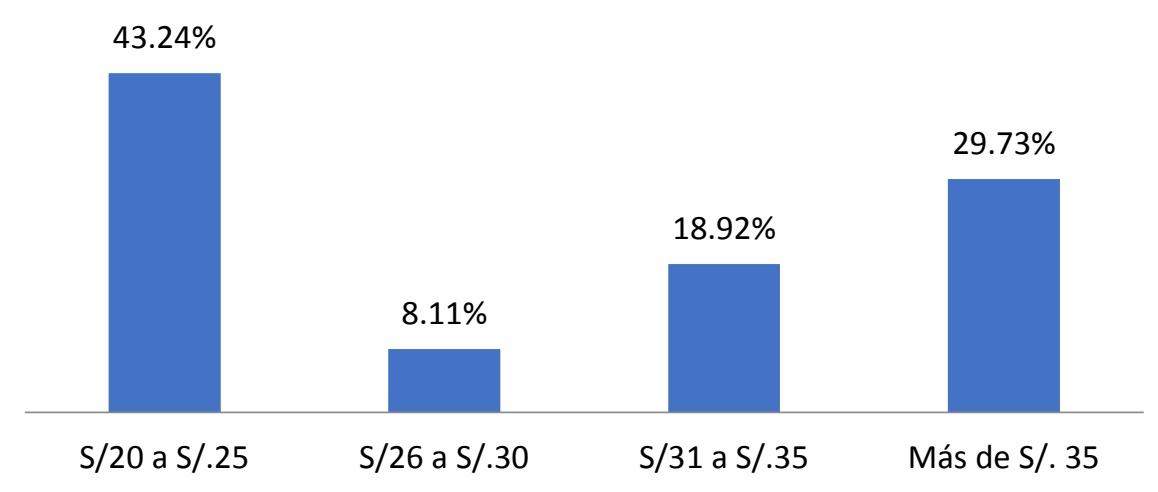

Figura 19. Precio promedio que gastan los encuestados por lavar sus autos. Tomado y adaptado de encuesta propia.

- El precio promedio que gastan los usuarios de esta clase de servicios se sitúa entre los 20 y 25 soles, obteniendo un 43\%. Sin embargo, cabe resaltar que casi un tercio de los encuestados gasta aproximadamente más de 35 soles en el lavado de su auto.



Figura 20. Precio que el público encuestado está dispuesto a pagar por el servicio brindado. Tomado y adaptado de encuesta propia.

- Otro punto a destacar es el valor que le dan los encuestados al proyecto brindado. La mayor parte de los encuestados pagaría hasta 35 soles por el servicio de lavado de autos que brinda el negocio. 
Es importante mencionar también que en el sondeo realizado se preguntó a los encuestados cuáles eras las características que valoran o valorarían ellos que se les brinde como complemento a un servicio como este. Ellos mencionaron (a)Espacios con wifi, (b)cafetería/degustaciones y (c) zona de confort en donde pueda usar sus dispositivos electrónicos.

Continuando con la información sabemos que, según el análisis de mercado, en la zona 7 donde se establecerán los productos, se tiene una demanda de 1,082,862 vehículos a los que se le puede brindar el servicio, ya que estos utilizan el lavado de autos. Sin embargo, debemos tomar en cuenta que ya existe una demanda cubierta por las actuales empresas de lavado de auto. Como se mencionará en el próximo punto, se conocen 4 principales empresas de Car Wash dentro de la zona 7. En el siguiente punto se detalla más sobre estas empresas, sin embargo, se mencionan ahora a modo informativo: (i) Procarwash (Surco), (ii) Pro detailing (La Molina), (iii) Garage (La Molina) y (iv) Fr Carwash (Surco).

El resultado del análisis de mercado que se obtuvo con un escenario conservador permitiría atender al 1\% del mercado efectivo. Esta cantidad corresponde a 7,023 vehículos al año. Esta cifra se podría comparar con la cantidad de vehículos que atienden nuestros principales competidores, sin embargo, por medidas de seguridad y políticas de privacidad de las empresas que hemos mencionadas, estos no revelaron la cantidad de autos que atendían diariamente. Por ese motivo buscamos otras empresas similares a la nuestra y pudimos obtener información sobre la cantidad de autos atendidos de la empresa HEVICLUBS la cual tiene un local de lavado de autos y se asemeja a nuestro proyecto, siendo una empresa nueva y pequeña. La información proporcionada fue la siguiente: 
Tabla 6: Número de autos atendidos en una empresa pequeña de Lavado de autos (empresa Heviclubs)

\begin{tabular}{|l|r|}
\hline Periodo & Cantidad (und) \\
\hline Día de semana & 15 a 20 \\
\hline Fin de semana & 35 a 40 \\
\hline 1 semana & 140 \\
\hline 1 mes & 560 \\
\hline 1 año & 6,720 \\
\hline
\end{tabular}

Nota: Tomado de entrevista al dueño de la empresa Heviclubsde. Elaboración propia.

Esta información se puede utilizar como punto de referencia y punto de partida para el proyecto propuesto.

Por último, se realiza un Análisis de flujo vehicular, el cual permite calcular la cantidad de autos que circulan por un cruce de avenidas, sustentando la cantidad de autos que se ha mencionado que atenderá el negocio.

Según Sergio Navarro Hudiel, docente de educación superior en la Universidad Nacional de Ingeniería de Nicaragua y con amplia experiencia en temas de transporte, menciona que: la tasa del flujo (q) es la frecuencia a la cual pasan los vehículos por un punto o sección trasversal de un carril o calzada. La tasa de flujo es pues el número de vehículos $(\mathrm{N})$ que pasan durante un intervalo de tiempo específico (T) a una hora, expresada en $\mathrm{veh} / \mathrm{min}$ o veh/seg. No obstante, la tasa de flujo (q) también puede ser expresada en veh/hora, teniendo cuidado con su interpretación, pues no se trata del número de vehículos que efectivamente pasan durante una hora completa o volumen horario (q) (https://sjnavarro.wordpress.com) 
La tasa del flujo se calcula entonces con la siguiente expresión:

$$
q=N / T
$$

Por otro lado, se tomó como referencia un estudio realizado por el Ministerio de Transportes y Comunicaciones en el año 2011, en el cual se realizó un perfil de tránsito de las principales vías del área metropolitana de Lima y Callao.

En este estudio se tiene uno de los cruces principales que podría afectar al negocio (Av. Javier Prado / Av. Flora Tristán). El presente plan de negocios actualiza la data del estudio en mención (MTC,2011), utilizando la fórmula que se mostró en el párrafo anterior y añadiendo además el segundo cruce importante para el proyecto (Av. Constructores / Av. Flora Tristán). Los datos obtenidos del estudio en mención (MTC,2011) fueron los siguientes:

Tabla 7: Flujo Vehicular 2004 (Av. Javier Prado Estel Av. Flora Tristán)

\begin{tabular}{|c|c|}
\hline \multicolumn{2}{|c|}{$\begin{array}{l}\text { Ubicación punto de aforo (Av. Javier Prado Este/ Av. Flora } \\
\text { Tristán) año } 2004\end{array}$} \\
\hline $\mathrm{N}$ & 93 \\
\hline Codigo & C55 \\
\hline Eje vial & JAVIER PRADO \\
\hline Ubicación & $\begin{array}{l}\text { Av. Javier Prado Este/ Av. } \\
\text { Flora Tristán }\end{array}$ \\
\hline Referencia & Pista Principal \\
\hline Flujo/2004/Mañana (7 a 11) & 20,858 \\
\hline Flujo/Hora Punta/Mañana & 7,572 \\
\hline
\end{tabular}

Nota: Tomado de "Perfil de tránsito en las principales vías del área metropolitana de Lima y Callao: Flujos vehiculares (años 2004-2009-2011) de Ministerio de Transportes y Comunicaciones. Elaboración propia. 
Tabla 8:Flujo Vehicular 2009 (Av. Javier Prado Estel Av. Flora Tristán)

\begin{tabular}{|c|c|}
\hline \multicolumn{2}{|c|}{$\begin{array}{l}\text { Ubicación punto de aforo (Av. Javier Prado Este/ Av. Flora } \\
\text { Tristán) año } 2009\end{array}$} \\
\hline $\mathrm{N}$ & 93 \\
\hline CODIGO & C55 \\
\hline EJE VIAL & JAVIER PRADO \\
\hline UBICACIÓN & $\begin{array}{l}\text { Av. Javier Prado Este/ Av. } \\
\text { Flora Tristán }\end{array}$ \\
\hline REFERENCIA & Pista Principal \\
\hline Flujo/2009/Mañana (7 a 11) & 28,141 \\
\hline Flujo/Hora Punta/Mañana & 10,087 \\
\hline
\end{tabular}

Nota: Tomado de "Perfil de tránsito en las principales vías del área metropolitana de Lima y Callao: Flujos vehiculares (años 2004-2009-2011) de Ministerio de Transportes y Comunicaciones. Elaboración propia.

El estudio realizó medidas por periodos llamados mañana, tarde y noche. Estos periodos tuvieron los siguientes horarios: Mañana (7:00 - 11:00), Tarde (12:00 - 16:00), Noche (17:00 - 21:00). Como se puede observar en las tablas anteriores ( 9 y 10) correspondientes al estudio de MTC desde el año 2004 al 2009 el flujo vehicular durante las mañanas en horario de 7 a 11 se ha incrementado de 20,858 a 28,141 por día. Esto nos da un incremento de $34 \%$ más vehículos en dicho horario. Además, considerando sólo el flujo en hora punta se tiene un incremento de 7,572 a 10,087 vehículos por hora.

Para el presente plan de negocios se busca calcular una tasa aproximada del flujo de autos en los dos cruces principales cercanos al negocio. Para esto se realizaron medidas en la calle utilizando la fórmula para hallar la tasa de flujo. 
Tabla 9: Tasa de flujo vehicular (10min,15min, 1hora)

\begin{tabular}{lrrrr}
\hline Zona & Periodo 1 & Periodo 2 & \multicolumn{2}{r}{ Rango por hora } \\
\hline J Prado/Flora & $10 \mathrm{~min}$ & $15 \mathrm{~min}$ & \multicolumn{1}{c}{1 hora $(60 \mathrm{~min})$} \\
Mañana $(7 \mathrm{am})$ & 420 & 695 & 2,520 & 2,780 \\
Tarde $(2 \mathrm{pm})$ & 380 & 590 & 2,280 & 2,360 \\
Constructores/Flora & $10 \mathrm{~min}$ & $15 \mathrm{~min}$ & 1 hora $(60 \mathrm{~min})$ \\
Mañana $(7 \mathrm{am})$ & 326 & 530 & 1,956 & 2,120 \\
Tarde $(2 \mathrm{pm})$ & 290 & 487 & 1,740 & 1,948 \\
\hline
\end{tabular}

Nota: Fuente y elaboración propia

Según los datos recopilados en dos intervalos de tiempo (10 y 15 minutos) y en dos periodos de tiempo (mañana y tarde), se proyectó para conseguir un promedio de flujo vehicular por hora en cada periodo. Los resultados muestran que en el cruce de la avenida Javier Prado con Flora Tristán durante la mañana transitan entre 2,520 y 2,780 vehículos por hora. Mientras que en la tarde transitan entre 2,280 a 2,360 vehículos por hora. Por otro lado, en el cruce de la avenida Constructores con Flor Tristán durante la mañana transitan entre 1,956 y 2,120 vehículos por hora. Mientras que en la tarde transitan entre 1,740 a 1,948 vehículos por hora.

Si realizamos una calculo con estos datos para determinar el flujo diario vehicular comprendido entre las 7 y 12 (periodo de la mañana) y entre las 12 y 5 (periodo de la tarde) tendremos que el flujo vehicular diario puede alcanzar los 25,700 vehículos $((2,780+2,360)$ x 5) en el cruce de Javier Prado con Flora Tristán y puede alcanzar los 20,340 vehículos $((2,120+$ 1,948) x 5) en el cruce de Constructores con Flora Tristán. Con estos datos se refuerza la cantidad de autos diarios que puede atender el negocio. Los cuales representan cerca del $0.05 \%$ del flujo vehicular de ambos cruces. 
Como conclusión tenemos que, según la encuesta realizada, 3 de cada 4 personas prefieren lavar su auto en establecimiento como los que ofrece este plan de negocios. Además, el precio a pagar por esta clase de servicios se mantiene en su mayoría entre un rango de 20 a 35 soles como máximo. También se debe decir que el consumo de esta clase de servicio es mensual, es decir, las personas por lo general lavan sus carros cada mes. Por otro lado, los servicios adicionales que esta clase de clientes busca son un lugar agradable y confortable, tener acceso a internet y una zona de cafetería.

La demanda total de la zona 7 que incluye a los distritos de San isidro, Miraflores, San Borja, Surco y La Molina es de más de 1 millón de vehículos. Sin embargo, el mercado que se piensa atender corresponde a 7,023 autos al año cantidad que es atendida regularmente por un negocio nuevo de lavado de autos (6,720). Haciendo un análisis más puntual a la zona del negocio, el resultado del flujo vehicular en los cruces aledaños permite mostrar que la cantidad de autos que se quiere atender no es desproporcional al parque vehicular.

\subsection{Análisis de la competencia}

Dentro del mercado local tenemos 4 grandes y principales competidores directos con nuestro proyecto. A pesar de que el mercado tiene un gran número de empresas dedicadas a este rubro, la mayoría no son formales, es decir no pagan impuestos. Además, la propuesta de valor de estos establecimientos está enfocada a los precios bajos que ofrecen. Como se mencionó las principales empresas para este proyecto son las siguientes:

- PROCARWASH

- PRO DETAILING

- el garage 


\section{- FR CARWASH}

A continuación, se realizará una descripción de las 4 empresas mencionadas, su ubicación, presentación de la misma, factor diferenciación y servicio ofrecidos al público.

\section{Tabla 10: Descripción de la empresa Pro Carwash}

\begin{tabular}{|l|l|}
\hline Ubicación & Av. Ayacucho Cdra. 04 Esq. con Doña Virginia, Urb. Los Rosales \\
Presentación & Surco. A 01 cuadra del cruce de Castilla con Ayacucho - SURCO \\
Empresa especializada en el lavado y detallado de autos, ofreciendo \\
un servicio profesional. \\
Ellos mencionan haber creado una filosofía PRO-CARWASH que no \\
usa productos abrasivos que dañan permanentemente su auto. Marca \\
auspiciadora de CCTC peruano (Campeonato) \\
Utilización de máquinas especializadas para el lavado y detallado de \\
autos; tales como hidro-lavadoras, aspiradoras profesionales, \\
pulidoras orbitales entre otras, así como también empleamos los \\
mejores productos importados para autos. Los servicios que brindan \\
son: Lavado PRO 1 (Servicio Express), Lavado PRO 2 (Servicio \\
básico), Lavado PRO 3 (Servicio completo), Lavado de salón, \\
Lavado motor, Descontaminado de pintura, Tratamiento de pintura, \\
Otros servicios.
\end{tabular}

Nota: Elaboración propia. Recuperado de www.procarwash.com.pe 


\section{Tabla 11: Descripción de la empresa Pro Detailing}

\begin{tabular}{|l|l|}
\hline Ubicación & Av. Javier Prado Este 5930 - LA MOLINA. \\
Presentación & PRO detailing PERU, es una empresa conformada por especialistas \\
de primer nivel en el área de lavado y cuidado de vehículos livianos \\
y pesados. \\
Ubiferenciación \\
Servicios prestados en avenida principal que conecta distritos de mayor nivel \\
Distintos tipos de lavado para automóviles (PRO1, PRO2 y PRO3), \\
corrección de pintura, pintado al horno, desabollado
\end{tabular}

Nota: Elaboración propia. Recuperado de www.prodetailing.com.pe

\section{Tabla 12: Descripción de la empresa Garage}

\begin{tabular}{|l} 
Ubicación \\
Presentación \\
Avenida Separadora Industrial 3180 - LA MOLINA \\
Centro de Servicio enfocado en el confort del usuario para el protección, \\
cuidado y estética vehicular. \\
Proporciona a los clientes artículos complementarios para sus vehículos y \\
para los propios clientes, tales como porta placas, billeteres, prendas de \\
vestir como polos polos y gorras. Tiene alianzas estratégicas con marca de \\
ropa. \\
Ofrecen productos exclusivos como Ceramic Pro (Protección pintura), 3M \\
Forrado (Wrapping vehicular), 3M Windows Films (Polarizado), Lavado \\
Express, Láminas de control solar.
\end{tabular}

Nota: Elaboración propia. Recuperado de https://www.facebook.com/pg/GaragePE 


\section{Tabla 13: Descripción de la empresa FR Carwash}

\begin{tabular}{ll|} 
Ubicación & Av. Caminos del Inca 3283 - SURCO \\
Presentación & $\begin{array}{l}\text { Empresa dedicada al lavado y cuidado estético del auto). } \\
\text { Diferenciación }\end{array}$ \\
Venta de artículos complementarios para los vehículos (muffler, timones, \\
ganchos de remolque, etc.). Participación como auspiciadores en eventos \\
de piques legales. \\
Lavado de salón, lavado premium, tratamiento de pintura, lavado de techo \\
interno, aspirado del interior, encerado con maquina orbital, \\
descontaminado de pintura, pulido exterior de faros.
\end{tabular}

Nota: Elaboración propia. Recuperado de https://www.facebook.com/Frcarwash/

Es importante mencionar los temas más resaltantes que los 4 competidores principales de este proyecto poseen como, por ejemplo:

- Brindan servicios y productos complementarios al lavado de autos, lo cual los hace muy atractivos para los clientes.

- Son conocidos en el medio local y tiene una publicidad en redes sociales muy destacada.

- Manejan auspicios a competencias automovilísticas y auspician a deportistas de la misma disciplina.

- Posee experiencia en el negocio y personal con conocimientos en el rubro.

Sin embargo, se ha observado que existen características que no han sido potenciadas o desarrolladas en la competencia como, por ejemplo:

- No existe una imagen de cuidado del medio ambiente con respecto a la utilización y contaminación del agua. 
- El ambiente de espera para los clientes no ha sido explotado al máximo. Probablemente por un tema de costos.

A continuación, se realiza un análisis más detallado utilizando la herramienta de Matriz del Perfil competitivo de las empresas ya mencionadas. La Matriz de perfil competitivo (MPC) permitirá conocer cuál de los competidores es el que sobresale, es decir, cual es el más fuerte del mercado. Esto se logrará analizando los principales factores claves de éxitos (FCE) de la industria, dándoles un valor ponderado y multiplicándolo por una calificación del 1 al 4 , las cuales tienen el siguiente significado: $1=$ débiles, $2=$ menos débiles, $3=$ fuertes y $4=$ muy fuertes (Kepner \& Tregoe, 1965). A continuación, se muestra la MPC:

\begin{tabular}{|c|c|c|c|c|c|c|c|c|c|c|}
\hline & \multirow[b]{2}{*}{ Factores Claves de Éxito } & \multirow[b]{2}{*}{ Ponderación } & \multicolumn{2}{|c|}{ Pro Carwash } & \multicolumn{2}{|c|}{ Garage } & \multicolumn{2}{|c|}{ Pro Detailing } & \multicolumn{2}{|c|}{ FR Carwash } \\
\hline & & & Calificación & $\begin{array}{l}\text { Puntaje } \\
\text { Ponderado }\end{array}$ & Calificación & $\begin{array}{l}\text { Puntaje } \\
\text { Ponderado }\end{array}$ & Calificación & \begin{tabular}{|l} 
Puntaje \\
Ponderado
\end{tabular} & Calificación & $\begin{array}{l}\text { Puntaje } \\
\text { Ponderado }\end{array}$ \\
\hline 1 & Variedad de servicios & $7 \%$ & 3 & 0.21 & 3 & 0.21 & 3 & 0.21 & 2 & 0.14 \\
\hline 2 & Publicidad en redes sociales & $7 \%$ & 4 & 0.28 & 3 & 0.21 & 2 & 0.14 & 2 & 0.14 \\
\hline 3 & Precios competitivos & $7 \%$ & 2 & 0.14 & 2 & 0.14 & 3 & 0.21 & 3 & 0.21 \\
\hline 4 & Ubicación & $7 \%$ & 3 & 0.21 & 2 & 0.14 & 4 & 0.28 & 3 & 0.21 \\
\hline 5 & Tiempo de experiencia en el rubro & $7 \%$ & 3 & 0.21 & 3 & 0.21 & 3 & 0.21 & 2 & 0.14 \\
\hline 6 & Calidad en Servicio al Cliente & $10 \%$ & 3 & 0.30 & 3 & 0.30 & 3 & 0.30 & 3 & 0.30 \\
\hline 7 & Cuidado del medio ambiente & $20 \%$ & 1 & 0.20 & 1 & 0.20 & 1 & 0.20 & 1 & 0.20 \\
\hline 8 & Zona de espera del cliente & $15 \%$ & 2 & 0.30 & 2 & 0.30 & 2 & 0.30 & 2 & 0.30 \\
\hline 9 & Post venta/Fidelización & $10 \%$ & 2 & 0.20 & 2 & 0.20 & 2 & 0.20 & 2 & 0.20 \\
\hline \multirow[t]{2}{*}{10} & Participación en eventos & $10 \%$ & 4 & 0.40 & 4 & 0.40 & 3 & 0.30 & 3 & 0.30 \\
\hline & & $100 \%$ & & 2.45 & & 2.31 & & 2.35 & & 2.14 \\
\hline
\end{tabular}

Figura 21: Matriz de perfil competitivo - empresas de lavado de autos. Elaboración propia.

Se puede observar que el resultado obtenido coloca como el competidor más fuerte a la empresa Pro Carwash. Sin embargo, haciendo un análisis global de todos los competidores podemos sacar como conclusión que los 4 principales competidores de este plan de negocios son muy parejos según la evaluación y tienden a ser competidores fuertes en el mercado. Sin embargo, los factores predominantes de medio ambiente y zona de espera del cliente son los que no los dejan despegar del todo. Es ahí, en donde este 
proyecto presentado se está enfocando y con el cual se puede sacar una ventaja a la competencia.

\subsection{Análisis de la cadena de valor}

El análisis de la cadena de valor permitirá desarrollar los puntos y/o actividades básicas que aportarán valor al negocio y al cliente final. Esta es una herramienta de ayuda para una buena planificación estratégica. Además, permitirá identificar claramente una ventaja competitiva en el proyecto. (Porter, 1985).

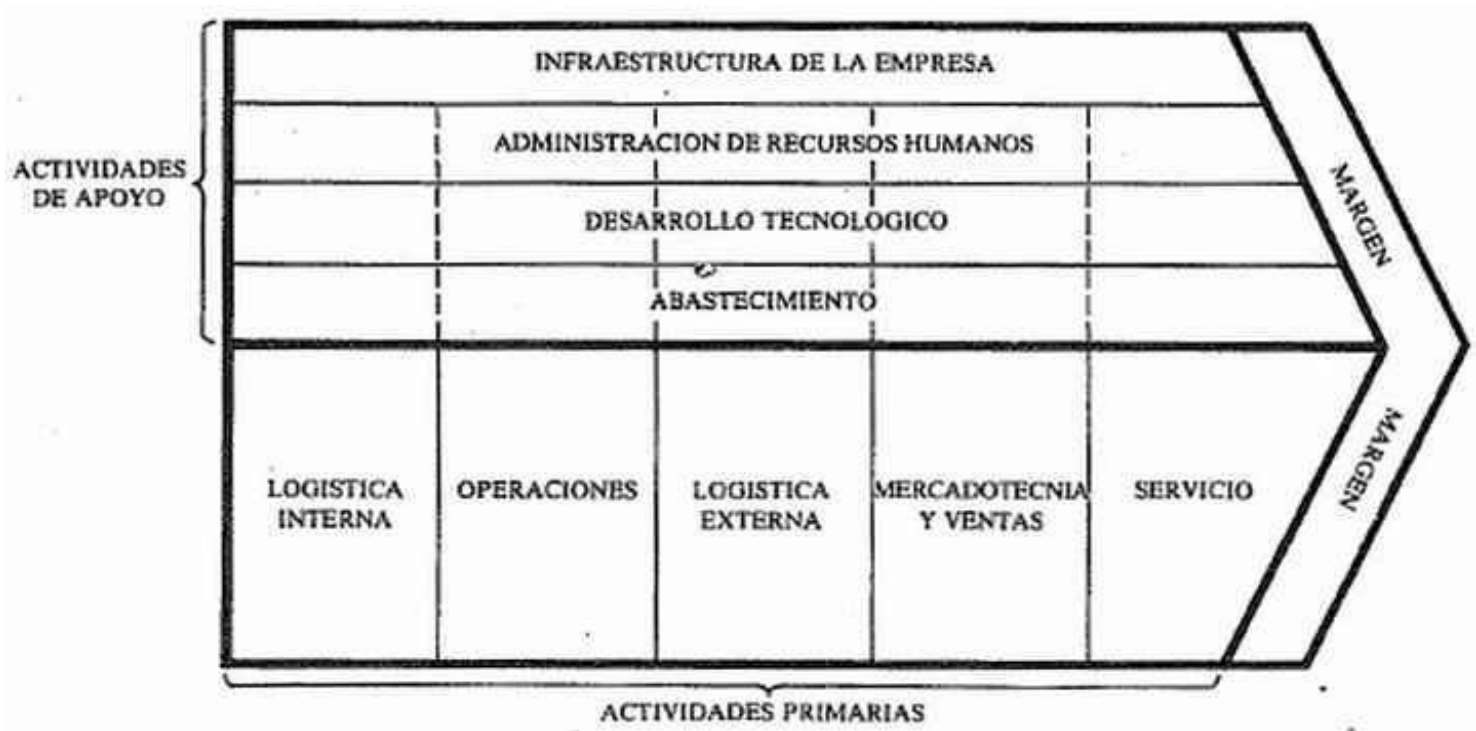

Figura 22. Cadena de valor de Michael Porter. Tomado de "The

Competitive Advantage: Creating and Sustaining Superior Performance de Michael Porter, 1985. Recuperado de https://www.gestiopolis.com/que-esla-cadena-de-valor/

Enfocándonos en las actividades primarias tenemos lo siguiente:

- Logística interna: está referida a la compra y abastecimiento de insumos utilizados directamente en el lavado y cuidado de los vehículos. En este punto la empresa utilizará las marcas más reconocidas de productos tales como $3 \mathrm{M}$ y SONAX, para dar una 
imagen de calidad y de interés por el cuidado del vehículo de los clientes. Además, será de suma importancia los equipos adquiridos para dar el servicio los cuales será de la marca KARCHER, líder mundial en este rubro.

- Operaciones: Esta referido a la utilización de los insumos, productos para cada tipo de servicio brindado. Aquí debemos pensar y estructurar cada servicio que se brindará para que sea el de más alta calidad, sumando insumos adecuados, atención personalizada y calidad del servicio. Además, es en este punto en donde se desarrollará el proceso de reutilización y descontaminado del agua, el cual es uno de los factores de diferenciación del proyecto.

- Logística externa: es donde se hace efectivo la entrega del servicio de lavado de autos. Debemos mencionar que los clientes tendrán un ambiente exclusivo de espera para poder entretenerse y poder estar cómodos.

- Mercadotecnia y ventas: es la difusión de la empresa y sus servicios principalmente en redes sociales, en clubes de autos, en eventos deportivos relacionados con los autos. Buscar imágenes que puedan formar parte de la marca y que sean reconocidas en el medio.

- Servicio: el proyecto se enfocará en buscar la fidelización de los clientes, creando evento o reuniones de encuentro en el propio local para fomentar el consumo de los servicios.

- Actividades de apoyo: estas actividades están enfocadas a la buena gestión de la administración, las finanzas, los recursos humanos, los procedimientos claros para brindar los servicios. En este punto se desarrollará otro de los factores de diferenciación, el cual es la inclusión de personal con discapacidad a la planilla de la empresa, para buscar su desarrollo tanto personal como profesional. 
Como resumen de la cadena de valor tenemos que la ventaja competitiva del proyecto está enfocada hacia tres puntos:

- Reutilización y descontaminación del agua utilizada, lo que generará ahorro del consumo de agua, permitiendo que no se desperdicie en cantidades considerables.

- Inclusión de personal con discapacidad, apoyándolo para su desarrollo profesional y personal, brindándole estabilidad económica y laboral (Ingreso a planilla).

- Desarrollo de zona de espera exclusiva para clientes. 


\section{CAPÍTULO III. PLAN DE MARKETING Y VENTAS}

\subsection{Estrategia de Producto}

El Proyecto que se desarrolla brinda el servicio de lavado de autos el cual dará como valor agregado principal un enfoque en el cuidado medioambiental, buscando comprometer a los clientes con el cuidado del agua. Además, se tendrá un enfoque en una nueva experiencia de servicio al cliente. La idea es no sólo centrarse en el lavado de autos sino darles a los clientes mayores comodidades para que disfrute del momento de espera y/o se relajen, otorgando comodidad al público objetivo

Kotler, Armstrong (2012) encontraron que por lo general los consumidores se enfrentan día a día a una gran cantidad de productos y servicios que podrían satisfacer necesidades, siendo los clientes los que forman expectativas ante las diversas ofertas que brinda el mercado, decidiendo comprar de acuerdo a ellas. Lo que se busca es lograr clientes satisfechos para tener una compra constante del producto o servicio, además de una recomendación, evitando así que vayan a la competencia.

Por ello, se resalta nuevamente que se tendrá un enfoque en un factor muy importante que es el cuidado del medio ambiente, el cual no está muy priorizado en el sector de lavado de autos. El proyecto se enfocará en el uso eficiente del recurso del agua, que es el más usado en el servicio del lavado de autos, tratando de utilizar también menos químicos mediante la utilización de productos premium bajos en agentes contaminantes, reduciendo así la contaminación del agua, pero a su vez haciendo que el proceso de lavado sea óptimo y de calidad. 
Teniendo en cuenta el cuidado del medio ambiente, nos enfocamos en el consumidor verde o ecológico, el cual es el consumidor que manifiesta su preocupación por el medio ambiente en su comportamiento de compra, quien está permanentemente buscando productos y/o servicios que sean percibidos como de menor impacto sobre el medio ambiente. Para estos consumidores el calificativo ecológico es un atributo muy valorado en el proceso de decisión de compra. Esta variable ecológica se verá reflejada en el local de servicio, en donde el propio cliente podrá observar el proceso de reciclaje y reutilización del agua.

Vemos también, que el consumidor verde, no sólo se preocupa por la satisfacción de sus necesidades, en este caso el lavado de su vehículo; sino también de la protección del entorno natural, esto hace que las empresas como la nuestra adoptemos enfocarnos en el marketing medioambiental, buscando alternativas que eviten la devastación de la naturaleza y repongan los deterioros producidos por el desarrollo industrial, por ello nosotros en el proceso de lavado de autos buscamos el reciclaje del agua para su cuidado y uso eficiente; para que este pueda ser empleado en el lavado de más autos sin mayor gasto del recurso. Además, buscaremos crear conciencia en las campañas de difusión del proyecto, resaltando la importancia del cuidado del agua y cómo los clientes pueden generar un impacto al consumir los servicios que se brindará.

Por otro lado, se desarrollará un factor referente al impacto social, ya que existen personas con algunas discapacidades, que les es más difícil encontrar un puesto laboral y a la vez que sea fijo; teniendo en cuenta que esta parte de la sociedad también requieren ser integrados en la parte laboral, la empresa busca integrarlos y hacerlos parte del grupo de trabajo 
para poder así brindar un buen servicio para los clientes, no sólo en el lavado de autos, sino también en la atención hacia ellos.

Kotler et al. (2012) encontraron que el concepto de marketing social señala que esta estrategia debería proporcionar valor a los clientes de forma que conserve o mejore el bienestar del consumidor como de la sociedad, cubriendo las necesidades actuales de los consumidores y de los negocios, logrando un marketing responsable a nivel social y ambiental.

En el Perú el servicio de lavado de autos es bastante informal, por lo que se busca una diferenciación. Por ese motivo, se realizó un pequeño sondeo el cual permitió conocer lo que el público objetivo quería realizar en el tiempo de espera del lavado de su auto, siendo otro de los factores en el que se diferenciará el negocio. Como resultado se dio que las personas tienen la expectativa que, el momento de espera sea agradable y placentero, dejando de lado el aburrimiento, buscando diferentes actividades a realizar en ese tiempo. Según la encuesta, las personas desean tener en estos momentos de espera ambientes de entretenimiento, salas donde encuentren televisión, wifi; por otro lado, también manifestaron que sería bueno contar con una cafetería.

El servicio básico que se brinda es el lavado de autos. El servicio real viene representado por el propio local con servicio de calidad, rapidez y enfocado al cliente, cuidado del medio ambiente, a través del reciclaje del agua y la sociedad. El servicio aumentado contaría con el registro de los clientes; brindándoles a los clientes futuras promociones de los servicios, realizando seguimiento a los clientes que realizaron servicios de lavado, manteniendo la buena relación de nuestros clientes, conociendo el grado de satisfacción con los servicios recibidos y logrando así la fidelización con ellos. 
Se ha empleado la Matriz de Ansoff para determinar nuestra estrategia de crecimiento brindando servicios en el lavado de autos que es un rubro que presenta mucha informalidad, en mercados nuevos; desarrollando así la estrategia de DIFERENCIACIÓN, la cual desarrollaremos brindando nuestro servicio de manera oportuna además de generar otro vínculo con nuestros clientes, dándoles mayor comodidad y un espacio para que sus momentos de espera sean agradables; además de que sean parte del cuidado de medio ambiente y sigamos integrándonos socialmente.

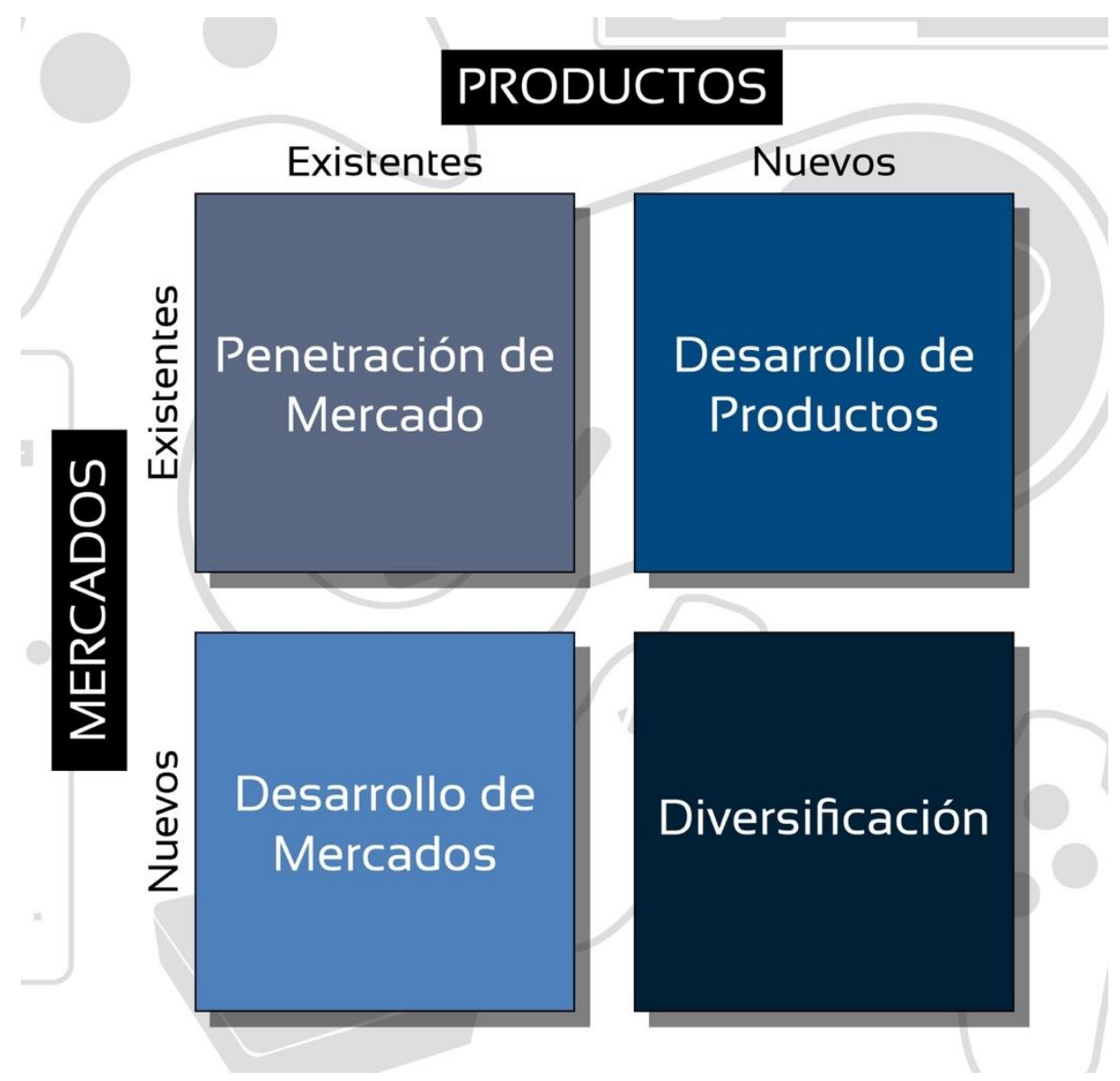

Figura 23. Matriz Ansoff - Oportunidades de crecimiento. Tomado de Igor Ansoff. Recuperado de https://aleixrisco.com/2014/06/05/igor-ansoff-lamatriz-de-ansoff-matriz-productomercado/ 


\subsection{Estrategia de Distribución}

El servicio de lavado de autos tendrá como estrategia de distribución un canal DIRECTO, debido a que el servicio se brindará sin acudir o requerir a otro canal, siendo el receptor del servicio el consumidor final, quien tiene el poder de decisión por información, referencia o por cercanía pues acude a nuestro local a recibir el servicio para su auto. El servicio se dará en el establecimiento con una venta tradicional del servicio y estrategia intensiva teniendo con el tiempo mayores establecimientos para seguir brindando el servicio.

Al brindarse el servicio en el punto de venta, brindaremos información en nuestro negocio sobre nuestro factor diferenciador, comunicando sobre la preocupación de nuestra empresa por el medio ambiente, además del confort y calidad del servicio que brindamos. En la sala de espera, se mostrará en un video el proceso de reciclaje del agua que realiza la empresa, mostrando paso a paso el proceso y comunicando el impacto que genera este ahorro de agua. Se usará material reciclado en todos los paneles informativos en donde se puede ver lista de precios, servicios u otros. Además, se tendrán tachos por colores buscando generar una cultura de reciclaje, ya no sólo de agua, sino de los materiales que usamos a diario. Esto con la finalidad de contagiar al cliente del espíritu reciclador.

Buscaremos también que nuestros clientes, al conocer nuestro servicio; nos recomienden con sus familiares y amigos, resaltan la preocupación por el medio ambiente que tiene la empresa. 


\subsection{Estrategia de Precio}

El proyecto de lavado de autos brindará valor agregado para los clientes otorgándoles una oferta ecológica y amigable con el medio ambiente, además de espacios tales como ambientes de comodidad para su tiempo de espera. Para tener en cuenta el precio a colocar por nuestros servicios se observa el precio de la competencia, los insumos que se utilizan para este servicio, además de la mano de obra, energía y agua.

Es importante mencionar que, a pesar de ser un servicio con alto valor agregado por enfoque al medio ambiente, también es un servicio con competencia informal. Por ese motivo se ingresará al mercado con la estrategia de penetración para poder así captar más clientes y que conozcan nuestro servicio y el valor que le damos al cuidado del medio ambiente y a su tiempo de espera, ofreciendo precios más bajos que la competencia, sin caer en una batalla de precios, la cual sería desfavorable para la imagen del negocio.

Los clientes podrán sacar su cita para su servicio por medio telefónico y/o redes sociales como Facebook, les ofrecemos a los clientes las formas de pago tanto efectivo, como tarjeta de crédito o débito. Por otro lado, se realizará campañas de reciclaje en el propio local, fomentando el cuidado del ambiente y generando descuentos y beneficios a quienes más apoyen están campañas. También se dará un servicio de seguimiento a los clientes por el servicio realizado, con la finalidad de brindarle asesoría para lograr el mejor cuidado de su vehículo, además de los servicios que puede tomar más adelante generando fidelidad con los clientes, manteniendo así una relación de confianza con ellos. 
Kotler et al. (2012) Encontraron que las decisiones de asignación de precios, al igual que otras decisiones de mezcla de marketing, deben empezar con el valor para el cliente. Cuando los consumidores adquieren un producto, intercambian algo de valor (el precio) para obtener algo de valor (los beneficios de tener o usar el producto). Una fijación de precios eficaz, orientada al comprador, implica entender qué tanto valor dan los consumidores a los beneficios que reciben del producto, y fijar un precio adecuado a dicho valor.

Una vez en el mercado también es bueno realizar una investigación, para conocer la valoración del factor diferenciador y de nuestro servicio; conocer si nuestro público objetivo se encuentra satisfecho con nuestro servicio, además de ser parte de una empresa verde tanto en sus procesos, como en la empresa; evaluando la posibilidad de subir nuestros precios, sin afectar el consumo de nuestros clientes; más bien mejorando la percepción de nuestros clientes y futuros clientes; además de mejorar nuestras utilidades.

La fijación de precios basada en el valor para el cliente utiliza las percepciones que tienen los compradores del valor, y no los costos del vendedor, como elemento fundamental para asignar precios. El proyecto brindará 3 tipos de servicios de lavado, 1 lavado de salón y 2 servicios del cuidado de pintura, los cuales tendrán los siguientes precios: 
Tabla 14: Tipos de servicios brindados por el negocio

\begin{tabular}{|l|}
\hline Servicio 1 - Servicio Express \\
\hline Lavado del vehículo con shampoo por fuera y silicona a los neumáticos y tablero \\
\hline Servicio 2 \\
\hline Lavado con shampoo, aspirado y detallado interno más silicona en el tablero y aromatizante \\
\hline Servicio 3 \\
\hline $\begin{array}{l}\text { Lavado con shampoo, aspirado y detallado interno más silicona en el tablero y aromatizante, } \\
\text { más encerado básico }\end{array}$ \\
\hline Lavado de salón \\
\hline Lavado se asientos, lavado de techo y lavado de tapiz. + Lavado 3 \\
\hline Descontaminación de pintura \\
\hline $\begin{array}{l}\text { Lavado } 3 \text { + Limpieza de toda la carrocería externa con descontaminante, al final se hace un } \\
\text { pulido. }\end{array}$ \\
\hline $\begin{array}{l}\text { Tratamiento de pintura } \\
\text { Lavado } 2 \text { + Pulido, abrillantado y encerado. }\end{array}$ \\
\hline
\end{tabular}

Nota: Fuente y elaboración propia.

Tabla 15: Precios en soles de cada servicio brindado

\begin{tabular}{|lrr|}
\hline Precios en soles & Automóvil & Camioneta \\
\hline Servicio 1 - Servicio Express & 23 & 32 \\
\hline Servicio 2 & 35 & 43 \\
Servicio 3 & 46 & 55 \\
\hline Lavado de salón & 280 & 360 \\
$\begin{array}{l}\text { Descontaminación de } \\
\text { pintura }\end{array}$ & 120 & 160 \\
Tratamiento de pintura & 320 & 420 \\
\hline
\end{tabular}

Nota: Fuente y elaboración propia.

\subsection{Estrategia de Promoción}

Al brindar un servicio y entrar al mercado, buscamos posicionarnos en la mente de nuestros clientes y ello lo conseguimos con la Promoción de nuestro servicio, desarrollaremos las diferentes P's en todo lo que abarca la promoción de nuestro servicio.

Kotler et al. (2012) encontraron que el posicionamiento de la compañía y de la marca debe basarse en el segmento y la necesidad; siendo nuestra marca un concepto que marca la diferencia. 
Buscaremos comunicar y realizar nuestra publicidad/ promoción de nuestro negocio como una empresa verde, una empresa que se preocupa por el cuidado del medio ambiente, tanto en la parte interna como externa; utilizando en el proceso la reutilización del agua como recurso muy importante para nosotros y siendo este factor valorado por nuestros consumidores. Nos enfocaremos en que el cliente tenga en cuenta que no sólo nos preocupamos por su auto, sino también del medio ambiente del cual somos parte.

- Publicidad: Iniciaremos y mantendremos en el tiempo la comunicación a través de las redes sociales tradicionales más utilizadas como es el caso de Facebook, Twitter, Instagram, entre otros, lo cual permitirá darle mayor información a nuestro público objetivo tanto del servicio de lavado de autos que brindamos, además de informarles que nos enfocamos y que para nuestra empresa es muy importante el cuidado eficiente del agua, nuestra preocupación por el cuidado del medio ambiente y la integración social que queremos realizar, además de todo lo que puede encontrar en nuestro local donde brindamos este servicio, donde también contaremos con un ambiente de espera para mayor comodidad de estos. Del mismo modo tendremos participación activa en webs ecológicas como Guía de reciclaje, Ecoelink, además de tener presencia en una nueva red social llamada Greentizen. Además, utilizaremos estos medios de comunicación para consultas y/o dudas de nuestro servicio, como también poder agendar un próximo servicio y que el cliente pueda optimizar su tiempo y no hacer su espera por el servicio mayor, siendo más cómodo para ellos.

- Facebook y Twitter: Página completa con información sencilla y precisa acerca del servicio. Igualmente, el uso de un 
lenguaje amigable al cliente, en posts continuos recordando a los seguidores acerca de las diferentes modalidades del servicio. Además de hacer presente nuestra preocupación por el medio ambiente, comunicando nuestra reutilización del agua como parte importante en nuestros procesos, mencionando la gran importancia que tiene para nosotros el cuidado del medio ambiente. También informar acerca de los eventos, promociones y avances de la empresa; en estas oportunidades hacerles conocer de nuestro diferenciador y de nuestros servicios. Procurar responder las consultas en el menor tiempo posible, así como agendar un próximo servicio de forma eficiente.

- Guía de reciclaje: Es una herramienta web, la cual tiene también su versión en aplicativo. Esta herramienta permitirá conocer todos los pasos y resolver muchas dudas sobre el proceso de reciclaje.

- Ecoelink: Permite compartir fotos y vídeos, discutir y proponer ideas ecológicas, y calcular tu impacto ambiental.

- Greentizen: la nueva red social de acciones ecológicas.

- Comunicación Directa: Por otro lado, también realizaremos una comunicación directa con los clubes de autos o agencias, para promocionar nuestros servicios, no dejando de lado la participación en eventos automovilísticos en los que se puede brindar información mediante volantes y algunos suvenires para que conozcan nuestra empresa y el servicio que brindamos, además de nuestra idea e importancia que le brindamos a cada cliente y la optimización de su tiempo. Comunicar que somos una empresa verde, preocupada por el medio ambiente y que nos enfatizamos en el cuidado del agua. 
- Hacer una investigación acerca de los clubes y agencias de autos más importantes, para tenerlas en cuenta en las campañas de promoción y publicidad.

- Promocionar el sistema de reciclaje de agua y cómo su reutilización permitirá generar un impacto positivo en el ambiente. Además, al asistir a eventos automovilísticos hacer hincapié en las reducciones de emisiones al medio ambiente. Promoviendo la responsabilidad y el cumplimiento oportuno de las revisiones técnicas de sus autos.

- Eventos: Al ser partícipes de eventos y también en nuestras redes sociales se colocará un video en el que presentamos cierta información de la empresa, así como los servicios que brindamos, buscando crear expectativa para con nuestra empresa y el servicio que brindamos; buscando un mayor interés del público que aún no nos conoce y recordando nuestra empresa a los que ya son nuestros clientes. También que somos una empresa verde, preocupados del medio ambiente.

- Participación activa en el evento Ecofest, el cual es el primer evento ecológico que se realiza en Lima. En este evento se podrá encontrar una selecta gama de la oferta existente de bienes, servicios, proyectos e ideas relacionados con las actividades que nos conectan con la naturaleza: ecoturismo, birdwatching (observación de aves), arte, pesca deportiva, fotografía natural, entre otras. La iniciativa fue dirigida al público en general de todas las edades que tienen interés en la naturaleza y la responsabilidad ambiental (fuente: https://www.uarm.edu.pe/Noticias/sociales/el-primer-festivalecologico-realizado-en-lima\#.WnG8YiPSHhM). 
- Participar en eventos realizados el día 22 de marzo, conocido como el día mundial del agua, con la finalidad de concientizar y enseñar al público objetivo acerca de las ventajas del servicio y por qué debería elegirlo. De este modo se busca atraer nuevos usuarios y se mantiene los que ya son asiduos.

- Participar de forma activa en todos los eventos que se realicen en el calendario medio ambiental peruano. (INTE-PUCP)

- Venta Personal: En nuestra empresa al ofrecer un servicio de lavado de autos realizaremos Venta Personal en el punto de venta, ya que pueden requerir el servicio sin previa cita o mediante nuestras redes sociales o telefónicamente agendar una cita, debido a que nuestro canal de distribución es directo, es de frente al consumidor final.

- Facilitar diferentes medios al cliente para agenciar el servicio. Procurar que el cliente esté informado de estas facilidades y así volver asiduos a clientes que se sienten más familiarizados con las redes sociales.

- Venta Directa: Al tener ya con el paso del tiempo nuestros clientes, realizaremos Venta Directa mediante call center, la que puede establecer relación de fidelización con nuestros clientes de manera más personalizada ofreciéndoles el servicio además de algunas ofertas y promociones; valorando así su fidelidad para con nuestro servicio. Nos enfocaremos en armar paquetes con servicios para nuestros clientes, los cuáles pueden acceder a ellos con paquetes mensuales, o según el tiempo en el que quieren obtener nuestros servicios. En este punto se darán descuentos importantes para todos aquellos clientes que aporten al reciclaje, ya que se piensa realizar 
campañas de reciclaje en conjunto con la municipalidad de la molina.

- Ofrecer ofertas a los usuarios que agencian a través del call center, de forma que prefieran esta forma directa de venta, la cual facilita el servicio, brindándoles información según la requieran nuestros consumidores, para que puedan tomar nuestros servicios y conozcan más nuestra empresa. Los clientes tendrán que venir al local con botellas de plásticos, vidrio, papel, cartón y todo material no degradable. Así ellos recibirán un descuento en sus servicios.

- Marketing Digital: Mediante nuestras redes sociales, emplearemos una conexión con nuestros clientes, haciéndoles partícipes de nuestros servicios, videos, ofertas, promociones y diversas comunicaciones para que ellos estén informados de nuestra empresa, nuestras innovaciones, logrando así posicionarnos. Nos enfocamos mucho en la parte digital y las redes sociales que nos hacen llegar de una forma más rápida a ellos, pudiendo dar información de nuestra empresa, los servicios que brindamos además de nuestra preocupación por el medio ambiente, de la calidad en los servicios y el confort que brindamos en el tiempo de espera de nuestros servicios.

- Trabajar en enganchar al público objetivo con gráficos y frases que sean atrayentes y representativas del servicio; como nos preocupamos por tu auto y por el medio ambiente. Mantener a los seguidores informados y responder las consultas de manera oportuna de nuestros servicios, horarios y disponibilidades.

- Informar a través de las redes sociales cómo otros países cuidan el medio ambiente con negocios similares al nuestro. 
- Informar de las nuevas tecnologías y buenas prácticas que aportan y permiten generar un desarrollo sostenible.

- Marketing Boca a Boca: Buscaremos que nuestros clientes tengan una buena y agradable experiencia para que recomienden mediante el Boca a Boca nuestro servicio. Además, que se encuentren vinculados en el cuidado del medio ambiente y la integración social. Por ello comunicaremos en la empresa que somos una empresa verde y nos preocuparemos por el consumidor medioambiental.

- Resaltar los beneficios del servicio, así como ofrecer un trato amigable y confiable. Comprender al cliente y facilitarle el uso de las instalaciones, así como optimizar el tiempo para beneficio de la empresa y el cliente. Poder captar también más consumidores verdes, que se preocupan por nuestro medioambiente.

- Mostrar en el contacto directo con el cliente una cultura verde en la empresa. Para esto se utilizarán tachos por colores, Se mantendrá el orden y limpieza del local, Se buscará usar materiales reciclado para nuestras operaciones y se tendrá un ambiente verde con mucha vegetación.

- Percepción: Buscaremos transmitir nuestro servicio enfocado al cliente, además de transmitirles nuestra preocupación por el medio ambiente y por la sociedad, logrando una percepción positiva del servicio y de nuestro negocio para con los demás.

- Resaltar los beneficios ambientales y sociales del servicio en redes sociales y en los eventos en los que se da información, logrando una buena percepción de la empresa ante el público. 
- Procesos: Nuestro proceso lo consideramos desde la toma del pedido del servicio, unos clientes lo tomarán en el local, otros lo solicitarán telefónicamente o por la red social; posteriormente en el local, el cliente deja su vehículo, el cuál pasa a ser lavado, mientras el cliente puede esperar en el local en nuestro ambiente de espera o recogerlo finalizado el servicio. Hacemos parte de nuestro proceso la reutilización del agua, como una empresa verde nos preocupamos y nos enfocamos en el cuidado del medio ambiente.

- Ofrecer diversas formas de solicitar el servicio, así como de pasar el tiempo mientras el auto está siendo lavado, incluyendo snacks o conexión wi-fi.

- Enseñarle al cliente cómo funciona el equipo de reciclaje de agua. El impacto que tiene a mediano y largo plazo el ahorro de agua. Animarlo a ser un consumidor verde.

- Productividad: Emplearemos el enfoque del cuidado de medio ambiente, optimizando el cuidado del agua, utilizándolo de manera eficiente, además de realizar el lavado en un menor tiempo manteniendo la calidad de nuestro servicio

- Contar con la tecnología adecuada y el mantenimiento de los equipos para hacer un uso responsable del agua y de los otros recursos del proceso, teniendo en cuenta también la optimización en el tiempo del servicio.

- Los equipos de lavado como lo son las hidro-lavadoras de alta presión permiten tener un ahorro y una eficiencia en el uso del agua. Sumado a eso la maquina recicladora aporta un porcentaje extra considerable, permitiendo atender la misma cantidad de autos con menos agua. 
- Personas: Nuestra empresa se viene enfocando tanto en el servicio al cliente como en nuestro personal que brinda el servicio. Por ello hemos visto importante destacar nuestro enfoque social, porque son pocas las empresas que integran a trabajar a personas con alguna limitación, nosotros creemos y apostamos por ellos, trabajando en nuestra empresa y apoyándolos en el trabajo diario. Nuestro personal estará enfocado en la satisfacción del cliente, brindando un servicio de calidad, y con los servicios añadidos que le brindamos desarrollando así la relación cliente-empresa logrando así fidelización.

- Priorizar el buen trato al cliente y ofrecer capacitación al personal para poder ofrecer un servicio de calidad. Establecer guías de acción para solucionar diferentes situaciones que se puedan presentar durante los procesos del servicio.

- Se propone que los trabajadores utilicen polos con frases ambientalistas, que promuevan la reflexión y el cuidado del medio ambiente. Además, todos los trabajadores estarán en capacidad de explicar el sistema de reciclaje y conocerán sus beneficios e impacto positivo e la sociedad.

\subsection{Proyección de Ventas}

La proyección de los vehículos que se atenderá será calculada en un horizonte de 5 años. Además, como se calculó en el capítulo anterior, se tomará inicialmente el 1\% del mercado como proyección conservadora en un negocio nuevo de este rubro. Esta proyección conservadora representa aproximadamente 7,023 vehículos atendidos al año. Luego de definir el porcentaje inicial que se buscará atender, se debe calcular el porcentaje de crecimiento para los siguientes años. Este crecimiento estará vinculado a 
las proyecciones que se tienen sobre el sector automotriz para los próximos años.

Según el presidente de la Asociación Automotriz del Perú, en los últimos 3 años, el crecimiento del sector automotriz se ha desacelerado año tras año. Sin embargo, con el cambio de gobierno las cosas pueden mejorar. Si se sigue en este camino y se concretan las propuestas que se vienen desarrollando en conjunto con las autoridades en el Congreso de la República y el Ministerio de Economía, las proyecciones de crecimiento del sector automotriz podrían llegar al 5 o $10 \%$. Estas cifras permitirían llegar a vender anualmente el $10 \%$ del parque vehicular (no menos de 250,000 unidades) que es lo ideal para un país que tiene circulando en sus calles alrededor de 2 millones y medio de vehículos (Derteano,2016). Con este comentario realizado por el presidente de la APP, podemos definir un escenario optimista el cual nos da un crecimiento del 10\% inicialmente.

Por otro lado, tenemos un informe sobre las perspectivas de la industria automotriz en el Perú realizado por IHS Markit para la APP en diciembre del 2016, la cual muestra un gráfico de la proyección del crecimiento de las ventas de vehículos ligeros en el Perú comenzando en el 2017 hasta 2026. El crecimiento que muestra el gráfico es de un crecimiento sostenido entre 6\% - 7\% anualmente (Vildozo, 2016). 


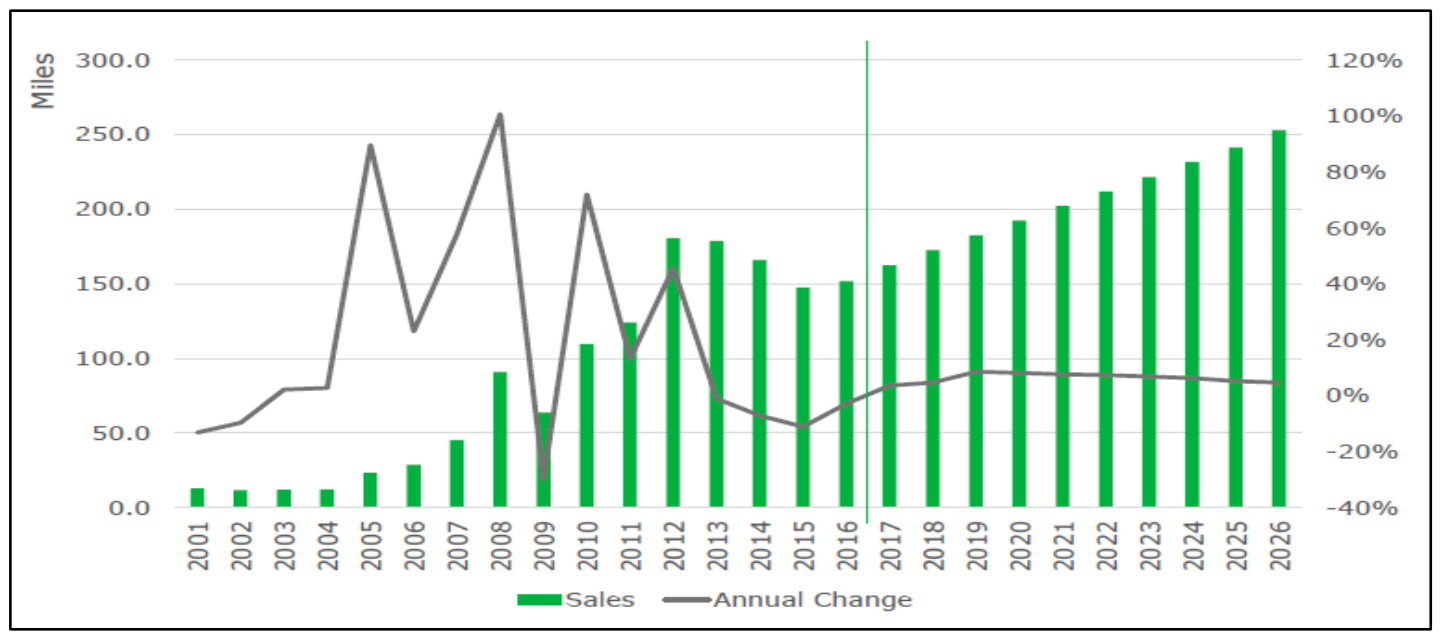

Figura 24. Proyección de ventas de vehículos ligeros en el Perú (20012026) en miles de unidades y crecimiento porcentual. Tomado de "Perspectivas de la industria automotriz Perú" elaborado por IHS Markit y Asociación Automotriz del Perú, 2016

De acuerdo a lo anterior, proyectaremos el crecimiento de las ventas o autos atendidos de la siguiente forma:

- Crecimiento de $10 \%$ para el primer año.

- Crecimiento de 7\% los años siguientes.

En el escenario planteado, iniciamos con 7,023 vehículos atendidos al año, los cuales representan el 1\% del mercado efectivo. Este escenario tendrá el crecimiento mencionado y terminará el año 5 del proyecto atendiendo a 9,464 vehículos.

Tabla 16: Proyección de ventas del negocio

\begin{tabular}{|l|r|r|r|r|r|}
\hline Año Proyecto & Año & Año & Año & Año & Año \\
\hline & $\mathbf{1}$ & $\mathbf{2}$ & $\mathbf{3}$ & $\mathbf{4}$ & $\mathbf{5}$ \\
\hline $\begin{array}{l}\text { Autos atendidos al } \\
\text { año(unid) } \\
1 \% \text { del mercado. }\end{array}$ & 7,023 & 7,725 & 8,266 & 8,845 & 9,464 \\
\hline
\end{tabular}

Nota: Fuente y elaboración propia. 


\section{CAPÍTULO IV. PLAN DE OPERACIONES}

\subsection{Ubicación geográfica}

Para elegir la mejor ubicación utilizaremos el método de los factores ponderados. Este método considera factores tanto cualitativos como cuantitativos que debe ser considerados para la localización. Lo que se hace es asignar un peso de importancia (ponderación) a todos los factores que concurren en la decisión de ubicarse en un determinado lugar; ello permite poder reunir y "sumar" las premisas cualitativas con las cuantitativas, razón por la que se trata del método más extendido (Heizar \& Render, 2004).

Con este método se busca definir en qué distrito se debe ubicará el negocio de Car Wash. Se analizarán los siguientes factores:

a) Fácil acceso desde vías principales: este factor se refiere al acceso de avenidas o calles principales hacia el local de atención, es decir, que el local se encuentra ubicado a pocas cuadras de avenida principales de alto tránsito vehicular.

b) Proximidad al mercado objetivo: este factor se refiere a una ubicación en la cual las personas a las que está dirigido este tipo de negocio tengan fácil acceso o estén en las proximidades de la zona en donde se ubica el negocio.

c) Costos indirectos: este factor está referido a todos aquellos costos en los que se incurre tales como: alquiler y servicios básicos.

d) Cercanía a la Mano de Obra: se evalúa la proximidad de las personas que pueden ser contratadas para trabajar en el negocio. Se evaluará si existen negocios similares cercanos, lo que puede dar opciones de personal viviendo en la zona o que pueden llegar sin ningún problema a la ubicación del local. 
e) Cercanía a socios estratégicos: se enfoca en estar cerca de negocios con distinta actividad comercial, pero con los cuales podrían realizarse alianzas estratégicas para generar mayor tráfico de vehículos.

Los distritos que se han considerado para la evaluación son La Molina, Surco, San Isidro y San Borja. Estos distritos se consideraron, ya que se realizó una búsqueda de alquiler de locales comerciales en los distritos de la zona 7. En la lista de esos distritos se pudieron encontrar ofertas comerciales sólo en estos 4 distritos.

El siguiente paso será definir un valor ponderado para cada factor y luego asignarle una puntuación del número 1 al 10 para poder calcular cuál de las ubicaciones sería las más adecuada. La puntuación va desde lo menos conveniente (1) hasta lo más conveniente (10) para el proyecto. Los 4 locales que se considera para la evaluación por factores son los siguientes: 
Tabla 17: Opciones de alquiler para el negocio



Nota: Fuente y elaboración propia. Información de precios de locales tomado de la web Urbania

A continuación, se muestra la elección de la ubicación por medio del método de factores ponderados.

\begin{tabular}{|c|c|c|c|c|c|c|}
\hline \multirow[b]{2}{*}{ \# } & \multirow[b]{2}{*}{ Factor } & \multirow[b]{2}{*}{ Peso } & \multicolumn{4}{|c|}{ Distritos } \\
\hline & & & La Molina & Surco & San Isidro & San Borja \\
\hline 1 & Fácil acceso desde vías principales & $20 \%$ & 10 & 8 & 8 & 8 \\
\hline 2 & Proximidad al mercado & $25 \%$ & 10 & 4 & 8 & 6 \\
\hline 3 & Costo indirectos & $25 \%$ & 8 & 4 & 2 & 6 \\
\hline 4 & Cercanía a la Mano de Obra & $15 \%$ & 7 & 5 & 5 & 7 \\
\hline \multirow[t]{2}{*}{5} & Cercanía a socios estratégicos de servicios complementarios. & $15 \%$ & 6 & 4 & 3 & 6 \\
\hline & & $100 \%$ & 8.45 & 4.95 & 5.3 & 6.55 \\
\hline
\end{tabular}

Figura 25. Matriz de Factores Ponderados para la elección del local. Fuente y elaboración propia. 
Como se observa, se ha seleccionado el local en el distrito de La Molina debido a que obtuvo un puntaje total de 8.45 .

Además, en la siguiente figura se muestra las zonas de alto tránsito que se dieron como resultado del análisis de flujo vehicular (línea roja), también tenemos cercanía a instituciones y empresas como: USIL, USMP, Pre U de Lima, Policlínico Essalud, Colegio Alpamayo, Sede Principal BCP. Además, en líneas naranjas se muestra una zona altamente comercial con negocios como restaurantes, panaderías, estéticas, bodegas, centros de copias y hoteles.

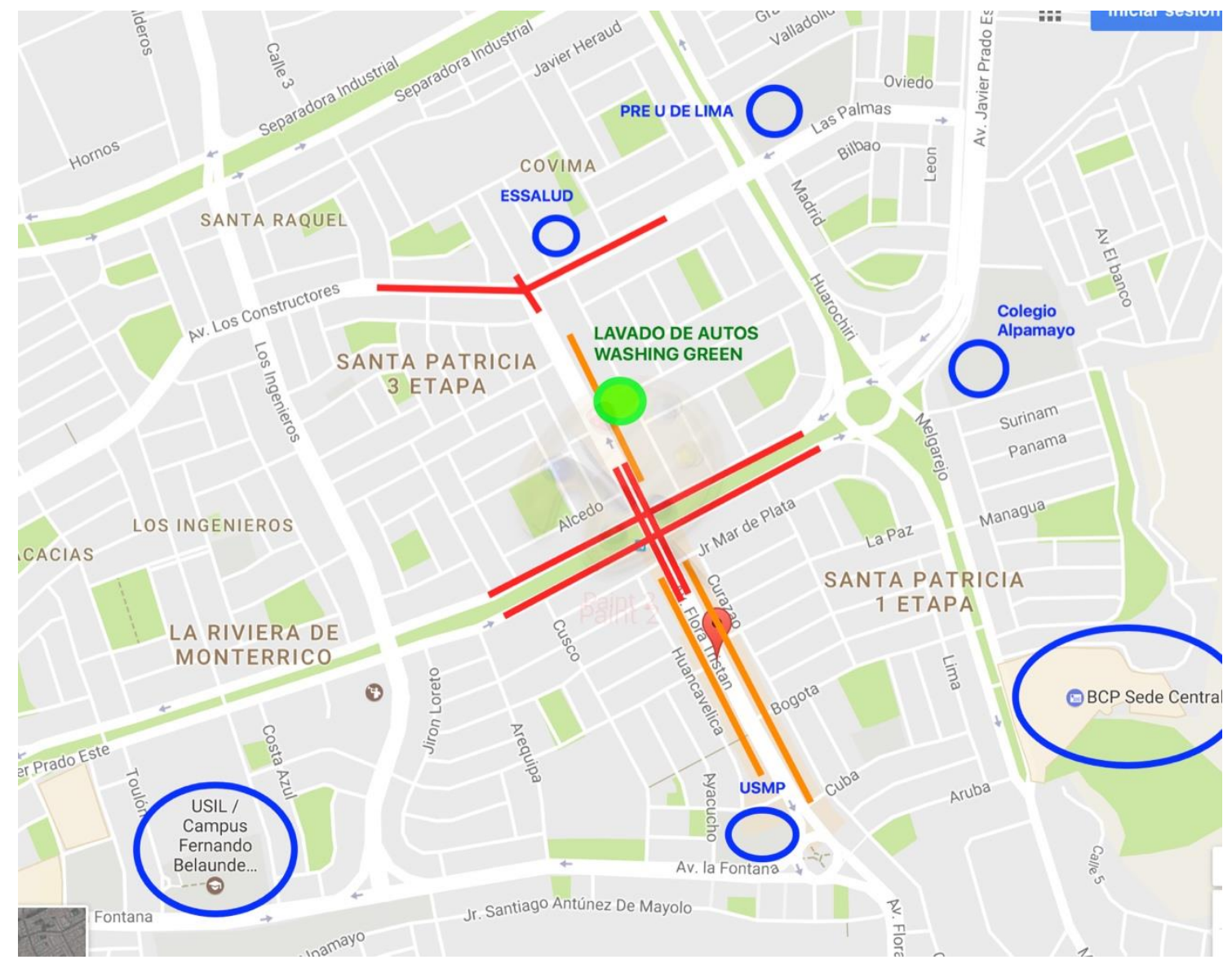

Figura 26. Flujo vehicular, instituciones y negocios cercanos al local. Fuente y elaboración propia. Mapa tomado de www.google.com/maps 


\subsection{Infraestructura}

El negocio de lavado de autos se iniciará en un local alquilado. La ubicación del local será en el distrito de La Molina. Aunque no está considerado dentro del proyecto, se plantea que en el futuro se puedan abrir sucursales en otros distritos.

El área de terreno del local que se alquilará es de 300 m2. Área estimada por el proyecto para iniciar el negocio. El local estará dividido de dos partes. La primera parte será el patio central de lavado y la segunda parte estará formada por una zona de oficinas y la sala de espera de los clientes. El local se acondicionará para que el público objetivo pueda observar el servicio brindado a cada auto, además podrán disfrutar de manera agradable al momento de esperar, hasta que el auto esté listo.

El diseño del local contará con diferentes ambientes, como es la recepción en donde se recibirá a los clientes que llegan para tomar alguno de los servicios y en donde se realizará los pagos respectivos después de la atención. En la recepción se confirmará si el cliente realizó alguna separación previa o no, y se le asignará un equipo de limpieza para que inicie los trabajos en su auto según lo solicitado y requerido.

El edificio contará también con una sala de espera, que será un ambiente pensado en nuestro cliente para que el disfrute de este tiempo, este ambiente tendrá una pequeña cafetería en la que se pondrá a la venta algunos productos para el consumo; además, el ambiente contará con muebles para la comodidad de nuestros clientes (sofás, mesas, sillas, etc.). Así mismo, se contará con un televisor para recrear el ambiente y darle una distracción al cliente. Por otro lado, el local tendrá conexión Wifi para que 
los clientes se puedan conectar a internet y navegar a través de sus dispositivos móviles, tablets o laptops.

El patio central del local es la zona en la que se lavarán los autos, ésta tendrá la capacidad de atender entre 4 y 5 autos al mismo tiempo. Se debe considerar dividir la zona principal en: (i) zona de lavado, lugar en donde su utilizaran las hidrolavadoras de alta presión se agua más champú para limpiar la parte externa de la carrocería; (i) zona de secado, en donde se secará con paños microfibra la carrocería y se aspirará los asientos si así lo contempla el servicio; (iii) zona de encerado, pulidos y otros, en donde se le dará el toque de brillo y acabo final al servicio; y por último la (iv)zona de espera para los autos, en donde estarán esperando ser recogidos por sus dueños.

Por otro lado, se tendrá una pequeña área administrativa en la que se toman las decisiones y organiza la empresa, esta será la zona de las oficinas. En este lugar estará la oficina del administrador del local, quien se reunirá periódicamente con los dueños o accionistas. Esta oficina principal estará con las puertas abiertas al público para poder conversar con el administrador con total transparencia. Finalmente, no se puede dejar de lado la necesidad de tener un área de almacén en donde se guardarán los utensilios necesarios para la limpieza de cada auto. A continuación, se adjunta la distribución del local: 


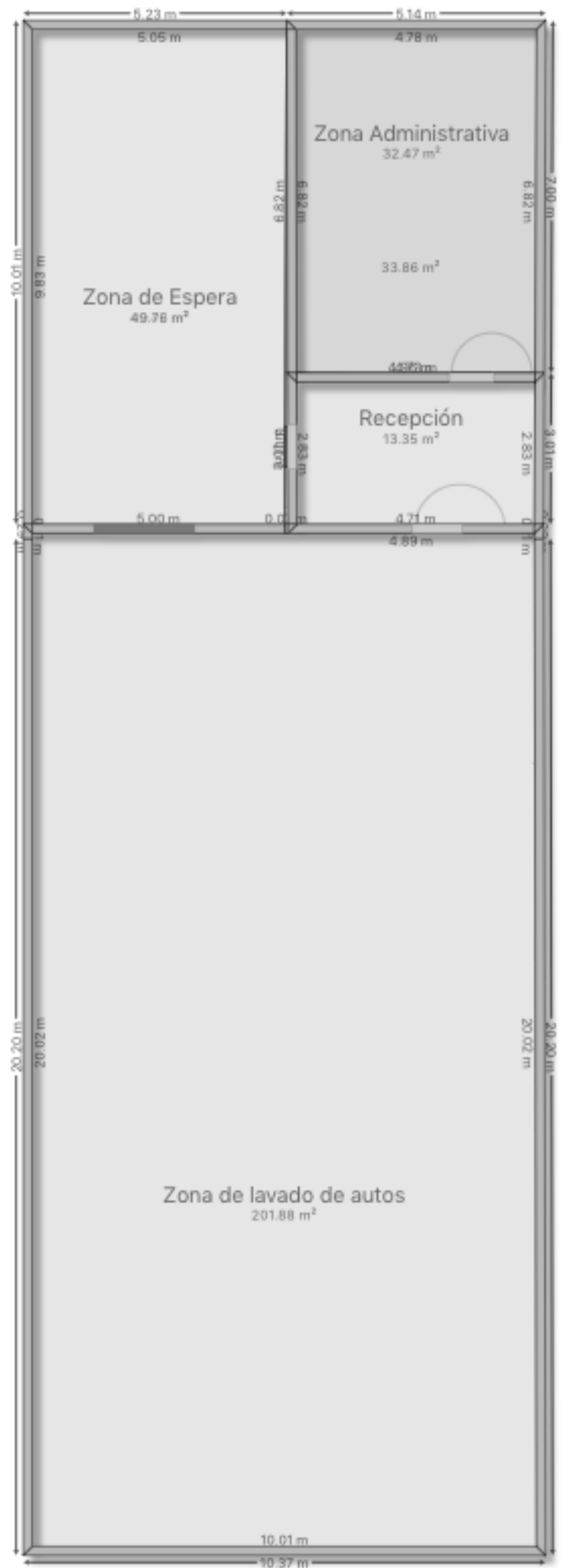

Figura 27. Distribución del local de lavado de autos. Fuente para elaboración de las medidas "www.urbania.pe". Elaboración propia. 


\subsection{Proceso productivo}

El proceso se inicia desde la solicitud del servicio. Esta solicitud puede ser vía telefónica, por red social o en el mismo local cuando asisten nuestros clientes. El cliente menciona qué tipo de lavado desea para su vehículo. Lo que sí tendremos en cuenta y respetaremos el orden de llegada y solicitud del servicio de lavado para el vehículo del cliente, en la recepción se tomarán los datos del cliente para poder mantener el contacto con ellos y los datos del vehículo a ser lavado; derivando así al área de lavado el vehículo e invitando al cliente a la sala de espera.

Antes de iniciar el proceso de lavado nuestro cliente recibirá una tarjeta con los datos de su vehículo para que lo recoja posteriormente. Nuestro cliente puede pasar a nuestra área de espera hasta que se termine con el proceso del lavado o elegir retirarse y regresar para cuando se haya terminado el proceso del lavado.

En el área de lavado se realizará el servicio solicitado dependiendo de lo que eligió nuestro cliente. El proceso de lavado se dará mediante el uso de dos hidrolavadoras de alta presión de la marca KARCHER lo último en equipos para lavado de autos, así mismo se utilizarán aspiradoras para la limpieza interna de los vehículos. Es importante mencionar que se utilizaran productos de limpieza de alta gama de las marcas 3M y SONAX, las más reconocidas del mercado.

En este punto es importante mencionar el valor agregado que dará este proyecto. Como se mencionó al principio este proyecto busca el cuidado del medio ambiente mediante el cuidado del recurso más utilizado, el agua. Para poder realizar el reciclaje y reutilización del agua se utilizará un equipo de reciclaje modelo ACUABOX de la marca ISTOBAL. El equipo 
consiste en un contenedor de reciclaje móvil, de fácil instalación y que no demanda mayor trabajo civil para ser instalado.

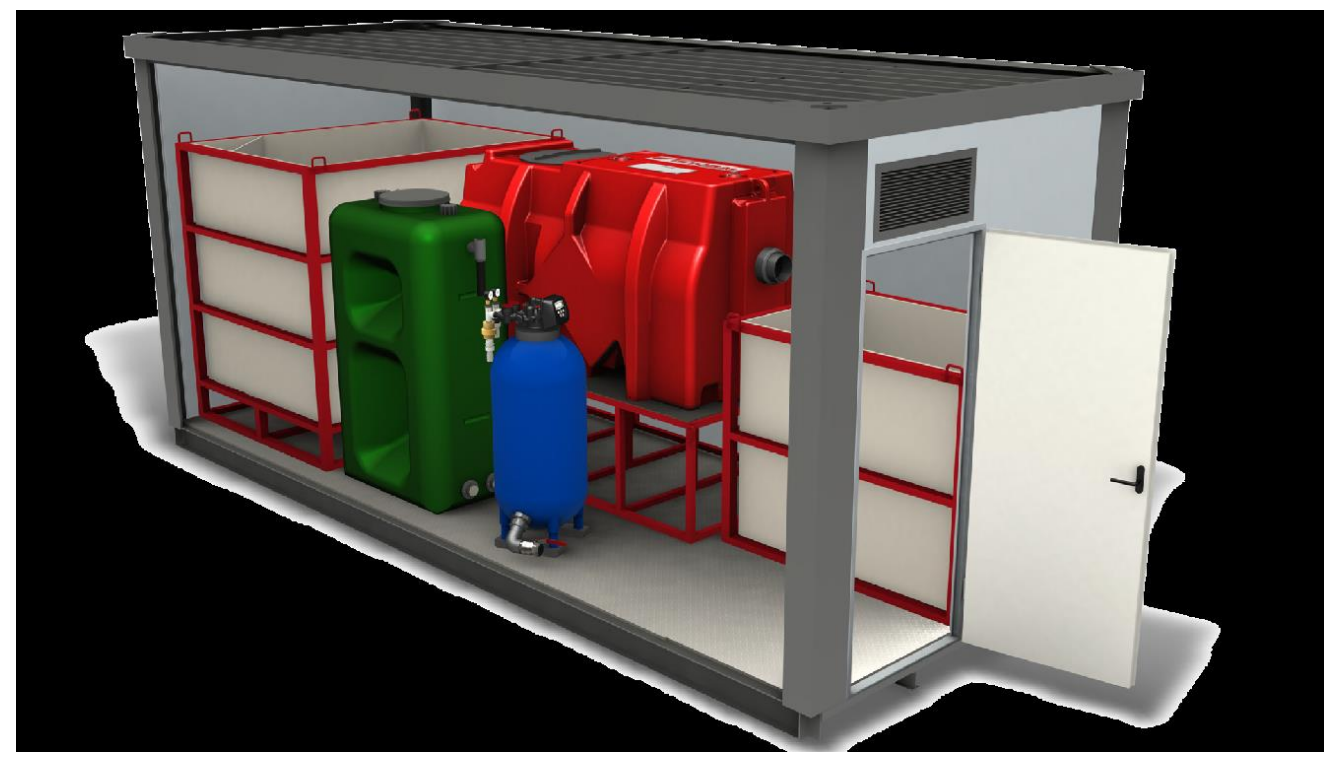

Figura 28. Equipo de reciclaje y recuperación de agua. Tomado de "Manual original contenedor de reciclaje móvil Acuabox" de ISTOBAL, 2017

Es importante mencionar que este equipo es especializado y está desarrollado de forma específica para tratar el agua residual procedente de los lavados de vehículos. Es práctico, ya que todos los equipos están instalados dentro de un contenedor de dimensiones estándar (2440x6000x2820 mm). Tiene un caudal de reciclaje máximo de $5 \mathrm{~m} 3$ por hora. El equipo de reciclaje tiene las siguientes etapas:

- Sedimentación y homogeneización

- Separación de hidrocarburos ( $<5 \mathrm{ppm}$ de aceites a la salida)

- Reciclaje físico

- Desinfección (opcional)

- Almacenamiento de agua reciclada

Luego de terminado el servicio el cliente realizará el pago del servicio ya sea con efectivo o con su tarjeta de crédito / débito para su mayor facilidad 
y alcance, recogiendo su vehículo posteriormente; así mismo mantendremos la comunicación con nuestro cliente, verificando la satisfacción de ellos, mediante un llamado y tomando también algunas recomendaciones para una mejora constante en nuestro servicio y el local en el que brindamos el servicio.

A continuación, se presentan dos figuras. La figura 25 muestra el diagrama de procesos general del servicio brindado sin detallar el lavado o servicio brindado, el cual puede variar dependiendo de lo que el cliente demande.

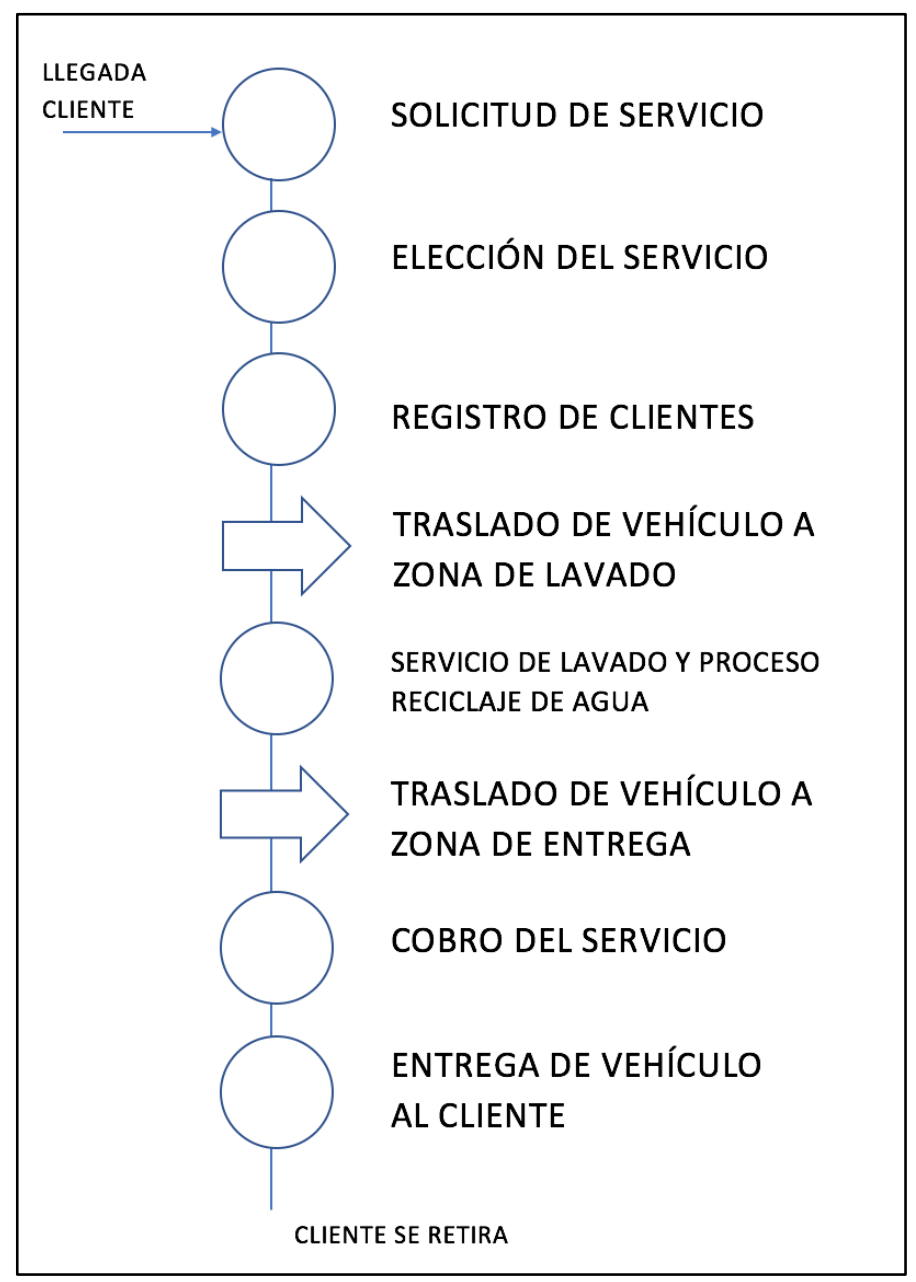

Figura 29. Diagrama de proceso general del servicio. Fuente y elaboración propia. 
Por otro lado, la figura 26 muestra el diagrama de proceso del lavado 1, el cual también es llamado lavado express.

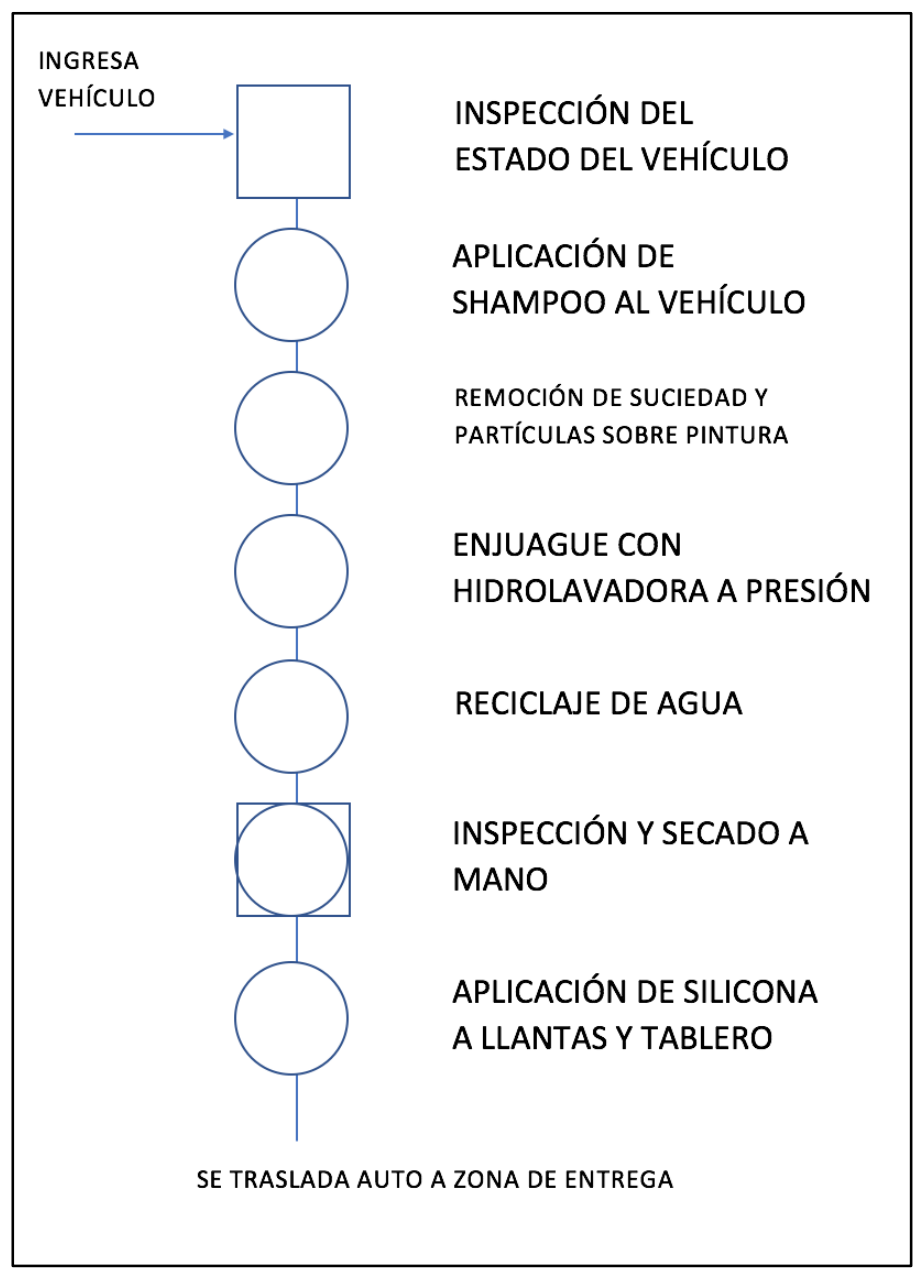

Figura 30. Diagrama de proceso del lavado 1 - Express. Fuente y elaboración propia.

\subsection{Regulación de licencias y políticas}

Para poder operar en el distrito de La Molina se deberá solicitar una licencia de funcionamiento, en el caso del proyecto esta licencia será una licencia de funcionamiento de establecimientos con un área de más de 100m2 hasta 500m2 con ITSE básica (Inspecciones técnicas en seguridad básicas) ex ante (antes del suceso), conjuntamente con anuncio publicitario luminoso o iluminado y/o toldo. 
Se considera que la solicitud de esta licencia es la más adecuada para el negocio, ya que la atención se realizará hasta horas de la noche, necesitando un anuncio publicitario iluminado en la puerta del local.

Para poder solicitar este tipo de licencia se deben tener en cuenta al momento de la presentación de documentos lo siguiente:

A. Requisitos Generales

a. Formato de solicitud de licencia, con carácter de declaración jurada, debidamente llenado, señalando Número de RUC, Número de DNI o Carné de Extranjería del solicitante. Número de DNI o Carné de Extranjería del representante legal, en caso de persona jurídica u otros entes colectivos; o tratándose de personas naturales que actúen mediante representación

b. Copia de vigencia de poder de representante legal en caso de personas jurídicas $\mathrm{u}$ entes colectivos. Tratándose de representación de personas naturales, se requiere de carta poder con firma legalizada.

c. Indicar número de comprobante de pago por derecho TUPA.

\section{B. Requisitos Específicos}

a. Copia simple del título profesional en el caso de servicios relacionados con la salud.

b. Copia simple de la autorización sectorial contenida en el Decreto Supremo N 006-2013-PCM o norma que lo sustituya o reemplace.

c. Copia simple de la autorización expedida por el Ministerio de Cultura, conforme a la Ley N 28296, Ley General del Patrimonio Cultural de la Nación. Excepto en los casos en que 
el Ministerio de Cultura haya participado en las etapas de remodelación y monitoreo de ejecución de obras previas inmediatas a la solicitud de la licencia del local por el cual se solicita la licencia.

C. Presentación de las siguientes vistas:

a. Diseño (dibujo) del anuncio y/o toldo con sus dimensiones, así como la indicación de los materiales de fabricación.

b. Una fotografía en la cual se aprecie el entorno urbano y la edificación donde se ubicará el anuncio y/o toldo considerando su posicionamiento virtual a partir de un montaje (dibujo)

D. Declaración Jurada del profesional responsable del diseño e instalación del anuncio.

E. En caso el anuncio supere el área de $12 \mathrm{~m} 2$ presentar: Memoria Descriptiva, especificaciones técnicas y planos de instalaciones eléctricas a escala conveniente, refrendada por profesional responsable.

A continuación, se muestra un flujograma de procedimiento para sacar la licencia de funcionamiento: 


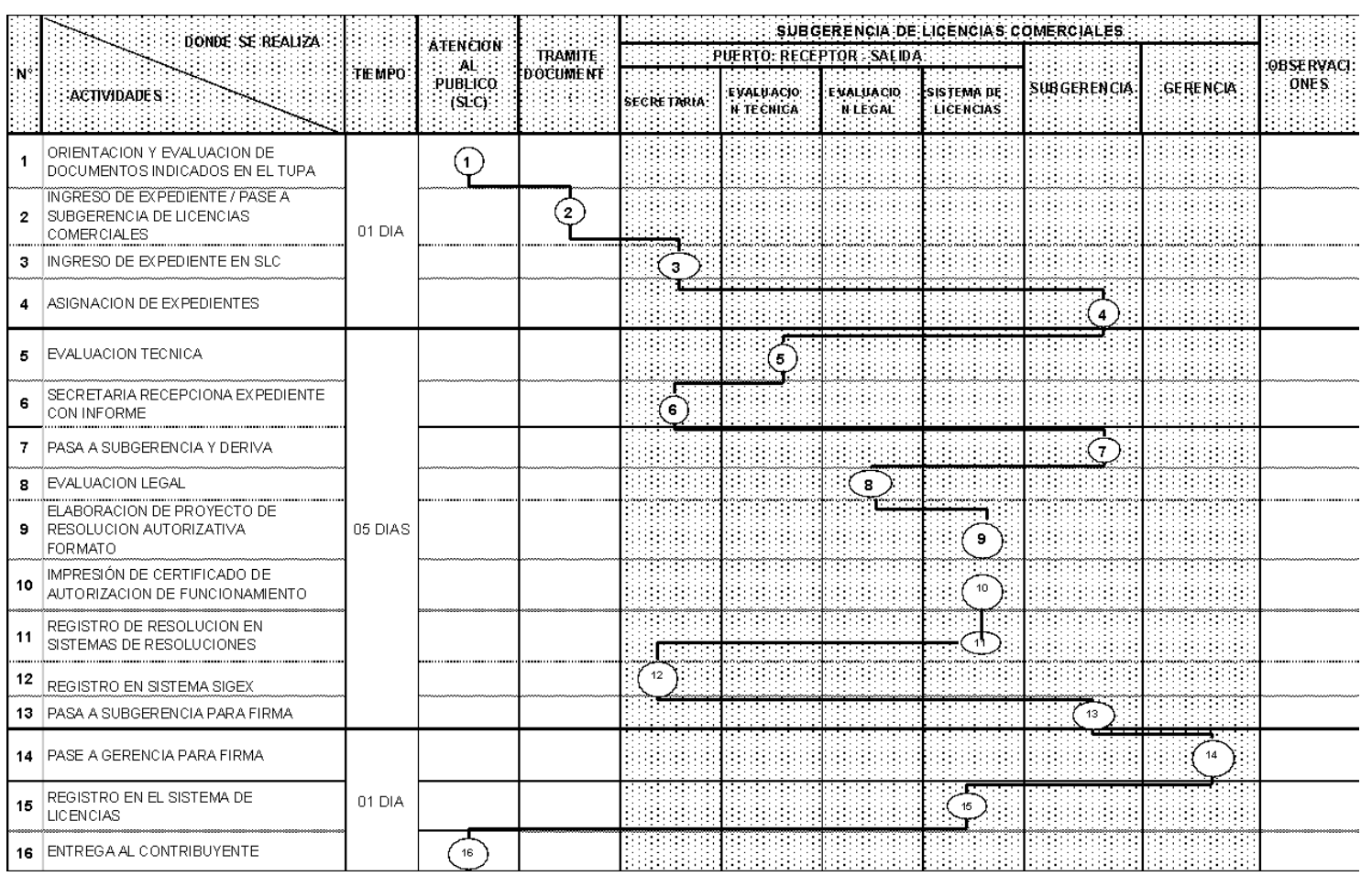

Figura 31. Flujograma para el trámite de la licencia de funcionamiento. Tomado de Municipalidad de la molina. Recuperado de http://www.munimolina.gob.pe/index.php/licencias-de-funcionamiento

\subsection{Costos de producción}

Los costos de producción para este proyecto serán los siguientes: (a) Costo mensual del alquiler, (b) Costo de los servicios básicos tales como agua, luz, teléfono, internet y cable, (c) costo de la mano de obra y (d) costo de los materiales y suministros utilizados.

\subsubsection{Costo mensual del alquiler}

Es el costo mensual que se pagará por el local de $300 \mathrm{~m} 2$ será de 3,500 dólares. 


\subsubsection{Costos de servicios básicos}

Tabla 18: Costos Serv. básicos anuales en soles (Energía, agua, teléfono)

\begin{tabular}{|c|c|c|c|c|c|}
\hline & Año 1 & Año 2 & Año 3 & Año 4 & Año 5 \\
\hline \# Autos atendidos & 7,023 & 7,725 & 8,266 & 8,845 & 9,464 \\
\hline Zona Productiva (Soles) & 15,556 & 16,888 & 17,913 & 19,010 & 20,184 \\
\hline Energía & 11,238 & 11,837 & 12,299 & 12,793 & 13,321 \\
\hline Maquina Recicladora & 5,234 & 5,234 & 5,234 & 5,234 & 5,234 \\
\hline Hidrolavadoras & 4,066 & 4,472 & 4,785 & 5,120 & 5,478 \\
\hline Aspiradoras & 1,937 & 2,130 & 2,279 & 2,438 & 2,609 \\
\hline Agua & 4,319 & 5,051 & 5,614 & 6,218 & 6,863 \\
\hline Hidrolavadoras & 4,319 & 5,051 & 5,614 & 6,218 & 6,863 \\
\hline Zona Administrativa (Soles) & 5,879 & 5,879 & 5,879 & 5,879 & 5,879 \\
\hline Teléfono/Cable/Internet & 1,679 & 1,679 & 1,679 & 1,679 & 1,679 \\
\hline Agua & 1,800 & 1,800 & 1,800 & 1,800 & 1,800 \\
\hline Luz & 2,400 & 2,400 & 2,400 & 2,400 & 2,400 \\
\hline
\end{tabular}

Nota: Fuente y elaboración propia. Información de precios del agua tomado de

www.sedapal.com.pe e información de precios de luz tomado de www.luzdelsur.com.pe

Se han calculado los costos anuales de energía (luz), agua, y servicios de telefonía. En el área productiva (operativa) es donde se tiene el mayor gasto. El promedio se tiene un gasto de más de 15 mil soles anuales. Además, el gasto de agua para las hidrolavadoras es de casi 7 mil soles al final del quinto año, esto considerando un ahorro por reutilización del agua. Por otro lado, en el área administrativa se ha considera un gasto anual de casi 6 mil soles, los que incluyen 140 soles de trío mensuales para servicios de internet, cable y teléfono; 150 soles mensuales de agua y 200 soles mensuales de luz aproximadamente.

También tendremos los costos de los servicios que enfocaremos en la publicidad de nuestro negocio, mencionados en nuestro plan de marketing, para dar a conocer a nuestros clientes nuestra empresa y servicios que brindamos. Para ello utilizaremos: 
Tabla 19: Costos por servicio de publicidad (Anuales)

\begin{tabular}{|c|c|}
\hline Servicios & St. \\
\hline Diseño de Página Web - Dominio & 400 \\
\hline Estrategia de Posicionamiento y Socialmedia (Redes Sociales) & 1,500 \\
\hline Artículos Merchandising & 3,000 \\
\hline
\end{tabular}

Nota: Fuente y elaboración propia

\subsubsection{Costo de la Mano de Obra}

El costo se calculará en base al personal que se desempeñará en la empresa. En el siguiente capítulo se detalla el Organigrama, el cual está formado por 6 personas. La estructura de la empresa estará conformada por un Administrador a la cabeza, seguido por un Coordinador de servicios y un Detailer o también llamado especialista en el detalle y lavado de autos. Finalmente se tendrá a cargo a 3 operarios que desempeñarán las labores directas de limpieza de los vehículos.

Tabla 20: Costo de Planilla (sin beneficios)

\begin{tabular}{|l|c|}
\hline OCUPACIÓN & Básico S. /Mes \\
\hline Administrador & $2,500.00$ \\
\hline Coordinar de Servicios & $1,500.00$ \\
\hline Detailer & $1,500.00$ \\
\hline Operarios (3) - 1000 C/U & $3,000.00$ \\
\hline
\end{tabular}

Nota: Fuente y elaboración propia

Como se muestra en la tabla anterior se detallan los sueldos que recibirán cada uno de los trabajadores según el puesto que desempeñarán. Para establecer el valor de los sueldos se revisó una publicación realizada por el diario Correo que tomó como fuente una lista publicada a inicio del 2016 por el Ministerio de Trabajo y Promoción del Empleo. Para el puesto de Administrador se buscará 
un Administrador de Empresas que según el MTPE gana en promedio 2,449 soles.

Para los puestos de Coordinador de Servicios y Detailer se buscará que sean personas con estudios en carreras técnicas y con amplia experiencia en el rubro. En este caso en MTPE nos da una cifra promedio de 1,505 soles para un Técnico en Administración Industrial. Finalmente, para los trabajadores que realizarán labores de operario se ha decidido pagar un sueldo por encima del sueldo mínimo (850 soles a mayo 2016) pagando 1000 soles a cada uno de ellos. A continuación, se muestran el costo total anual de cada uno tomando las gratificaciones, el aporte a Essalud y CTS.

\section{Tabla 21: Costos laborales total de la Planilla (Anuales) en soles}

\begin{tabular}{|l|r|r|r|r|r}
\hline OCUPACIÓN & Gratif & CTS & Essalud & Sueldo & $\begin{array}{c}\text { Total } \\
\text { Remun }\end{array}$ \\
\hline Administrador & $5,000.00$ & $2,916.67$ & $2,700.00$ & $30,000.00$ & $40,616.67$ \\
\hline Coordinar de Servicios & $3,000.00$ & $1,750.00$ & $1,620.00$ & $18,000.00$ & $24,370.00$ \\
\hline Detailer & $3,000.00$ & $1,750.00$ & $1,620.00$ & $18,000.00$ & $24,370.00$ \\
\hline Operarios (3) - 1000 C/U & $6,000.00$ & $3,500.00$ & $3,240.00$ & $36,000.00$ & $48,740.00$ \\
\hline
\end{tabular}

Nota: Fuente y elaboración propia

\subsubsection{Materiales y equipos que se utilizaran para los servicios de}

\section{limpieza:}

- 3M Paño de Microfibra

- 3M Limpiador de Cuero y Vinil

- 3M Limpiador de Aros y Llantas

- 3M Pulidor

- 3M Cera 2 en 1

- 3M Shampoo para Lavado

- 3M Cera Performance Finish 
- 3M Silicona

- 3M Renovador

- SONAX Esponja llantas/aros

- SONAX Cepillo especial

- SONAX Pano de microfibra exterior

- SONAX Exterminador de olores

- SONAX XTREME Pulimento para metal

- SONAX Xtreme Active, Champú 2 en 1

Como equipos tenemos:

- "Lavadora de alta presión agua fría de uso profesional (Modelo: Karcher HD 6/13")

- "Aspiradora en seco/humedo de Uso Profesional (Modelo: Kärcher NT 35/1").

- Pulidora Orbital 7" 1200 W Black \& Decker

- "Contenedor de reciclaje móvil (Modelo: ISTOBAL ACUABOX")

A continuación, se muestra un cuadro con las marcas, productos y descripción de los mismos, con el precio aproximado de cada uno: 
Tabla 22: Precio de insumos y materiales para lavado de autos

\begin{tabular}{lll}
\hline Tamaño & Materiales & $\begin{array}{l}\text { Precio } \\
\text { (Soles) }\end{array}$ \\
\hline $1 \mathrm{und}$ & 3M Paño de Microfibra & 16.90 \\
$473 \mathrm{ml}$ & 3M Limpiador de Cuero y Vinil & 29.90 \\
$473 \mathrm{ml}$ & 3M Limpiador de Aros y Llantas & 29.90 \\
$473 \mathrm{ml}$ & 3M Pulidor & 25.90 \\
$473 \mathrm{ml}$ & 3M Cera 2 en 1 & 33.90 \\
$473 \mathrm{ml}$ & 3M Shampoo para Lavado & 19.90 \\
$473 \mathrm{ml}$ & 3M Cera Performance Finish & 40.00 \\
$480 \mathrm{ml}$ & 3M Silicona & 19.90 \\
$480 \mathrm{ml}$ & 3M Renovador & 15.90 \\
$1 \mathrm{und}$ & SONAX Esponja llantas/aros & 22.90 \\
$1 \mathrm{und}$ & SONAX Cepillo especial & 57.34 \\
$1 \mathrm{und}$ & SONAX Pano de microfibra exterior & 13.76 \\
$500 \mathrm{ml}$ & SONAX Exterminador de olores & 33.94 \\
$150 \mathrm{ml}$ & SONAX XTREME Pulimento para metal & 21.50 \\
$500 \mathrm{ml}$ & SONAX Xtreme Active, Champú 2 en 1 & 29.65 \\
$1 \mathrm{LT}$ & SONAX Profiline Cut Max & 192.00 \\
$1 \mathrm{LT}$ & SONAX Profiline Cut\&Finish & 107.00 \\
$400 \mathrm{ml}$ & SONAX Preparador de Pintura & 50.00 \\
\hline
\end{tabular}

Nota: Fuente y elaboración propia

Tabla 23: Precio de Maquinaria y Equipos en soles

\begin{tabular}{|lrrr}
\hline $\begin{array}{l}\text { Maquinaria y Equipos } \\
\text { Maquinaria para limpieza de autos }\end{array}$ & Cantidad & \multicolumn{1}{c}{ Soles } & \multicolumn{1}{c}{ Total Soles } \\
profesional & & & $\mathbf{1 2 , 8 3 7 . 5 2}$ \\
$\begin{array}{l}\text { Modelo: Karcher HD 6/13 } \\
\text { Aspiradora en seco/humedo de Uso Profesional }\end{array}$ & 2 & $4,203.83$ & $8,407.66$ \\
$\begin{array}{l}\text { Modelo: Karcher NT 35/1 } \\
\text { Pulidora Orbital 7" 1200 W Black \& Decker }\end{array}$ & 2 & $2,015.03$ & $4,030.06$ \\
Maquinaria Reciclaje de Agua & 2 & 199.90 & 399.80 \\
Contenedor de reciclaje movil & & & $\mathbf{1 1 7 , 4 1 4 . 0 0}$ \\
Modelo: ISTOBAL ACUABOX & 1 & $117,414.00$ & $117,414.00$ \\
\hline
\end{tabular}

Nota: Fuente y elaboración propia

Para determinar el uso de cada materiales o insumo se realizó benchmarking con la empresa Heviclubs. Durante 1 mes se llevó la cuenta aproximada de cuantos autos podían ser atendidos por cada presentación de producto. La empresa Heviclubs tiene un negocio nuevo (tiempo de 
operación menor a 1 año) de lavado de autos, el cual permite a este proyecto utilizar su información como data base para los cálculos. El resultado de este cálculo se presenta en el siguiente cuadro:

\section{Tabla 24: Número de autos atendidos por insumo}

\begin{tabular}{lll}
\hline Tamaño & Materiales & $\begin{array}{l}\text { Usado en \# } \\
\text { autos }\end{array}$ \\
$1 \mathrm{und}$ & 3M Paño de Microfibra & 20.00 \\
$473 \mathrm{ml}$ & 3M Limpiador de Cuero y Vinil & 15.00 \\
$473 \mathrm{ml}$ & 3M Limpiador de Aros y Llantas & 20.00 \\
$473 \mathrm{ml}$ & 3M Pulidor & 20.00 \\
$473 \mathrm{ml}$ & 3M Cera 2 en 1 & 20.00 \\
$473 \mathrm{ml}$ & 3M Shampoo para Lavado & 15.00 \\
$473 \mathrm{ml}$ & 3M Cera Performance Finish & 20.00 \\
$480 \mathrm{ml}$ & 3M Silicona & 10.00 \\
$480 \mathrm{ml}$ & 3M Renovador & 10.00 \\
$1 \mathrm{und}$ & SONAX Esponja llantas/aros & 10.00 \\
$1 \mathrm{und}$ & SONAX Cepillo especial & 35.00 \\
$1 \mathrm{und}$ & SONAX Pano de microfibra exterior & 20.00 \\
$500 \mathrm{ml}$ & SONAX Exterminador de olores & 15.00 \\
$150 \mathrm{ml}$ & SONAX XTREME Pulimento para metal & 10.00 \\
$500 \mathrm{ml}$ & SONAX Xtreme Active, Champú 2 en 1 & 15.00 \\
$1 \mathrm{LT}$ & SONAX Profiline Cut Max & 3.00 \\
$1 \mathrm{LT}$ & SONAX Profiline Cut\&Finish & 3.00 \\
$400 \mathrm{ml}$ & SONAX Preparador de Pintura & 2.00 \\
\hline
\end{tabular}

Nota: Fuente y elaboración propia

Por otro lado, se realizó una tabla para determinar que productos son utilizados para cada tipo de servicio que se brindará. De este modo, podremos tener un cálculo más preciso del costo de material que se tendrá por cada servicio realizado y por cada auto atendido. A continuación, se muestra la tabla en mención: 
Tabla 25: Materiales utilizados para cada servicio

\begin{tabular}{|c|c|c|c|c|c|c|}
\hline & SERV 1 & SERV 2 & SERV 3 & LAV SALON & DESCONT & TRATAM \\
\hline \multicolumn{7}{|l|}{ Materiales } \\
\hline 3M Paño de Microfibra & $\mathbf{x}$ & $\mathbf{x}$ & $\mathbf{x}$ & $\mathbf{x}$ & $\mathbf{x}$ & $\mathbf{x}$ \\
\hline 3M Limpiador de Cuero y Vinil & & & & $\mathbf{x}$ & & \\
\hline 3M Limpiador de Aros y Llantas & & $x$ & $\mathbf{x}$ & $\mathbf{x}$ & $x$ & $\mathbf{x}$ \\
\hline 3M Pulidor & & & & & $\mathbf{x}$ & \\
\hline 3M Cera 2 en 1 & & & & $\mathbf{x}$ & & \\
\hline 3M Shampoo para Lavado & $\mathbf{x}$ & $x$ & & & & $\mathbf{x}$ \\
\hline 3M Cera Performance Finish & & & $\mathbf{x}$ & & $x$ & \\
\hline 3M Silicona & $\mathbf{x}$ & $x$ & $\mathbf{x}$ & $x$ & $\mathbf{x}$ & $\mathbf{x}$ \\
\hline 3M Renovador & & & & $\mathbf{x}$ & & \\
\hline SONAX Esponja Ilantas/aros & $\mathbf{x}$ & $x$ & $x$ & $\mathbf{x}$ & $x$ & $\mathbf{x}$ \\
\hline SONAX Cepillo especial & & $x$ & $\mathbf{x}$ & $\mathbf{x}$ & $x$ & $\mathbf{x}$ \\
\hline SONAX Pano de microfibra exterior & $\mathbf{x}$ & $\mathbf{x}$ & $\mathbf{x}$ & $\mathbf{x}$ & $\mathbf{x}$ & $\mathbf{x}$ \\
\hline SONAX Exterminador de olores & & $\mathbf{x}$ & $\mathbf{x}$ & $\mathbf{x}$ & $\mathbf{x}$ & $\mathbf{x}$ \\
\hline SONAX XTREME Pulimento para metal & & & $\mathbf{x}$ & $\mathbf{x}$ & $\mathbf{x}$ & \\
\hline SONAX Xtreme Active, Champú 2 en 1 & & & $\mathbf{x}$ & $\mathbf{x}$ & $\mathbf{x}$ & \\
\hline SONAX Profiline Cut Max & & & & & & $\mathbf{x}$ \\
\hline SONAX Profiline Cut\&Finish & & & & $\mathbf{x}$ & & $\mathbf{x}$ \\
\hline SONAX Preparador de Pintura & & & & & & $\mathbf{x}$ \\
\hline
\end{tabular}

Nota: Fuente y elaboración propia

La siguiente tabla muestra el costo de los insumos utilizados por servicio y por cada vehículo atendido. Es decir, lo que me cuesta cada vehículo de acuerdo al consumo que se utiliza en el servicio prestado.

Tabla 26: Costos unitario de los insumos por vehículo atendido.

\begin{tabular}{lr} 
COSTOS UNITARIOS & Soles \\
\hline Servicio 1 - Servicio Express & 7.14 \\
Servicio2 & 12.54 \\
Servicio 3 & 17.34 \\
Lavado de salón & 56.28 \\
Descontaminación de pintura & 20.33 \\
Tratamiento de pintura & 137.20 \\
\hline
\end{tabular}

Nota: Fuente y elaboración propia

Como resumen final se presenta un cuadro en el cual se agrupan todos los costos mencionados en este capítulo. Como se puede ver a continuación el cuadro muestra los costos en soles y por año en los que incurriría la empresa de acuerdo al plan de negocios presentado. 
Tabla 27: Resumen de costos de producción (soles)

\begin{tabular}{|c|c|c|c|c|c|c|}
\hline Costos e Inversión & Año 0 & Año 1 & Año 2 & Año 3 & Año 4 & Año 5 \\
\hline Costo sevicios básicos & & $S / .21,435$ & $S / .22,767$ & $S / .23,792$ & $S / .24,889$ & $S / .26,063$ \\
\hline Zona Productiva (Soles) & & $S / .15,556$ & $\mathrm{~S} / .16,888$ & $S / .17,913$ & $S / .19,010$ & $S / .20,184$ \\
\hline Energía & & $\mathrm{S} / .11,238$ & $\mathrm{~S} / .11,837$ & S/.12,299 & $\mathrm{S} / .12,793$ & $\mathrm{~S} / .13,321$ \\
\hline Agua & & $S / .4,319$ & $S / .5,051$ & $S / .5,614$ & $S / .6,218$ & $S / .6,863$ \\
\hline Zona Administrativa (Soles) & & $S / .5,879$ & $S / .5,879$ & $S / .5,879$ & $S / .5,879$ & $S / .5,879$ \\
\hline Teléfono/Cable/Internet & & $S / .1,679$ & $S / .1,679$ & $S / .1,679$ & $S / .1,679$ & $S / .1,679$ \\
\hline Agua & & $\mathrm{S} / .1,800$ & $\mathrm{~S} / .1,800$ & $\mathrm{~S} / .1,800$ & $\mathrm{~S} / .1,800$ & $S / .1,800$ \\
\hline Luz & & $\mathrm{S} / .2,400$ & $\mathrm{~S} / .2,400$ & $\mathrm{~S} / .2,400$ & $\mathrm{~S} / .2,400$ & $S / .2,400$ \\
\hline Costo alquiler local & & $S / .138,600$ & $S / .138,600$ & $S / .138,600$ & $S / .138,600$ & $S / .138,600$ \\
\hline Costo mano de obra & & $S / .138,097$ & $S / .138,097$ & $S / .138,097$ & $S / .138,097$ & $S / .138,097$ \\
\hline Administrador & & $40,616.67$ & $40,616.67$ & $40,616.67$ & $40,616.67$ & $40,616.67$ \\
\hline Coordinar de Servicios & & $24,370.00$ & $24,370.00$ & $24,370.00$ & $24,370.00$ & $24,370.00$ \\
\hline Detailer & & $24,370.00$ & $24,370.00$ & $24,370.00$ & $24,370.00$ & $24,370.00$ \\
\hline Operarios (3) - $1000 \mathrm{C} / \mathrm{U}$ & & $48,740.00$ & $48,740.00$ & $48,740.00$ & $48,740.00$ & $48,740.00$ \\
\hline Inversión maquinaria y equipos & $S / .130,252$ & & & & & \\
\hline Costo de insumos de limpieza & & $S / .167,170$ & $S / .183,887$ & $S / .196,759$ & $S / .210,533$ & $S / .225,270$ \\
\hline
\end{tabular}

Nota: Fuente y elaboración propia 


\section{CAPÍTULO V. PLAN DE RECURSOS HUMANOS}

\subsection{Organización funcional}

El proyecto será registrado como un Sociedad Comercial de Responsabilidad Limitada (S.C.R.L.). Esto debido a que los propietarios intelectuales consideran que presenta las características más adecuadas con el negocio. La característica principal es que el capital está divido en participaciones iguales, pero no se denominan acciones. Además, los socios no pueden exceder de veinte y no responden por las obligaciones sociales Otra característica a mencionar es que el capital social estará integrado por las aportaciones de los socios, y será depositado en una entidad bancaria o financiera del sistema financiero nacional a nombre de la sociedad. Con respecto a la administración de la sociedad, ésta podrá ser encargada a uno o más gerentes, los cuales pueden ser socios o no, quienes la representarán. Es importante mencionar que los gerentes o administradores responden frente a la sociedad por los daños y perjuicios causados (Ley General de Sociedades, 1997).

\subsection{Organigrama}

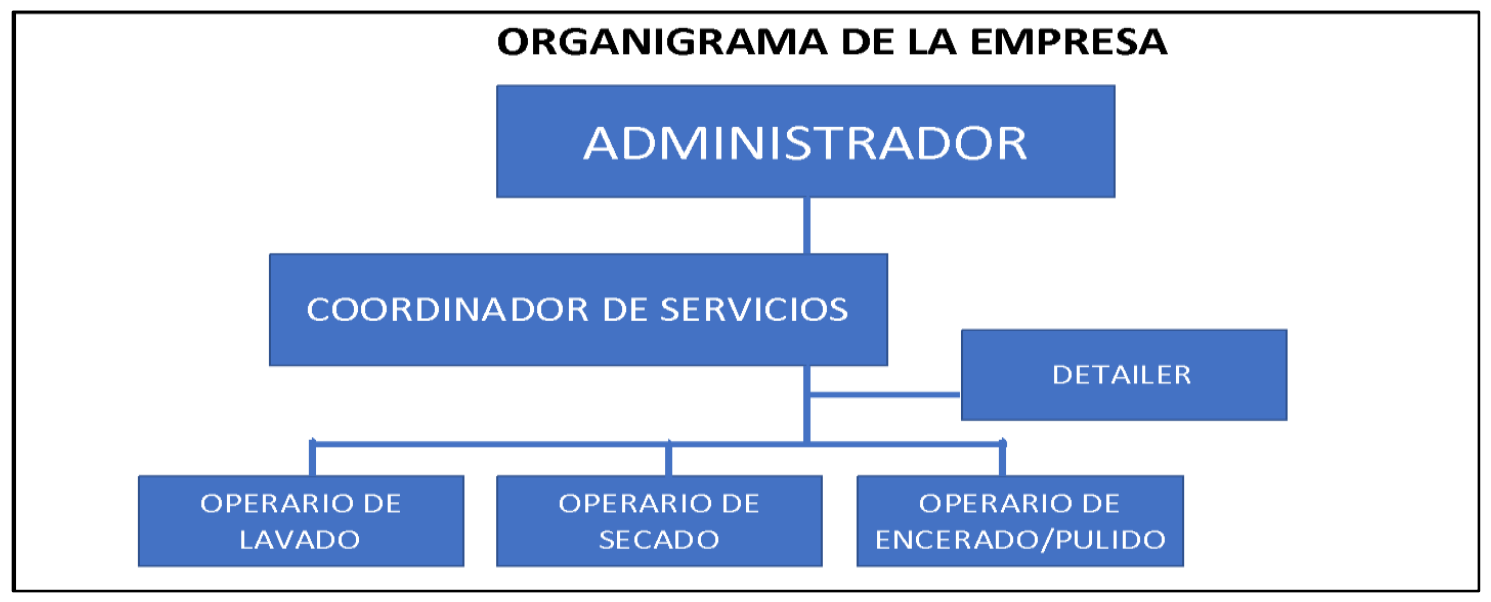

Figura 32. Organigrama de la empresa. Fuente y elaboración propia. 
La figura anterior muestra el organigrama del proyecto. En él podemos observar que se tendrá 6 personas en total trabajando en la empresa.

El administrador es la cabeza del grupo humano que trabajará en el car wash, tendrá toda la responsabilidad de manejo y control de los aspectos empresariales tales como: contabilidad, cobranzas, pagos de planillas, registro de asistencia, atención directa con el cliente, asignación de servicios utilizando los medios digitales (página web y whatsapp). También se hará cargo de la promoción, publicidad y comunicación con nuestro público objetivo para dar a conocer nuestro local, servicios y diferenciación ante otros servicios de car wash, mencionando también la concientización de nuestra empresa por el uso y cuidado del medio ambiente, teniendo un cuidado y uso eficiente del recurso que empleamos en el lavado de autos, el agua.

Continuando con el organigrama tenemos al Detailer, que realizará funciones de asistencia para el Administrador. Además, verá la parte logística, para la compra de insumos y materiales que requerimos para el servicio a brindar, además de la limpieza del local. Todas estas actividades no serán restrictivas para que pueda apoyar en caso haya un incremento de la demanda. Como Detailer su experiencia y conocimiento de los procesos de lavado de autos es integral.

Finalmente, el área de operaciones, tendremos a nuestro personal especializado que brindará el servicio de lavado. Este grupo humano estará formado por un Coordinador de Servicios, quién dirigirá todas las actividades del personal operario, conociendo cada uno de los procesos realizados para los autos de los clientes (lavado, secado, encerado, pulido). 
Así mismo, el Coordinador podrá efectuar labores inmersas del propio proceso en caso la demanda suba en determinado momento del día. A su cargo estarán 3 operarios los cuales deberán conocer a detalle cada uno de los procesos, ya que no están especializados en determinados pasos sino deberán conocer todas las actividades.

Es importante resaltar que la empresa busca la inclusión social de personas con discapacidad. Por ese motivo se ha habilitado una vacante dentro del staff de la empresa para que una persona con discapacidad pueda postular, ser evaluada y posteriormente pertenecer a la empresa. Se debe mencionar que existe instituciones que integran y ayudan a personas con discapacidad, siendo una de estas la empresa Amerinka, ubicada en Pueblo Libre, la cuál trata discapacidades como: motora o de la movilidad, auditiva, del habla, mental, intelectual o visual. El propósito que tiene esta entidad es brindar apoyo en rehabilitación física a personas que así lo requieran, además han diseñado cursos de capacitación ocupacional que podrían permitir la reinserción social y laboral.

\subsection{Política de contratación}

Al ser una pequeña empresa, las políticas de contratación se ven centradas en los siguientes puntos:

i. Todo tipo de persona tiene derecho a postular y ser evaluada por la empresa. Será seleccionada bajo el criterio de sus capacidades profesionales, evaluadas previamente por la Administración de la empresa.

ii. Con fines de inclusión social, se evaluará a personas provenientes de distintas clases sociales, con diferentes tipos de discapacidad. 
iii. La Planificación de la selección y reclutamiento del personal lo realizará el Administrador de la empresa. Sin embargo, los socios de la S.C.R.L evaluarán también a los candidatos finales.

iv. La posición deberá ser valorizada, calculando así los costos que ésta generaría a la empresa. El Administrador es responsable de este punto.

v. La selección final del candidato será decidida por el Administrador y ambos socios de la empresa.

vi. Con la finalidad de apoyar al personal de la empresa y brindarle posibilidades de crecimiento se prioriza el reclutamiento interno. Sin embargo, de no cumplir con los requisitos solicitados se procederá a realizar un reclutamiento externo.

vii. Como norma general no se acepta contratar personas que sean familiares del personal hasta cuarto grado de consanguineidad o segundo grado de afinidad.

viii. Ninguna persona podrá ser contratada por menos del sueldo mínimo permitido en el país.

ix. Al momento de contratar al personal, es de carácter obligatorio tener un file del postulante y nuevo trabajador de la empresa con toda la información y formatos requeridos.

\subsection{Política salarial}

La política salarial ayudará a determinar el marco de referencia para todos los sueldos de los trabajadores de la empresa. En el caso de este proyecto la política salarial presenta los siguientes objetivos: 
- Captar personal con talento y las capacidades necesarias para cubrir los puestos del negocio.

- Establecer una remuneración acorde con su preparación, experiencia y logros de objetivos. Del mismo modo las remuneraciones de todo el personal deben ser equitativas a sus responsabilidades y labores.

- Promover la competitividad y motivar al personal para el mejor desempeño de sus funciones.

- Difundir al personal lo criterios de evaluación tomados en cuenta para sus calificaciones y consecuentes bonos, premios y remuneraciones.

Una política salarial debe poseer la descripción de las funciones que realiza cada puesto, indicando a quien reporta y el nivel académico y de experiencia que debe tener. También debe realizar una clasificación y agrupación de cargos que tengas similitudes en habilidad, experiencia y responsabilidad. Además, el rango salarial debe ser determinado de acuerdo a un análisis de mercado y/o de acuerdo a salarios de trabajadores en los mismos puestos en empresas similares al rubro en que se desempeña el negocio. Así mismo, se debe tener cuidado con los niveles salariales de acuerdo a la agrupación previa antes mencionada, para así asegurar la equidad de sueldos a todo nivel. Por último, se debe establecer la posibilidad de aumentar la remuneración base de acuerdo a una evaluación previa de desempeño (Stacey Irwin Downey, 1999).

Teniendo en cuenta lo anterior la política salarial será la siguiente:

- La contratación del personal y el salario que este percibirá será determinado de acuerdo a las funciones y responsabilidades que tendrá en el cargo al que se le contrata, a su vez también se tomará en cuenta el nivel de formación académica y la experiencia laboral. 
- El pago del sueldo será mensual y será depositado en la cuenta corriente o de ahorros del empleado.

- El empleado podrá solicitar un adelanto de su sueldo y se le otorgará previa evaluación de la Administración. El monto no podrá exceder el $50 \%$ de su sueldo mensual. Al final del periodo contable se le descontará dicho adelanto para el pago final.

- Del salario mensual de los empleados se realizará los siguientes descuentos: Aportaciones AFP o ONP, Impuesto 5ta categoría, préstamos concedidos, deudas a la empresa.

- La empresa no realizará pagos de horas extras.

- El bono anual entregado a los trabajadores dependerá de su evaluación de desempeño, de su asistencia durante el año laborado, y sus participaciones destacadas o faltas que se hayan dado. 


\section{CAPÍTULO VI: PLAN FINANCIERO}

\subsection{Inversiones}

Se ha detallado a continuación la inversión que se realizará para el inicio de las operaciones del proyecto.

\section{1..1. Inversiones en activo fijo}

Las inversiones en equipos las tenemos detalladas en la tabla 24. Para el área operativa se consideran dos lavadoras de alta presión y dos aspiradoras profesionales de la marca Karcher. Además, se considera el equipo de reciclaje de la marca ISTOBAL modelo ACUABOX, con el cual se realizará el proceso de reutilización del agua. Por otro lado, para el tratamiento de la pintura se comprará una pulidora orbital.

Para implementar la sala de confort de los clientes se tomará en cuenta la compra de un televisor de 65 pulgadas, dos sofás de dos cuerpos, 4 sillas y dos escritorios. Para las oficinas y área administrativa se comprarán dos computadoras de escritorio una HP y una LENOVO. También, se tendrá un escritorio y una vitrina mostrador de aluminios de segunda para esta área. La inversión en equipos se estima en 143,292 soles.

Es importante también mencionar las obras físicas en las que se invertirá, tales como el vaciado y nivelado de lozas, el pintado de oficinas interiores y fachados, y por último las instalaciones eléctricas. Esta inversión tendrá un costo de 10,700 soles. Como Inversión total tangible tendremos 153,992 soles. 
Tabla 28: Inversión Tangible del proyecto

\begin{tabular}{|c|c|c|c|}
\hline Inversión Tangible (S/.) & & & 153,992 \\
\hline Inversión en Equipos (S/.) & & & 143,292 \\
\hline Detalle & Cantidad & Precio Uni. (S/.) & Total (S/.) \\
\hline Lavadora de alta presión agua fría de uso & & & \\
\hline profesional & 2 & 4,204 & 8,408 \\
\hline Aspiradora en seco/humedo de Uso Profesional & & & \\
\hline Modelo: Karcher NT 35/1 & 2 & 2,015 & 4,030 \\
\hline Contenedor de reciclaje movil & & & \\
\hline Modelo: ISTOBAL ACUABOX & 1 & 117,414 & 117,414 \\
\hline Pulidora Orbital 7" 1200 W Black \& Decker & 2 & 199.90 & 399.80 \\
\hline Televisor LED 4K 65 - Miray & 1 & 3,999 & 3,999 \\
\hline Sofá 2 cuerpos Mertens Beige - Mica & 2 & 499 & 998 \\
\hline Escritorio Tijuca 2 Cajones Imbuia - Mica & 2 & 199 & 398 \\
\hline Silla Verona - Basement Home & 4 & 400 & 1,598 \\
\hline Escritorio Galaxia - Pisopak & 1 & 499 & 499 \\
\hline Vitrina y mostrador de aluminio ( $2 \mathrm{da}$ ) & 1 & 350 & 350 \\
\hline All in One 23" Intel Core i5 4 GB 1 TB Windows 10 - HP & 1 & 3,499 & 3,499 \\
\hline All in One Lenovo 21.5" Intel Core i3 1TB 4 GB & & & \\
\hline RAM - LENOVO & 1 & 1,699 & 1,699 \\
\hline Obras físicas y terrenos (S/.) & & & 10,700 \\
\hline Vaceado y nivelado de lozas de concreto (200 m2) & & & 4,200 \\
\hline Pintado de oficinas interiores y fachada & & & 3,000 \\
\hline Cableado e instalación eléctrica & & & 3,500 \\
\hline
\end{tabular}

Nota: Fuente y elaboración propia

\section{1..2.Inversiones en capital de trabajo}

En la tabla 25 podemos observar los montos considerados para el Capital de trabajo. En primer lugar, observamos los gastos pre operativos y administrativos los cuales incluyen útiles de oficina, movilidad, telefonía, internet, cable, agua y luz. Así como 2 equipos celulares para comunicación. Estos costos están considerados aproximadamente para 3 meses. Además, se considera el pago adelantado del alquiler del local durante el primer año. Por otro lado, el costo de la planilla es considerado para 3 meses de operación del negocio. En este costo se consideran las 6 personas que integran la planilla ya descrita. El monto previsto para 3 meses es de 34,524 
soles. Finalmente, se tiene el costo de los insumos para 3 meses de operación. Este monto asciende a 26,214 soles.

\section{Tabla 29: Capital de Trabajo}

\begin{tabular}{|lr|}
\hline Capital de Trabajo (S/.) & $\mathbf{2 0 4 , 6 4 8}$ \\
Detalle & Total \\
Gastos Administrativos y Pre Operativos (S/.) & $\mathbf{5 , 3 1 0}$ \\
Papelería y Utiles de Oficina & 1,500 \\
Movilidad & 2,000 \\
Telefonia + Internet+cable magico (3 meses) & 420 \\
Celulares (2 equipos) & 340 \\
Agua (3 meses) & 450 \\
Luz (3 meses) & 600 \\
Alquiler (S/.) (12 meses) & 138,600 \\
Planilla (S/.) (3 meses) & $\mathbf{3 4 , 5 2 4}$ \\
Administrador & 10,154 \\
Coordinar de Servicios & 6,093 \\
Detailer & 6,093 \\
Operarios & 12,185 \\
Insumos (S/.) (3 meses) & $\mathbf{2 6 , 2 1 4}$ \\
3M Paño de Microfibra & 2,636 \\
3M Limpiador de Cuero y Vinil & 1,555 \\
3M Limpiador de Aros y Llantas & 1,555 \\
3M Pulidor & 1,347 \\
3M Cera 2 en 1 & 1,763 \\
3M Shampoo para Lavado & 1,035 \\
3M Cera Performance Finish & 2,080 \\
3M Silicona & 1,035 \\
3M Renovador & 827 \\
SONAX Esponja llantas/aros & 1,786 \\
SONAX Cepillo especial & 1,789 \\
SONAX Pano de microfibra exterior & 2,147 \\
SONAX Exterminador de olores & 1,765 \\
SONAX XTREME Pulimento para metal & 3,354 \\
SONAX Xtreme Active, Champú 2 en 1 & 1,542 \\
\hline
\end{tabular}

Nota: Fuente y elaboración propia

\section{1..3.Inversiones en activos intangibles}

En la tabla 26 tenemos las inversiones realizadas en activos intangibles. Para este proyecto se han considerado como tales, el costo de constitución de la empresa, el costo de la licencia de 
funcionamiento y el costo de tasa de inspección de defensa civil. Este monto sumado es de 2,204 soles.

Tabla 30: Inversión intangible del proyecto

\begin{tabular}{|lr|}
\hline Invesrsión Intangible (S/.) & $\mathbf{2 , 2 0 4}$ \\
\hline Gastos de Constitución (S/.) & $\mathbf{2 , 2 0 4}$ \\
Detalle & $\underline{\text { Total }}$ \\
\hline Constitución de la empresa & 1,000 \\
Licencia de funcionamiento & 579 \\
Tasa de inspección defensa civil & 626 \\
\hline
\end{tabular}

Nota: Fuente y elaboración propia

Finalmente, en la tabla 27 se muestra un resumen de la inversión tangible e intangible, así como también el capital de trabajo tomado en cuenta. El total de inversión es de 360,845 soles.

\section{Tabla 31: Inversión total}

\begin{tabular}{|lr|}
\hline Inversión Total (S/.) & 360,845 \\
\hline Inversión Tangible & 153,992 \\
Invesrsión Intangible & 2,204 \\
Capital de Trabajo & 204,648 \\
\hline
\end{tabular}

Nota: Fuente y elaboración propia

\subsection{Financiamiento}

El financiamiento del proyecto será asumido el $100 \%$ por los accionistas. Los accionistas y autores de este plan de negocios asumirán el total del riesgo porque confían en el proyecto realizado y pueden asumir el riesgo.

\subsubsection{Costo de Oportunidad}

Para poder calcular el costo de oportunidad del proyecto, y debido a que se piensa financiar el total del monto con dinero propio, se 
utilizó el método del CAPM para poder hallar el COK (Costo de oportunidad). Según el modelo CAPM la rentabilidad esperada (Ri) es calculada por la tasa de interés sin riesgo (Rf) mas una prima de riesgo. Esta prima de riesgo está en función de la beta $(\beta)$, la cual será aplicada a la diferencia entre la rentabilidad del mercado $(\mathrm{Rm})$ y la tasa libre de riesgo (Rf). Entonces el modelo planteado queda de la siguiente forma (Fernández, Fernández, Rodríguez, 2007):

$$
\overline{R_{i}}=R_{f}+\beta\left(\bar{R}_{m}-R_{f}\right)
$$

Para calcular la rentabilidad esperada hemos utilizado los siguientes datos:

1. Tasa libre de riesgo (Rf): Bonos del tesoro de EUA

2. Beta $(\beta)$ : Betas de EUA del sector autopartes (el sector más cercano y similar al proyecto).

3. Rendimiento del mercado (Rm): se utilizó el indicador S\&P/BVL PERU SELECT INDEX de la bolsa de valores de Lima.

\section{Tabla 32: Cálculo de COK o rentabilidad (Ri)}

\begin{tabular}{|lr|}
\hline Método CAPM & \\
rf & 3.00 \\
B & 1.12 \\
RM & 19.18 \\
Prima Riesgo Mercado & 16.18 \\
& \\
COK & 21.12 \\
COK & \\
VAN & $\mathbf{2 1 . 1 2 \%}$ \\
TIR & S/.191,423 \\
\hline
\end{tabular}

Nota: Fuente y elaboración propia 


\subsection{Estados financieros proyectados}

\subsubsection{Balance General}

Tabla 33: Balance General (soles)

\begin{tabular}{|c|c|c|c|c|c|c|}
\hline \multicolumn{7}{|l|}{ BG } \\
\hline & & Año 1 & Año 2 & Año 3 & Año 4 & Año 5 \\
\hline TOTAL ACTIVO & 156,196 & 282,874 & 416,054 & 570,152 & 750,636 & $1,164,004$ \\
\hline Activo Corriente & 0 & 155,337 & 317,175 & 499,931 & 709,074 & $1,151,099$ \\
\hline Caja y Bancos & 0 & 155,337 & 317,175 & 499,931 & 709,074 & $1,151,099$ \\
\hline \multicolumn{7}{|l|}{ Existencias Netas } \\
\hline Activo No Corriente & 156,196 & 127,538 & 98,880 & 70,221 & 41,563 & 12,904 \\
\hline Activos Fijos netos & 156,196 & 127,538 & 98,880 & 70,221 & 41,563 & 12,904 \\
\hline TOTAL PASIVO & 0 & 38,003 & 51,355 & 61,636 & 72,636 & 84,407 \\
\hline Pasivo Corriente & 0 & 38,003 & 51,355 & 61,636 & 72,636 & 84,407 \\
\hline Tributos Por Pagar & 0 & 38,003 & 51,355 & 61,636 & 72,636 & 84,407 \\
\hline Pasivo No Corriente & 0 & 0 & 0 & 0 & 0 & 0 \\
\hline TOTAL PATRIMONIO & 156,196 & 244,871 & 364,699 & 508,516 & 678,000 & $1,079,597$ \\
\hline Capital Social & 156,196 & 156,196 & 156,196 & 156,196 & 156,196 & 156,196 \\
\hline Recuperacion Capital Trabajo & & & & & & 204,648 \\
\hline Utilidades Acumuladas & & & 88,675 & 208,503 & 352,320 & 521,804 \\
\hline Utilidad/Perdida del ejercicio & & 88,675 & 119,828 & 143,817 & 169,484 & 196,949 \\
\hline TOTAL PASIVO Y PATRIMONIO & 156,196 & 282,874 & 416,054 & 570,152 & 750,636 & $1,164,004$ \\
\hline
\end{tabular}

Nota: Fuente y elaboración propia

En el balance general presentado, se muestra en los activos dos clases, los activos corrientes tales como caja y bancos. En esta cuenta tenemos los fondos que tiene la organización. En el caso del proyecto es un modelo de negocio que permite tener liquidez constante para el manejo de las operaciones, debido a que el pago de los servicios es a contra-entrega. Estos pagos se pueden dar tanto en efectivo como con tarjeta de mediante POS. Por otro lado, tenemos los activos no corrientes, los cuales son todos aquellos equipos en los que se ha invertido para las operaciones de la empresa. Se observa que año tras año va disminuyendo de acuerdo a que se ha considerado una depreciación lineal de 5 años.

En las cuentas pasivas tenemos como pasivo corriente los tributos o impuesto a la renta por pagar cada año. En cambio, en el pasivo no corriente no se mantiene ninguna cuenta. Finalmente, como Patrimonio se ha considerado el capital social aportado al inicio del 
proyecto, la recuperación del capital de trabajo para el quinto año y la acumulación de los resultados cada año.

\subsubsection{Estado de Pérdidas y Ganancias}

El estado de resultado nos muestra el movimiento de las cuentas con la finalidad de ver si el resultado del ejercicio de cada periodo ha sido favorable o desfavorable representado por las utilidades netas obtenidas. Se puede observar que durante el tiempo de proyectado de operación del negocio se mantiene un margen bruto del $70 \%$ de los ingresos. Sin embargo, este se ve reducido con mayor fuerza debido a los altos gastos administrativos que se manejan. Alrededor del $90 \%$ de estos gastos están representados por la planilla y el alquiler del local.

Luego de haber descontado los gastos operativos, se tiene el primer año un margen operativo del 20\%, llegando hasta $33 \%$ el quinto año. Como puede observarse no se consideran gastos financieros, debido a que no se mantiene ninguna deuda con el sistema financiero, ya que el proyecto es financiado al 100\% por los autores intelectuales.

Como resumen podemos mencionar que el proyecto maneja utilidades desde el primer año. Teniendo una ganancia el primer año del $14 \%$ con respecto a los ingresos, y llegando a casi a $23 \%$ el último año proyectado de operación. A continuación, se muestra el Estado de Resultados: 
Tabla 34: Estado de Resultados (soles)

\begin{tabular}{|c|c|c|c|c|c|}
\hline \multicolumn{6}{|l|}{ EERR } \\
\hline & Año 1 & Año 2 & Año 3 & Año 4 & Año 5 \\
\hline Ingreso por ventas & 625,539 & 688,092 & 736,259 & 787,797 & 842,943 \\
\hline Costo de Ventas & 182,727 & 200,775 & 214,673 & 229,543 & 245,454 \\
\hline Utilidad Bruta & 442,812 & 487,317 & 521,586 & 558,254 & 597,489 \\
\hline GASTOS ADMINISTRATIVOS & 311,234 & 311,234 & 311,234 & 311,234 & 311,234 \\
\hline Planillas & 138,097 & 138,097 & 138,097 & 138,097 & 138,097 \\
\hline Alquiler Local & 138,600 & 138,600 & 138,600 & 138,600 & 138,600 \\
\hline Servicios & 5,879 & 5,879 & 5,879 & 5,879 & 5,879 \\
\hline Depreciación & 28,658 & 28,658 & 28,658 & 28,658 & 28,658 \\
\hline GASTOS DE VENTAS & 4,900 & 4,900 & 4,900 & 4,900 & 4,900 \\
\hline Marketing & 4,900 & 4,900 & 4,900 & 4,900 & 4,900 \\
\hline Diseño y Mantenimiento Web & 400 & 400 & 400 & 400 & 400 \\
\hline Estrategia de Posicionamiento y Socialmedia & 1,500 & 1,500 & 1,500 & 1,500 & 1,500 \\
\hline Artículos Merchandising & 3,000 & 3,000 & 3,000 & 3,000 & 3,000 \\
\hline Utilidad Operativa & 126,678 & 171,183 & 205,452 & 242,120 & 281,355 \\
\hline \multicolumn{6}{|l|}{ GASTOS FINANCIEROS } \\
\hline \multicolumn{6}{|l|}{ Ingresos Financieros } \\
\hline \multicolumn{6}{|l|}{ Egresos Financiero } \\
\hline Utilidad Antes de impuesto & 126,678 & 171,183 & 205,452 & 242,120 & 281,355 \\
\hline I Renta (30\%) & 38,003 & 51,355 & 61,636 & 72,636 & 84,407 \\
\hline Utilidad Neta & 88,675 & 119,828 & 143,817 & 169,484 & 196,949 \\
\hline
\end{tabular}

Nota: Fuente y elaboración propia

Por otro lado, es importante mencionar el costo de ventas en este capítulo. El cual es un costo realizado en base a la cantidad de autos atendidos por el costo unitario de cada material usado. Además, se considera la energía y el agua utilizada y reciclada por los equipos y maquinas que se usaran. (Capítulo 4). La energía esta calcula en base a los equipos de lavado y secado. Así, como el costo en agua se calcula con el ahorro que da la máquina recicladora. A continuación, se muestra los detalles de los componentes del costo de ventas: 
Tabla 35: Costo de ventas del proyecto (soles)

\begin{tabular}{|c|c|c|c|c|c|}
\hline & Año 1 & Año 2 & Año 3 & Año 4 & Año 5 \\
\hline \# Autos atendidos & 7,023 & 7,725 & 8,266 & 8,845 & 9,464 \\
\hline Total Costo de insumos & $S / .167,170$ & S/.183,887 & $S / .196,759$ & $S / .210,533$ & $S / .225,270$ \\
\hline Energía & $S / .11,238$ & $S / .11,837$ & $S / .12,299$ & $S / .12,793$ & $S / .13,321$ \\
\hline Maquina Recicladora & S/.5,234 & S/.5,234 & S/.5,234 & S/.5,234 & S/.5,234 \\
\hline Hidrolavadoras & $S / .4,066$ & $S / .4,472$ & $S / .4,785$ & $S / .5,120$ & $S / .5,478$ \\
\hline Aspiradoras & S/.1,937 & $S / .2,130$ & $S / .2,279$ & $S / .2,438$ & $S / .2,609$ \\
\hline Agua & $S / .4,319$ & $S / .5,051$ & $S / .5,614$ & $S / .6,218$ & $S / .6,863$ \\
\hline Hidrolavadoras & $S / .4,319$ & $S / .5,051$ & $S / .5,614$ & $S / .6,218$ & $S / .6,863$ \\
\hline Costo de ventas & $S / .182,727$ & $S / .200,775$ & $S / .214,673$ & $\mathrm{~S} / .229,543$ & $S / .245,454$ \\
\hline
\end{tabular}

\subsubsection{Flujo de Caja}

Se ha proyectado el flujo de caja para un horizonte de 5 años. Se toma en cuenta un año que podemos llamar inicial o Año 0. En este año tenemos toda la inversión y los gastos para que inicie el negocio. Se presenta a continuación tres partes: (i) Flujo de Capital, (ii) Flujo de caja Operativo y (iii) Flujo de caja Económico. El flujo de caja financiero no es considerado ya que la inversión será asumida $100 \%$ por los accionistas.

Es importante mencionar que no se considera valor de recupero de bienes intangibles, ya que tanto las modificaciones como los tramites de licencia de funcionamiento son puntuales para el local, el cual es alquilado y no les pertenece a los propietarios intelectuales del proyecto. Además, no considera un monto de recuperación de los bienes tangibles como la maquinaria y equipos, ya que estos están considerados con una depreciación lineal de 5 años, el tiempo que duraría el proyecto. 
Tabla 36: Flujo de Capital

\begin{tabular}{|c|c|c|c|c|c|c|}
\hline Periodo & Año 0 & Año 1 & Año 2 & Año 3 & Año 4 & Año 5 \\
\hline Invesrión activos fijo e intangible & $-S / .156,196$ & & & & & \\
\hline Capital de Trabajo & $-S / .204,648$ & & & & & \\
\hline Recuperacion Capital de Trabajo & & & & & & $S / .204,648$ \\
\hline FLUJO DE CAPITAL & $-S / .360,845$ & & & & & $S / .204,648$ \\
\hline
\end{tabular}

Nota: Fuente y elaboración propia

Tabla 37: Flujo de caja operativo

\begin{tabular}{|c|c|c|c|c|c|c|}
\hline Periodo & Año 0 & Año 1 & Año 2 & Año 3 & Año 4 & Año 5 \\
\hline Ingreso por ventas & & $S / .625,539$ & $S / .688,092$ & S/.736,259 & S/.787,797 & $S / .842,943$ \\
\hline Total Ingresos & $\mathrm{S} / .0$ & S/.625,539 & $S / .688,092$ & S/.736,259 & S/.787,797 & $S / .842,943$ \\
\hline Costo de ventas & & S/.182,727 & S/.200,775 & $S / .214,673$ & $S / .229,543$ & $S / .245,454$ \\
\hline Gastos Adm/Vtas/Pre Op & & $S / .316,134$ & $S / .316,134$ & $S / .316,134$ & $S / .316,134$ & $S / .316,134$ \\
\hline Planillas & & S/.138,097 & S/.138,097 & S/.138,097 & $\mathrm{S} / .138,097$ & $S / .138,097$ \\
\hline Alquiler Local & & $S / .138,600$ & $S / .138,600$ & $S / .138,600$ & $S / .138,600$ & $S / .138,600$ \\
\hline Servicios & & $S / .5,879$ & $S / .5,879$ & $S / .5,879$ & $S / .5,879$ & $S / .5,879$ \\
\hline Depreciación & & $S / .28,658$ & $S / .28,658$ & $S / .28,658$ & $\mathrm{~S} / .28,658$ & $\mathrm{~S} / .28,658$ \\
\hline Marketing & & $\mathrm{S} / .4,900$ & $\mathrm{~S} / .4,900$ & $\mathrm{~S} / .4,900$ & $\mathrm{~S} / .4,900$ & $\mathrm{~S} / .4,900$ \\
\hline Total Egresos & $\mathrm{S} / .0$ & $-S / .498,860$ & $-S / .516,909$ & $-S / .530,806$ & $-S / .545,677$ & $-S / .561,588$ \\
\hline UAI & $S / .0$ & S/.126,678 & $\mathrm{S} / .171,183$ & $S / .205,452$ & $S / .242,120$ & $\mathrm{~S} / .281,355$ \\
\hline Impuesto & & $\mathrm{S} / .38,003$ & $\mathrm{~S} / .51,355$ & $\mathrm{~S} / .61,636$ & $\mathrm{~S} / .72,636$ & $\mathrm{~S} / .84,407$ \\
\hline Utilidad Neta & $S / .0$ & $S / .88,675$ & $\mathrm{~S} / .119,828$ & $S / .143,817$ & S/.169,484 & S/.196,949 \\
\hline Depreciación & & $\mathrm{S} / .28,658$ & $\mathrm{~S} / .28,658$ & $\mathrm{~S} / .28,658$ & $\mathrm{~S} / .28,658$ & $\mathrm{~S} / .28,658$ \\
\hline FLUJO DE CAJA OPERATIVO & $S / .0$ & $\mathrm{~S} / .117,333$ & $S / .148,487$ & $S / .172,475$ & $S / .198,143$ & $S / .225,607$ \\
\hline
\end{tabular}

Nota: Fuente y elaboración propia

Tabla 38: Flujo de caja económico

\begin{tabular}{|lcrrrrr|}
\hline Periodo & Año 0 & Año 1 & Año 2 & Año 3 & Año 4 & Año 5 \\
FLUJO DE CAPITAL & $-S / .360,845$ & $\mathrm{~S} / .0$ & $\mathrm{~S} / .0$ & $\mathrm{~S} / .0$ & $\mathrm{~S} / .0$ & $\mathrm{~S} / .204,648$ \\
FLUJO DE CAJA OPERATIVO & $\mathrm{S} / .0$ & $\mathrm{~S} / .117,333$ & $\mathrm{~S} / .148,487$ & $\mathrm{~S} / .172,475$ & $\mathrm{~S} / .198,143$ & $\mathrm{~S} / .225,607$ \\
\hline FLUJO DE CAJA ECONOMICO & $-\mathrm{S} / . \mathbf{3 6 0 , 8 4 5}$ & $\mathrm{S} / . \mathbf{1 1 7 , 3 3 3}$ & $\mathrm{S} / . \mathbf{1 4 8 , 4 8 7}$ & $\mathrm{S} / . \mathbf{1 7 2 , 4 7 5}$ & $\mathrm{S} / . \mathbf{1 9 8 , 1 4 3}$ & $\mathrm{S} / . \mathbf{4 3 0 , 2 5 5}$ \\
\hline
\end{tabular}

Nota: Fuente y elaboración propia

\subsection{Análisis de sensibilidad}

A continuación, se muestra el análisis de sensibilidad del proyecto. En este análisis se mostrará cómo afecta a la rentabilidad del proyecto (VAN y TIR) la principal variable que consideramos podría generar cambios directamente al negocio: el crecimiento del sector automotriz. 
Inicialmente se ha estimado según investigaciones realizadas por la APP que el crecimiento en los próximos años será de $10 \%$ el primer año y de un crecimiento sostenido de 7\% anual para los próximos. Sin embargo, para el análisis se han tomado dos escenarios más. Como en todo análisis de sensibilidad se tendrán dos escenarios adicionales al proyecta por el plan de negocios. Esto es con la finalidad de tener una opción optimista que permita atraer la atención de los inversionistas, y la otra es una opción conservadora la cual nos permita considera riesgos hacia el plan pero que permita mostrar la fortaleza de la idea de negocio.

Primero se considerará un crecimiento del 5\%, es decir 2 puntos por debajo de lo pronosticado (Escenario Conservador) y el segundo escenario considera $8 \%$, es decir, 1 punto por encima del pronóstico (Escenario Optimista).

El escenario optimista que considera un crecimiento del $8 \%$ está basado en la data histórica del crecimiento de los automóviles del parque automotor nacional en los últimos 10 años, aproximadamente desde 2004 al 2015 el crecimiento promedio a lo largo de estos años ha sido de $8.51 \%$ (INEI \& BBVA, 2012-2015). Además, observando los últimos 10 años (Del 2003 al 2012), el crecimiento del parque automotor total ha sido de $8.48 \%$ (MTC \& SUNARP, 2012). Por otro lado, la elección del escenario conservador en el cual se considera un crecimiento de $5 \%$ se basa en el análisis del crecimiento del PBI en los últimos años (2005-2015). El cual según las variaciones porcentuales cada año nos dice que el año 2009 tuvo su menor crecimiento (1.05\%) en la última década (BCRP, 2016). En ese año el crecimiento del parque automotor sólo alcanzó el 5.27\%. (SUNARP \& MTC, 2012) 
A continuación, se muestran los escenarios mencionados en una tabla:

Tabla 39: Escenarios de crecimiento - Sector automotriz peruano

\begin{tabular}{|lccccc}
\hline Años & $\mathbf{2 0 1 7}$ & $\mathbf{2 0 1 8}$ & $\mathbf{2 0 1 9}$ & $\mathbf{2 0 2 0}$ & $\mathbf{2 0 2 1}$ \\
\hline Inicial (autos atendidos) & 7,023 & 7,725 & 8,266 & 8,845 & 9,464 \\
\hline $\begin{array}{l}\text { Escenario 1 } \\
\text { Crecimiento del 5\% }\end{array}$ & 7,023 & 7,374 & 7,632 & 7,899 & 8,176 \\
\hline $\begin{array}{l}\text { Escenario 2 } \\
\text { Crecimiento del 8\% }\end{array}$ & 7,023 & 8,076 & 8,924 & 9,862 & 10,897 \\
\hline
\end{tabular}

Nota: Fuente y elaboración propia

Tabla 40: Resultados análisis sensibilidad (variable: crecimiento del sector automotriz)

\begin{tabular}{|lccc|}
\hline & $\begin{array}{c}\text { Escenario } \\
\text { Inicial }\end{array}$ & $\begin{array}{c}\text { 1er } \\
\text { Escenario }\end{array}$ & $\begin{array}{c}\text { 2do } \\
\text { Escenario }\end{array}$ \\
\hline VAN & $\mathrm{S} / .191,423$ & $\mathrm{~S} / .123,580$ & $\mathrm{~S} / .263,824$ \\
\hline TIR & $39 \%$ & $33 \%$ & $44 \%$ \\
\hline
\end{tabular}

Nota: Fuente y elaboración propia

Como se puede observar, esta es una variable crítica y el crecimiento y prosperidad del negocio está altamente relacionada con la cantidad de autos que se atenderá y por ende con el crecimiento del sector automotriz. Los resultados del análisis muestran que a pesar de que el sector podría no crecer como se espera, el negocio mantiene las perspectivas de rentabilidad que se habían estimado. Es decir, tanto como si baja o sube el crecimiento del sector, el negocio se verá afectado, pero permanecerá teniendo una rentabilidad positiva y seguirá estando aceptado por los resultados del VAN y TIR.

Otra variable que debe considerarse son los costos de los insumos. A pesar de que el precio de compra de estos insumos es en moneda nacional, las marcas que utilizará el negocio son extranjeras (3M y SONAX), por lo tanto, el precio de los insumos podría variar en determinadas circunstancias. Es así, que tomaremos dos posibles escenarios. Un 
escenario negativo en el cual hay un incremento en los costos de los insumos en un $20 \%$ y uno positivo en el que mejoraría sus precios y el costo para el negocio se reduciría en $10 \%$. A continuación, se muestran los escenarios:

Tabla 41: Escenarios de variación de costos de los insumos

\begin{tabular}{|c|c|c|c|}
\hline \multirow{2}{*}{ COSTOS UNITARIOS } & \multirow{2}{*}{ Inicial } & Escenario 1 & Escenario 2 \\
\hline & & $+20 \%$ & $-10 \%$ \\
\hline Servicio 1 - Servicio Express & 7.14 & 8.57 & 6.43 \\
\hline Servicio2 & 12.54 & 15.04 & 11.28 \\
\hline Servicio 3 & 17.34 & 20.80 & 15.60 \\
\hline Lavado de salón & 56.28 & 67.54 & 50.65 \\
\hline Descontaminación de pintura & 20.33 & 24.39 & 18.29 \\
\hline Tratamiento de pintura & 137.20 & 164.64 & 123.48 \\
\hline
\end{tabular}

Nota: Fuente y elaboración propia

Tabla 42: Resultados análisis sensibilidad (variable: costo de insumos)

\begin{tabular}{|lccc|}
\hline & $\begin{array}{c}\text { Escenario } \\
\text { Inicial }\end{array}$ & $\begin{array}{c}\text { 1er } \\
\text { Escenario }\end{array}$ & $\begin{array}{c}\text { 2do } \\
\text { Escenario }\end{array}$ \\
\hline VAN & $\mathrm{S} / .191,423$ & $\mathrm{~S} / .113,256$ & $\mathrm{~S} / .230,506$ \\
\hline TIR & $39 \%$ & $32 \%$ & $43 \%$ \\
\hline
\end{tabular}

Nota: Fuente y elaboración propia

Como se observa, esta variable afecta también al proyecto. Sin embargo, la rentabilidad del negocio se mantiene positiva, sustentando la viabilidad y rentabilidad asegurada del proyecto.

\subsection{Evaluación de rentabilidad de la empresa}

Para realizar el análisis de rentabilidad hemos utilizado el flujo de caja económico. También hemos calculado el COK o rentabilidad esperada mediante el CAPM, el cual dio como resultado $21.12 \%$. Las variables a analizar son el VAN y TIR. 
Tabla 43: Flujo de Caja a ser analizado (VAN,TIR)

\begin{tabular}{|lcrrrrr|}
\hline Periodo & Año 0 & Año 1 & Año 2 & Año 3 & Año 4 & Año 5 \\
FLUJO DE CAPITAL & $-S / .360,845$ & $\mathrm{~S} / .0$ & $\mathrm{~S} / .0$ & $\mathrm{~S} / .0$ & $\mathrm{~S} / .0$ & $\mathrm{~S} / .204,648$ \\
FLUJO DE CAJA OPERATIVO & $\mathrm{S} / .0$ & $\mathrm{~S} / .117,333$ & $\mathrm{~S} / .148,487$ & $\mathrm{~S} / .172,475$ & $\mathrm{~S} / .198,143$ & $\mathrm{~S} / .225,607$ \\
\hline FLUJO DE CAJA ECONOMICO & $\mathrm{-S} / .360,845$ & $\mathrm{~S} / .117,333$ & $\mathrm{~S} / .148,487$ & $\mathrm{~S} / .172,475$ & $\mathrm{~S} / .198,143$ & $\mathrm{~S} / .430,255$ \\
\hline
\end{tabular}

Nota: Fuente y elaboración propia

Continuando con el análisis, como se mencionó se utilizó el flujo de caja económico y el COK, para calcular el VAN y la TIR. Estos fueron los resultados:

Tabla 44: Cálculo del VAN y TIR

\begin{tabular}{|lr|}
\hline VAN & $S / .191,423$ \\
TIR & $39 \%$ \\
\hline
\end{tabular}

Nota: Fuente y elaboración propia

Como se observa el proyecto es aceptado de acuerdo a la teoría ya que el VAN $>0$ y la TIR $>$ COK. 


\section{CAPÍTULO VII: CONCLUSIONES Y RECOMENDACIONES}

\subsection{Conclusiones}

- El proyecto presentado es rentable ya que posee un VAN igual a 191,423 mil soles, el cual es mayor a cero. Además, tiene una TIR de $39 \%$, mayor al COK de $21.12 \%$.

- La inversión inicial del proyecto puede ser asumida por los accionistas al $100 \%$ porque están dispuestos a asumir el riesgo y creen en la viabilidad y rentabilidad del proyecto.

- El análisis de sensibilidad mostró que el negocio es sólido y mantiene márgenes de rentabilidad a pesar de los distintos escenarios cambiantes que pueden darse. El impacto más grande disminuiría la rentabilidad a $32 \%$, siendo este valor aún mayor que el $21.12 \%$ del costo de oportunidad.

- Según el sondeo realizado el $75 \%$ de las personas utilizan o han utilizado los servicios de lavado de autos. Además, casi el $80 \%$ de los encuestados lava su carro en un promedio de 15 a 30 días.

- La competencia tiene mayor diversidad de servicios y productos, además de experiencia en el rubro. Sin embargo, no han priorizado proyectar una imagen de cuidado por el medio ambiente, ni se han preocupado por apoyar a un sector de la sociedad, que en nuestro caso son las personas discapacitadas, ni han mostrado una oferta de negocio enfocada en la comodidad del cliente.

- El sector automotriz en el Perú ha crecido y proyecta hacia el futuro un crecimiento importante, lo cual pronostica un futuro prometedor para todos aquellos negocios relacionados con este sector.

- El proyecto tiene un enfoque de cuidado ambiental lo cual genera un impacto en la sociedad y permite ofrecer al público una oferta 
distinta a las actuales. Además, la inclusión de personal con alguna discapacidad en la planilla, fomenta el crecimiento y apoyo a todas aquellas personas discapacitadas que desean seguir trabajando.

- La oferta de locales comerciales para este tipo de negocios es reducida o nula en zonas financieras y turísticas (San Isidro y Miraflores). Es por ese motivo que se optó por los otros distritos de la zona 7 para evaluar la ubicación del negocio.

\subsection{Recomendaciones}

- Se considera importante analizar la rentabilidad del proyecto, optando por nuevos y más baratos sistemas de limpieza de agua, debido a que este equipo representa más del $75 \%$ de la inversión en activos tangibles.

- Es recomendable realizar un análisis de precios con respecto al valor agregado brindado, es decir, ver la posibilidad de subir el precio por el valor medioambiental que se está dando. Actualmente, los precios ofrecidos son competitivos en el mercado.

- Se recomienda mantener la estructura organizacional para así maximizar las utilidades. Si se abriera otro local, sí sería conveniente incrementar el personal.

- La diversificación de los servicios y la inclusión de productos dentro de este negocio, potenciaría las cualidades que ya muestra el plan. Es recomendable ampliar la gama de servicio abarcando trabajos de embellecimiento y estética. 


\section{REFERENCIAS BIBLIOGRÁFICAS}

1. Asociación Peruana de Empresas de Investigación de Mercado [APEIM]. (2016). Niveles Socioeconómicos.

2. BBVA Continental. (2015). Situación Automotriz.

3. Borello A. (1994). El plan de negocios. España. Ediciones Díaz de Santos.

4. Cristiana, I. (2009). The influence of car wash facilities over the wáter quality in Craiova. Aerul Si Apa Componente Ale Mediului.

5. Derteano, E. (2016). El duro desafí que fue este 2016 y la aventura que nos espera el 2017. Todoautos.

\section{https://peru.todoautos.com.pe/blog/mercado-automotriz-peru/}

6. Editorial Vértice (2004). Dirección de Operaciones. España: Publicaciones Vértice S.L.

7. El-Ashtoukhy, E-S.Z., Amin, N.K., Fouad, Y.O. (2015). Treatment of real wastewater produced from Mobil car wash station using electrocoagulation technique. Alexandria University, Alexandria, Egypt.

8. Fernández, L., Fernández, S., Rodríguez, A. (2007). La práctica de las finanzas de empresa. Delta Publicaciones.

9. Heizer, J., Render, B. (2004). Principios de administración de operaciones. México: Pearson Educación. 
10.Instituto Nacional de Estadística e Informática [INEI]. (2010). Clasificación industrial internacional uniforme.

11.Kotler, P., Keller, K. (2006). Dirección de Marketing. México: Pearson Educación.

12.Kotler, P., Armstrong, G. (2012). Marketing. México: Pearson Educación.

13.Ley General de Sociedades. Ley N ${ }^{\circ}$ 26887, Diario El Peruano, Lima, Perú, 1997.

14.Ministerio de Transporte y Comunicaciones[MTC] \& Superintendencia Nacional de Registros Públicos[SUNARP]. (2012). Parque automotor nacional por clase de vehículos.

15.Nadzirah, Z., Nor Haslina, H., Rafidah, H. (2015). Removal of important parameter from car wash wastewater. International Integrated Engineering Summit.

16.Osterwalder, A., Pigneur, Y. (2011). Generación de modelos de negocio. Barcelona: Grupo Planeta.

17.Porter, M. (1985). Competitive Advantage. Free Press.

18.Radulescu, C., et al. (2011). Analysis of waste wáter from ecological car wash. Journal of Science and Arts.

19.Reyes, O. (2013). Nuevas tendencias en el negocio electrónico.

20.Shilpa, J. (2013). Geo Car-Wash A Planet Friendly Enterprise. MBA Department New Horizon College Of Engineering. 
21.Vildozo, G. (2016). Perspectivas de la industria automotriz Perú. 


\section{ANEXOS}

\section{Anexo 1: Formato de encuesta para Sondeo}

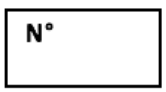

\section{ENCUESTA}

Buenos días/tardes/noches, somos alumnos de la universidad San Ignacio Loyola, estamos realizando un estudio para el lanzamiento de una idea de negocio. Le agradecería que me brinde unos minutos de su tiempo para rellenar esta encuesta. ¡Muchas gracias!

1. ¿Utiliza el Servicio de CAR WASH?

a) $\mathrm{Si}$

b) No (Fin de la encuesta)

2. ¿Con qué frecuencia utiliza el servicio de Car Wash?
a) Semanalmente
b) Quincenalmente
c) Mensualmente
d) Otros

3. ¿Cuánto gasta normalmente en este tipo de servicio?
a) $\mathrm{S} / .20$ a S/.25
b) S/. 26 a S $/ .30$
c) S/. 31 a S/. 35
d) Más de S/. 35

4. ¿Normalmente cuánto tiempo se demoran en lavar su auto?
a) 10 minutos
b) 20 minutos
c) 30 minutos
d) 40 minutos
e) 1 hora
f) Más de 1 hora

5. ¿Qué servicios toma normalmente?
a) Lavado Express
b) Lavado Básico
c) Lavado Completo
d) Lavado de Salón
e) Otros

6. ¿Qué tan importante considera los siguientes factores para ir a un Car Wash?

\begin{tabular}{|c|c|c|c|c|c|}
\hline & 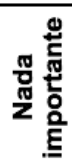 & 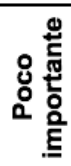 & 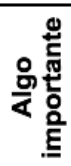 & 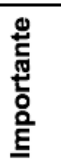 & 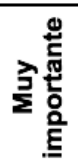 \\
\hline Precio & 1 & 2 & 3 & 4 & 5 \\
\hline $\begin{array}{c}\text { Cercanía a } \\
\text { mi casa }\end{array}$ & 1 & 2 & 3 & 4 & 5 \\
\hline $\begin{array}{c}\text { Cercanía a } \\
\text { mi centro } \\
\text { laboral }\end{array}$ & 1 & 2 & 3 & 4 & 5 \\
\hline Servicio & 1 & 2 & 3 & 4 & 5 \\
\hline
\end{tabular}

\section{ESTUDIO DEL CONCEPTO}

Servicio de Limpieza de tu vehículo, en el cuál en el tiempo de espera te ofrecemos diversos servicios como cafetería y áreas de entrenamiento, para que tu espera no sea aburrida.

7. Si este servicio de Car Wash saldría al mercado ¿Estaría dispuesto a ir y adquirir el servicio?

a) Definitivamente si tomaría el servicio.

b) Probablemente tomaria el servicio.

c) No sabría si tomar o no tomar el servicio.

d) Probablemente no tomaría el servicio.

e) Definitivamente no tomaría el servicio.

8. ¿En qué distrito le preferiria que se encuentre el local donde ofreceremos el servicio?

a) La Molina

b) San Isidro

c) San Borja

d) Surco

d) Otros:

9. ¿Cuánto estaría dispuesto a pagar por este servicio?
a) $\mathrm{S} / .20$ a S/ 35
b) $S / .36$ a $S / .50$
c) $\mathrm{S} / .51$ a $\mathrm{S} / .80$
d) $S / .81$ a 100
e) Más de S/. 100

10. ¿Con qué frecuencia utilizaría el servicio de Car Wash?
a) Semanalmente
b) Quincenalmente
c) Mensualmente
d) Otros

11. ¿En su tiempo de espera que otros servicios le gustaria recibir? (RM)

a) Cafetería

b) Simuladores 


\section{Anexo 2: Tabulación de resultados del Sondeo}

\begin{tabular}{|c|c|c|c|c|c|c|c|c|c|c|}
\hline $\mathrm{N}^{\circ}$ & P1 & P2 & P3 & P4 & P5 & P7 & P8 & P9 & P10 & NSE \\
\hline 1 & 1 & 2 & 4 & 5 & 3 & 3 & 4 & 2 & 2 cafetería & B \\
\hline 2 & 1 & 3 & 3 & 3 & 1 & 1 & 1 & 1 & 1 wifi & B \\
\hline 3 & 1 & 1 & 1 & 2 & 2 & 2 & 3 & 3 & 3 ambientes col & orA \\
\hline 4 & 2 & & & & & & & & & B \\
\hline 5 & 1 & 3 & 3 & 4 & 3 & 1 & 2 & 1 & 1 salones de de & es: $A$ \\
\hline 6 & 2 & & & & & & & & & B \\
\hline 7 & 1 & 2 & 4 & 3 & 3 & 2 & 1 & 1 & 1 sala tv, wifi & B \\
\hline 8 & 1 & 1 & 1 & 5 & 4 & 1 & 4 & 1 & 1 salones con d & $d: B$ \\
\hline 9 & 2 & & & & & & & & & B \\
\hline 10 & 2 & & & & & & & & & B \\
\hline 11 & 1 & 3 & 1 & 4 & 2 & 3 & 1 & 3 & 3 cafetería & C \\
\hline 12 & 2 & & & & & & & & & B \\
\hline 13 & 1 & 2 & 2 & 3 & 1 & 2 & 1 & 2 & 2 ambientes de & $B$ \\
\hline 14 & 1 & 3 & 3 & 2 & 3 & 1 & 1 & 1 & 1 wifi & B \\
\hline 15 & 1 & 1 & 1 & 4 & 2 & 1 & 2 & 3 & 3 cafetería & B \\
\hline 16 & 1 & 3 & 4 & 3 & 2 & 1 & 4 & 1 & 1 ambientes de & $B$ \\
\hline 17 & 1 & 1 & 1 & 5 & 3 & 3 & 1 & 2 & 2 salones de de & $B B$ \\
\hline 18 & 2 & & & & & & & & & B \\
\hline 19 & 1 & 1 & 3 & 4 & 3 & 1 & 3 & 3 & 3 wifi & B \\
\hline 20 & 1 & 2 & 1 & 4 & 2 & 1 & 2 & 2 & 2 degustaciones & es $B$ \\
\hline 21 & 1 & 2 & 4 & 3 & 3 & 1 & 4 & 1 & 1 cafetería & B \\
\hline 22 & 1 & 2 & 1 & 4 & 3 & 1 & 1 & 2 & 2 ambientes de & $A$ \\
\hline 23 & 2 & & & & & & & & & B \\
\hline 24 & 2 & & & & & & & & & B \\
\hline 25 & 1 & 3 & 1 & 3 & 2 & 3 & 2 & 2 & 2 salones de de & es $B$ \\
\hline 26 & 1 & 1 & 4 & 4 & 3 & 2 & 1 & 1 & 1 cafetería & B \\
\hline 27 & 2 & & & & & & & & & C \\
\hline 28 & 2 & & & & & & & & & B \\
\hline 29 & 1 & 3 & 4 & 4 & 3 & 1 & 3 & 1 & 1 wifi & A \\
\hline 30 & 1 & 1 & 1 & 3 & 2 & 1 & 2 & 1 & 1 wifi & B \\
\hline 31 & 1 & 2 & 3 & 2 & 1 & 1 & 1 & 2 & 2 ambientes col & r'B \\
\hline 32 & 1 & 3 & 2 & 4 & 3 & 3 & 2 & 1 & 1 cafetería & B \\
\hline 33 & 1 & 1 & 1 & 3 & 3 & 1 & 1 & 3 & 3 salones de de & es $C$ \\
\hline 34 & 2 & & & & & & & & & B \\
\hline 35 & 1 & 3 & 1 & 3 & 2 & 2 & 1 & 1 & 1 wifi & B \\
\hline 36 & 2 & & & & & & & & & C \\
\hline 37 & 1 & 3 & 1 & 3 & 2 & 2 & 1 & 2 & 2 wifi & B \\
\hline 38 & 1 & 2 & 1 & 3 & 2 & 1 & 4 & 1 & 1 cafetería & B \\
\hline 39 & 2 & & & & & & & & & B \\
\hline 40 & 1 & 3 & 4 & 4 & 2 & 2 & 2 & 1 & 1 salones de de & es $B$ \\
\hline 41 & 1 & 3 & 1 & 2 & 3 & 2 & 3 & 2 & 2 wifi & B \\
\hline 42 & 1 & 2 & 4 & 2 & 1 & 1 & 2 & 1 & 1 cafetería & B \\
\hline 43 & 1 & 3 & 1 & 4 & 3 & 1 & 2 & 2 & 2 wifi & A \\
\hline 44 & 1 & 2 & 1 & 3 & 2 & 1 & 2 & 1 & 1 cafetería & C \\
\hline 45 & 1 & 2 & 3 & 4 & 3 & 1 & 2 & 1 & 1 salones con de & $d: B$ \\
\hline 46 & 1 & 2 & 4 & 2 & 2 & 1 & 3 & 1 & 1 ambientes cor & $\operatorname{sic}$ \\
\hline 47 & 1 & 2 & 4 & 3 & 2 & 1 & 4 & 1 & 1 salones de de & B $B$ \\
\hline 48 & 1 & 3 & 3 & 4 & 3 & 1 & 4 & 2 & 2 cafetería & C \\
\hline 49 & 1 & 3 & 2 & 3 & 2 & 1 & 4 & 2 & 2 cafetería & B \\
\hline 50 & 1 & 3 & 4 & 5 & 4 & 1 & 4 & 2 & 2 wifi & A \\
\hline
\end{tabular}


Anexo 3: Entrevista realizada al dueño de una empresa similar a la del proyecto

\section{ENTREVISTA}

Buenos días. Mi nombre es Omar Miranda y estamos realizando un Plan de negocios sobre una empresa de lavado de autos.

Nos gustaría que comparta su experiencia con nosotros con respecto a diversos temas relacionado específicamente al mercado de lavado de autos. La información recopilada será estrictamente para uso académico.

\section{Datos Personales}

Nombre: Hernán Vílchez

Empresa a la que representa: Heviclubs

Fecha: 15-03-17

\section{Datos generales de la empresa}

1. ¿Cuál es el nombre de su empresa?

Buenos días, la empresa se llama Heviclubs.

2. ¿Cuántos años de fundada tiene su empresa?

Aproximadamente tenemos 1 año operando como car wash.

3. ¿Qué tipos de actividades realiza su empresa?

Como lo dije, somos un local de lavado de autos y servicios adicionales como tratamientos de pintura y algunos tipos de instalaciones eléctricas.

4. ¿A qué rubro se dedica?

Lavado de autos es nuestra actividad principal, estamos en Servicios automotrices si se quiere decir.

\section{Perfil del consumidor}

1. ¿Son los hombres o las mujeres los que más acuden a su local?

Podría decirse que la mayoría que viene a lavar sus carros son hombres. A veces vienen acompañados con señoras o señoritas. No digo que nunca venga una mujer a lavar su auto, sí he tenido clientes mujeres también.

2. En tu opinión, ¿que porcentaje de hombre y mujeres se atiende en tu local? Yo calculo que debe ser alrededor de casi 80 por ciento los hombres que vienen a comparación de las mujeres, que sería un 20 por ciento o un poco más quizá. 
3. ¿Qué características observas en tus clientes masculinos?

Los hombres cuando vienen se quedan mirando el auto, están constantemente detrás de las personas o las personas que están a cargo del vehículo. Ellos cuidan y cuestionan cada detalle del servicio. Por ejemplo, si ven que falta una mancha o algo pequeño lo hacen notar al instante.

4. ¿Qué características observas en tus clientes femeninos?

La mayoría de mujeres prefiere esperar a que terminen de lavarlo, muchas veces en el propio auto, o sino también en una pequeña sala que tiene unas cuantas sillas.

5. ¿En qué lugar esperan tus clientes mientras sus autos son lavados?

Como te dije, por lo general la mayoría espera cerca del auto (parado) o dentro del auto si se siente cansado. Algunos van a la pequeña sala de espera, pero la verdad es que todos se notan bastante aburridos por no tener un lugar donde sentarse a esperar, pero bueno ese no es el enfoque que le doy a mi negocio.

6. ¿Tienes alguna sala de espera? Descríbela.

Claro, ya te lo había comentado. Bueno es pequeña como puedes ver, tiene dos sillas y una pequeña mesa con algunas revistas de productos y carros. La verdad es un espacio bastante reducido.

7. ¿Has recibido algún comentario sobre la sala de espera?

$\mathrm{Si}$, sobre todos de las personas que ya conozco que vienen regularmente a atenderse, Me piden lugar donde sentarse, pero con más comodidad, me dicen que el servicio al cliente debe explotarse por ese lado, pero aún no modifico nada.

8. ¿Qué otros beneficios buscan los clientes cuando han sido atendidos?

Lo que más suena es el tema del internet, me refiero al wifi. Aquí en el local el único que usa el internet soy yo y lo manejo desde mi celular o mi internet portátil si quiero hacer algún pedido. No tenemos wifi.

9. ¿Los clientes refieren tu negocio a otros clientes potenciales?

He tenido caso en los que me dicen que son amigos de tal o cual persona.

10. ¿Son los hombres o las mujeres los que más refieren clientes?

Generalmente creo que las mujeres porque los hombres son muy poco de comentar creo yo. La mayoría de referidos comprobados han sido de mujeres.

11. ¿Cuál es el medio de pago preferido por los clientes?

Antes yo solo cobraba en efectivo, pero por pedido de varios clientes y por la practicidad es la tarjeta para los que hacen servicios con costos más altos. Sin embargo, yo atiendo bastante a personas que vienen de paso, llámese taxistas u otros y generalmente ellos pagan al contado. 


\section{Demanda de clientes y servicios brindados}

1. ¿Cuánto cobras por lavar el auto en el servicio de lavado básico?

Bueno, el cobro por un lavado básico completo esta entre 20 soles para autos y 30 para camionetas. En verdad, los precios varían porque a veces solo quieren un chapuzón en agua y bueno eso es menos.

2. ¿Qué tipos de servicios brindas?

Como te había dicho, nosotros hacemos lavados de auto que varían según los detalles de acabado que el cliente quiera, lavado con champú, aspirado de interiores, lavado de asientos. Pero también damos servicio de descontaminación y tratamiento de pintura. Además, podemos hacer algunas instalaciones de alarmas, luces, radios, etc.

3. ¿Cuántos autos atiendes aproximadamente al día?

Eso depende mucho del día, porque es diferente un día de semana y los fines de semana. Mira por ejemplo en la semana alcanzamos los 20 carros diarios y a veces más algunos días, pero los días sábado estamos llenos en el local normalmente pueden venir hasta 50 carros, pero 40 es el promedio de los fines de semana. Domingo no atendemos.

4. ¿Has calculado cuántos autos atienden mensualmente en promedio? La verdad que no, pero con lo que te digo calcúlalo. Yo creo que podemos llegar hasta 150 en varios meses.

5. ¿Nos podrías decir aproximadamente cuáles son los servicios que más consumen los clientes? ¿Tienes datos detallados de eso?

Bueno datos detallados en el cuaderno podríamos ver qué cantidad fue el mes pasado, pero normalmente los autos se atienden para lavado, ya sea los distintos tipos de servicios que damos. Cuando son trabajos más grandes y a pesar de que se les ofrece buenos precios, el consumo de esos servicios es menor. Si quieres un aproximado te diría que casi un $80 \%$ viene al local a lavar su auto, y la mayoría se va por el lavado básico o el completo que es con encerado. El resto que queda aproximadamente $20 \%$ se divide entre tratamientos de pintura, lavado de salón y descontaminaciones. 
Anexo 4: Gastos de dominios y publicidad en redes

\section{Compra de Dominio y Diseño de Página Web:}

Hosting Medium

300 MB Espacio Disco

5 Base de datos MySQL

50 Correos Propios

10 GB Transferencia Mensual

20 Sub-Dominios

Panel de Control

Soporte 24/7 gratuito

Diseño Web HTML5

S/. 300

Fuente:http://www.arenavisual.com/

\section{Publicidad en Facebook, Instagram y Audience Network:}

\section{El importe mínimo por día varía entre \$1 y \$5 diarios.}

Cuando empieces a anunciarte, tendrás la opción de elegir un presupuesto diario un presupuesto del conjunto de anuncios, además del importe total que quieres gastar. Para la mayoría de los anuncios, el importe mínimo que puedes gastar por día varía de $\$ 1$ a $\$ 5$, aunque puede que gastes más en función de lo que optimices.

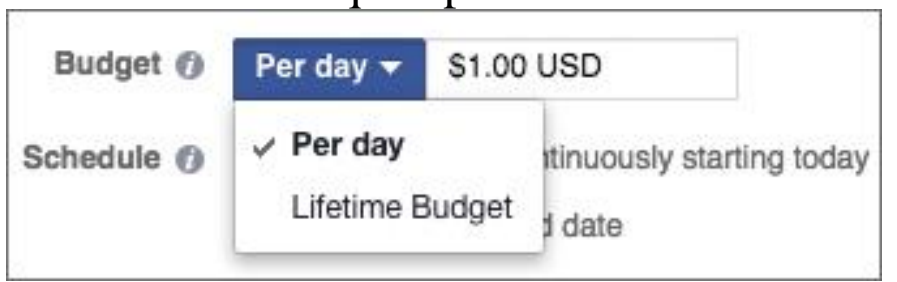

Tu presupuesto, el tipo de puja que elijas, los públicos a los que te dirijas (un público amplio o un público con intereses, comportamientos y datos demográficos muy concretos) y otros muchos factores determinarán el número de personas que ven o hacen clic en tu anuncio en función de tu presupuesto.

Para conocer cómo pueden afectar tu presupuesto, tu segmentación y tu puja al número de personas a las que puedes llegar, prueba una de nuestras herramientas:

\section{Publicaciones promocionadas}

Ve a tu página y haz clic en Promocionar publicación u obtén información sobre cómo promocionar publicaciones. Elige tus preferencias de segmentación, selecciona un presupuesto y consulta el alcance estimado para ver a cuántas personas podría llegar tu anuncio con el 
presupuesto y las preferencias de segmentación que definiste. Haz clic en Cancelar si no quieres continuar con la promoción.

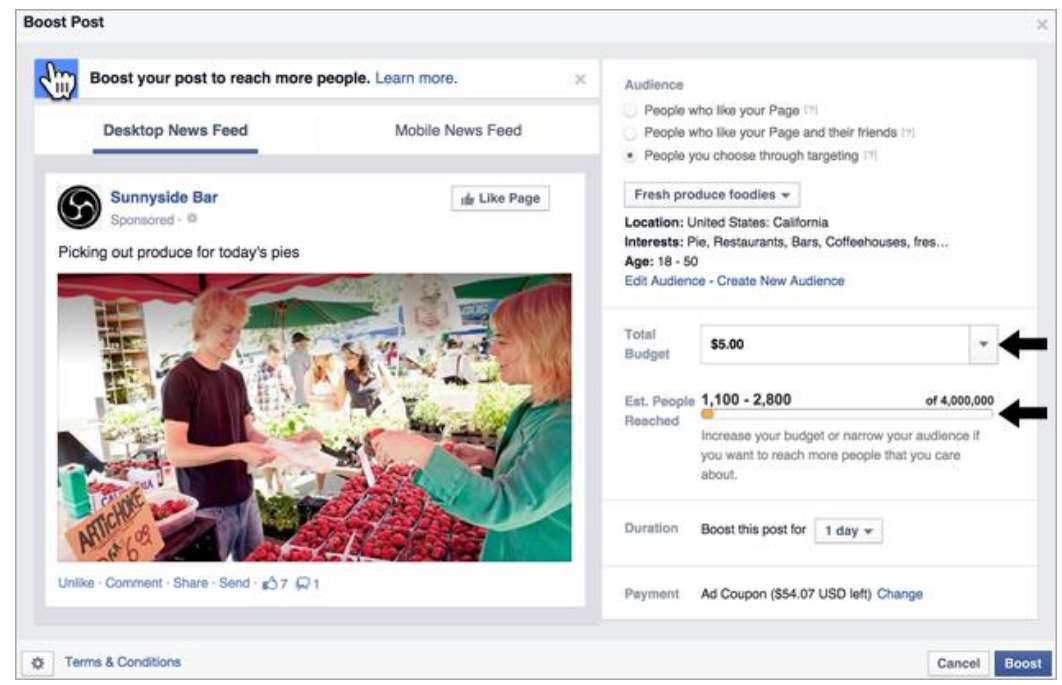

Fuente:https://es-la.facebook.com/business/help/201828586525529

\section{Creación de anuncios}

También puedes probar la herramienta de creación de anuncios. En la herramienta de creación de anuncios, selecciona un objetivo, elige entre las diferentes opciones de segmentación y consulta el alcance potencial.

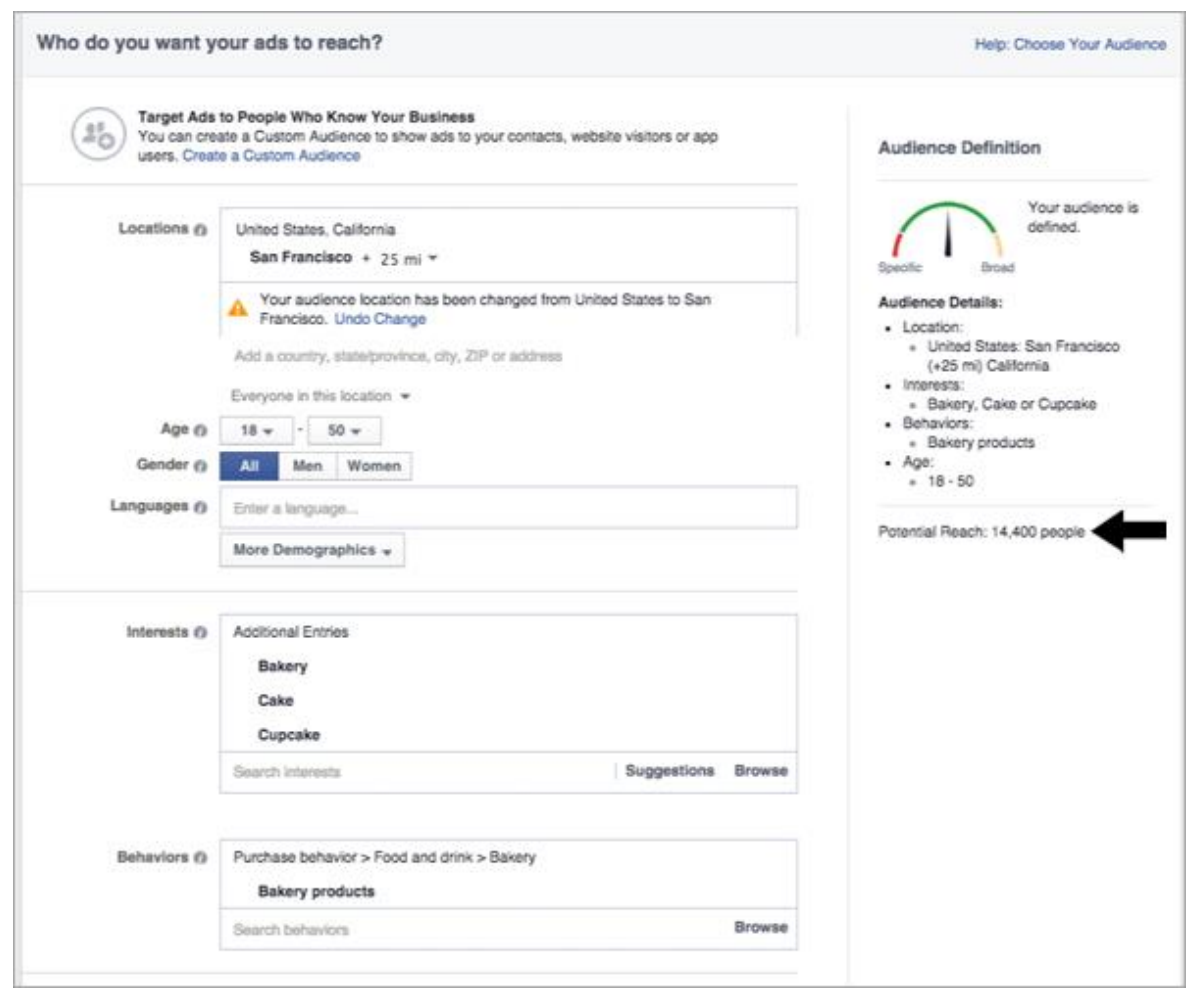

Fuente:https://es-la.facebook.com/business/help/201828586525529 
A continuación, elige un presupuesto y un calendario, y consulta el alcance diario estimado. Este es el número estimado de personas a las que puede llegar tu anuncio por día.

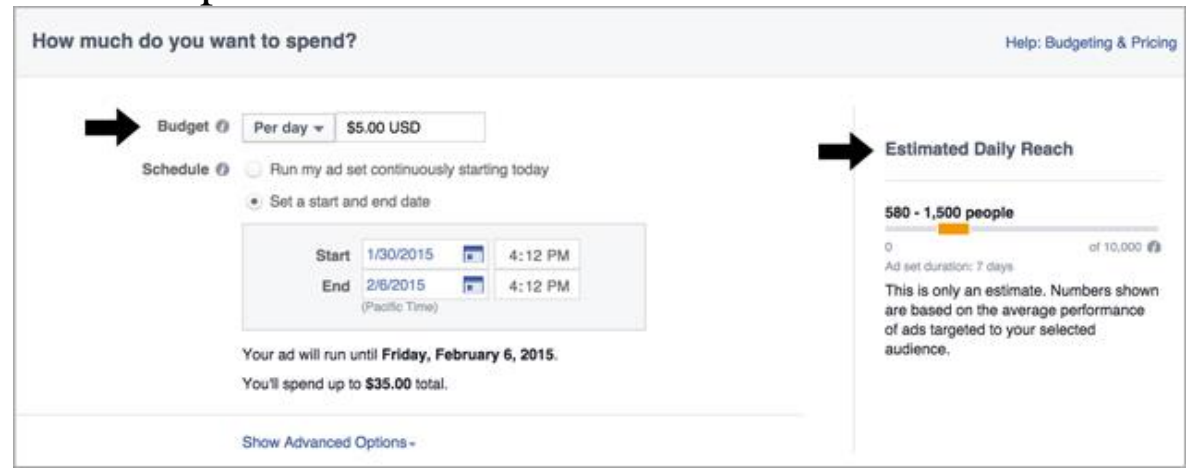

Fuente:https://es-la.facebook.com/business/help/201828586525529 